University of San Diego

Digital USD

2005-06-01

\title{
Essential Features of Cultural Proficiency in American International Schools in Latin America: A Delphi Study
}

Rebecca McBride Bustamante EdD

University of San Diego

Follow this and additional works at: https://digital.sandiego.edu/dissertations

Part of the Leadership Studies Commons

\section{Digital USD Citation}

McBride Bustamante, Rebecca EdD, "Essential Features of Cultural Proficiency in American International Schools in Latin America: A Delphi Study" (2005). Dissertations. 754.

https://digital.sandiego.edu/dissertations/754

This Dissertation: Open Access is brought to you for free and open access by the Theses and Dissertations at Digital USD. It has been accepted for inclusion in Dissertations by an authorized administrator of Digital USD. For more information, please contact digital@sandiego.edu. 


\title{
ESSENTIAL FEATURES OF CULTURAL PROFICIENCY IN AMERICAN INTERNATIONAL SCHOOLS IN LATIN AMERICA: A DELPHI STUDY
}

\author{
by \\ REBECCA MCBRIDE BUSTAMANTE \\ A dissertation submitted in partial fulfillment \\ of the requirements for the degree of \\ Doctor of Education \\ University of San Diego
}

June 2005

Dissertation Committee

Johanna S. Hunsaker, Ph.D.

Paula A. Cordeiro, Ed.D.

Susan M. Zgliczynski, Ph.D. 
(C) Copyright by Rebecca McBride Bustamante 2005

All Rights Reserved 


\begin{abstract}
American international schools in Latin America can play a vital role in preparing future leaders to effectively interact with people of diverse cultures. These schools provide ideal settings for exploring how policies, programs, and practices that reflect diverse perspectives and encourage intercultural learning might enhance global leadership development.

Multidisciplinary reviews of the literature reveal a dearth of studies examining culture and leadership development in American international schools in Latin America. The model of cultural proficiency provides a comprehensive framework for exploring how these schools might proactively and effectively respond to diversity in a crosscultural environment and develop globally competent leaders.

This exploratory study aimed to uncover how formal school leaders, working in American international schools throughout Latin America, would characterize cultural proficiency in these schools and what barriers they might encounter. The Delphi method was used to systematically collect the opinions of a geographically disbursed panel of 35 experts representing 25 schools in 14 different countries. Participants completed three rounds of open-ended, on-line questionnaires to determine group consensus on essential features of cultural proficiency; the influence of school leaders; challenges and barriers; and potential success indicators for measuring and monitoring school-wide cultural proficiency and global leadership development.

Key findings supported the theoretical framework and suggested a need for American international schools in the Latin American region to consciously assess cultural proficiency and develop school-wide strategies that consider: shared vision
\end{abstract}


building, global curriculum, cultural awareness training, community service, leader influence and development. Resistance to change and elitist and ethnocentric values of students, parent, and teacher groups were cited as primary barriers to cultural proficiency development. Specific strategies for confronting these barriers were also identified.

Recommendations include the need for school leaders and supporting credentialing and international education associations to recognize the tremendous impact of culture in these schools and develop comprehensive strategies for cultural proficiency development and assessment. Graduate education programs should enhance development of culturally proficient, global-minded school leaders and teachers to work in international schools. Future research is recommended to further explore cultural proficiency and leadership development in specific school contexts, using multiple methods. 


\section{DEDICATION}

This work is dedicated to my wise and loving parents, Drs. Byron and Judith McBride, who have always inspired me, through example and intelligence, to recognize and do what is morally right. They have provided me with unconditional love and enduring support at every turn, as I muddle through this lifetime adventure.

I further dedicate this work to my ebullient and supportive husband, Nelson, "el berraco," who has patiently endured me throughout this dissertation process. I thank him for being a wonderful life partner and appreciate the exuberant passion and energy he brings to my life.

I thank my beautiful children, Isabella and Nicolas, who have overdosed on macaroni and cheese and sacrificed quality time with mom so she can write and write.

I also dedicate this work to my dear lifelong friend, Dr. Rosalind Pierson whose "old soul" knows me like no other and never lets me down. I appreciate your willingness to intellectually hash out ideas with me and guide me through this process.

I value the influence of my siblings: Mikle, the gifted and nurturing educator; Jonathan, the creative and worldly Manhattan entrepreneur; and my quirky, artistic sister Amy, whose talents and virtues are too extensive to describe.

I am appreciative to my in-laws, Jorge Bustamante and Lula Hernandez for their dedication to family and their perpetual enthusiasm about life. I thank them for being supportive of me and interested in what I do.

Thank you all for your love and support throughout this process. 


\section{ACKNOWLEDGEMENTS}

This work would not have been possible without the support of many people. I wish to thank my committee members, Dr. Paula Cordeiro and Dr. Susan Zgliczynski. I am grateful to Dr. Cordeiro for her interest in international schools and for setting up the special international educator cohort, which allowed me to pursue a doctoral degree while living in Brazil. I am appreciative to Dr. Zgliczynski for introducing me to the idea of organizational cultural competence and coaching me on the Delphi method. I am particularly grateful to my dissertation chair and advisor, Dr. Johanna Hunsaker for her support and mentoring over the past few years. I consider her a competent organizational theorist and a wonderful role model. I greatly admire her incredible sense of balance and zest for life.

My learning and growth at the University of San Diego has been supported by many others. I have been particularly challenged and enriched by the numerous courses I have taken with Dr. Robert Donmoyer, who stretched my personal epistemology to a point of self-transformation. I also feel deeply fortunate to have shared intense summers with some other members of my cohort whom I now consider dear, lifelong friends including: Tiffany Carpenter, Catriona Moran, Brian Mathews. I am also thankful to Pat Taepke for the nurturing she provided to all cohort members and to Beth Yemma for her tremendous assistance with every detail of the graduate program. I thank you for all the fun, intellectual stimulation, and emotional support. 


\section{TABLE OF CONTENTS}

ACKNOWLEDGEMENTS. viii

TABLE OF CONTENTS .ix

LIST OF TABLES xiv

\section{CHAPTER ONE: INTRODUCTION TO THE STUDY}

Introduction. 1

Statement of the Problem ................................................... 2

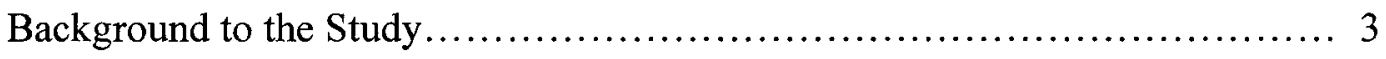

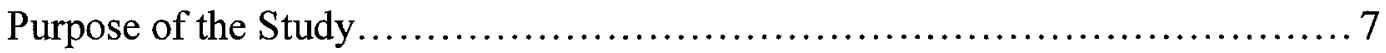

Research Questions.........................................................

Limitations and Assumptions.................... ........................ .

Background of the Researcher........................................ 10

Definition of Terms......................................................11

CHAPTER TWO: REVIEW OF THE LITERATURE

Introduction........................................................ 13

The Meaning of Culture ................................................... 14

Theoretical Development of the Concept of Cultural Proficiency............... 15

Individual Intercultural Competence.................................16

Organizational Cultural Competence................................ 17

Similarities in Constructs............................................ 20

Cross-cultural Organizations and Diversity................................21

Cultural Diversity in Business Organizations.......................... 22

Cross-cultural Organizational Theory ............................... 25 
Cultural Proficiency in Schools.

Model of Cultural Proficiency for Schools as a Theoretical Framework......27

Multicultural Education................................................ 32

School Leadership and Diversity...................................... 33

Global Education and Cultural Proficiency.......................... 35

Cultural Proficiency in International Schools................................ 38

Summary........................................................... 44

\section{CHAPTER THREE: RESEARCH DESIGN AND METHODOLOGY}

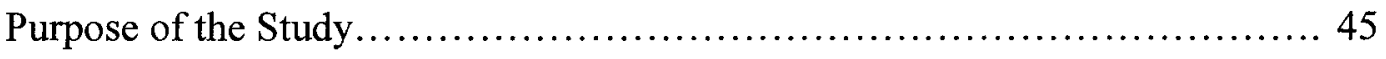

The Delphi Method...................................................47

Development of Delphi Method.....................................48

Strengths and Limitations of the Delphi Method.......................... 49

Selection of the Delphi Method for this Study............................... 51

Participant Selection.................................................. 52

Institutional Review Board ............................................ 56

Data Collection..................................................... 57

Advantages of Electronic Mail and On-line Questionnaires................. 58

Disadvantages of Electronic Mail and On-line Questionnaires...............59

Researcher Role................................................. 60

Pre-Delphi: Pre-test of Round One Questionnaire...................... 61

Data Collection: Round One..........................................61

Data Collection: Round Two......................................... 63

Data Collection: Round Three......................................64 
Data Collection: Background Questionnaire..........................6 67

Data Analysis...................................................... 68

First Round Data Analysis..........................................69

Second Round Data Analysis..................................... 70

Third Round Data Analysis........................................ 71

Background Questionnaire........................................71

Evaluation of the Delphi Method for this Study .............................. 72

Advantages of the Delphi Method for this Study........................ 72

Disadvantages of the Delphi Method for this Study...................... 74

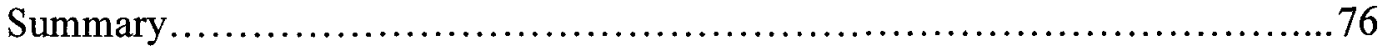

\section{CHAPTER FOUR: FINDINGS OF THE STUDY}

Introduction......................................................... 78

Key Findings...................................................... 79

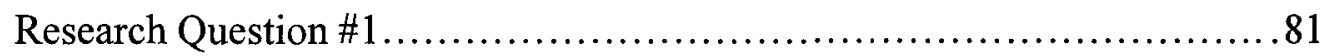

Research Question \#2 ............................................ 85

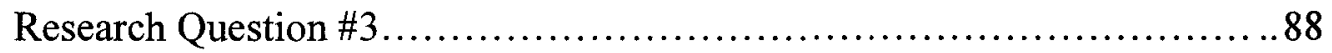

Research Question \#4.............................................. 92

Expert Panel Suggestions for Approaching Primary Barriers..............94

General Challenges of Managing American International Schools in Latin America....................................................97

Research Sub-question $\# 1 \ldots \ldots \ldots \ldots \ldots \ldots \ldots \ldots \ldots \ldots \ldots \ldots \ldots \ldots \ldots \ldots$

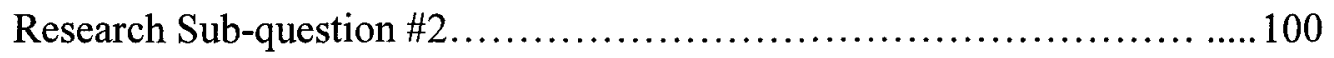

Background Information on Expert Panel Participants..................... 102

Summary ............................................................ 103 
CHAPTER FIVE: IMPLICATIONS, LIMITATIONS, AND RECOMMENDATIONS

Introduction........................................................... 104

Summary of the Study................................................ 104

Summary of the Findings........................................... 106

Implications of Findings............................................ 108

Essential Features of Cultural Proficiency and

the Theoretical Framework............................................ 109

Leadership Implications.......................................... 110

Barriers to Cultural Proficiency.......................................... 112

General Need for a Cultural Proficiency Framework.....................116

Advantages of the Delphi Method and On-line Questionnaires............... 118

Limitations of the Study .............................................. 119

Recommendations....................................................... 119

International Associations and Accreditation Organizations................119

Graduate Programs in Teaching and Educational Administration............123

Recommendations for Future Research................................. 124

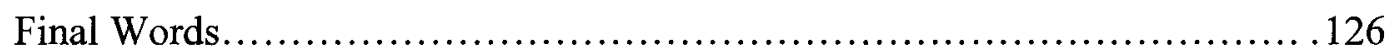

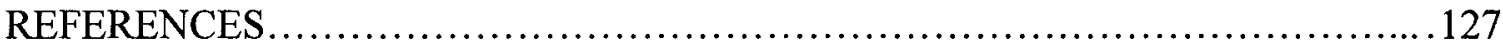

\section{APPENDICES}

A. Delphi Process: Schedule of Activities............................... 140

B. Expert Panel Recruitment Letter..................................... 142

C. Informed Consent Form............................................ 145

D. Round One: Cover Letter............................................ 148

xii 


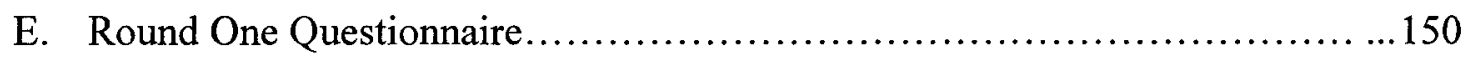

F. Cover Letter-Round One: Compiled Results................................153

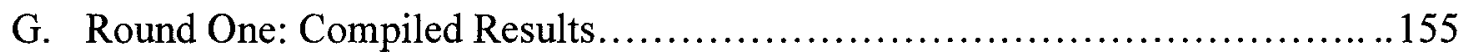

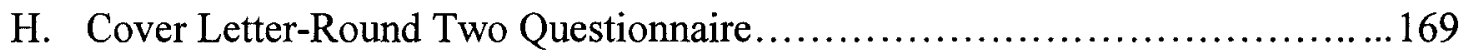

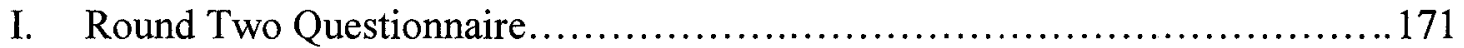

J. Round Two: Compiled Results........................................... 175

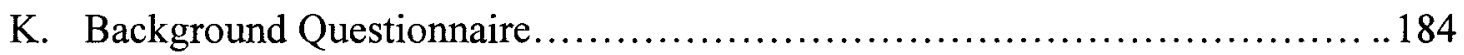

L. Background Questionnaire: Compiled Results........................... 187

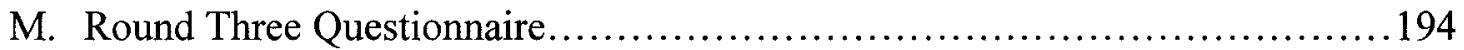

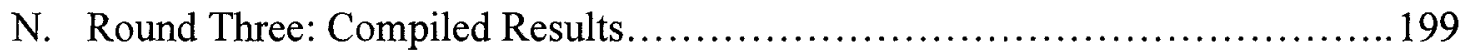




\section{List of Tables}

Table 1. Success indicators to measure school-wide cultural proficiency.......... p.100

Table G1. Global leadership development............................... p.156

Table G2. Academic challenges....................................... 158

Table G3. Behavioral/academic challenges................................. 159

Table G4. School mission and policy challenges............................. p. 160

Table G5. Demographic challenges.......................................... 160

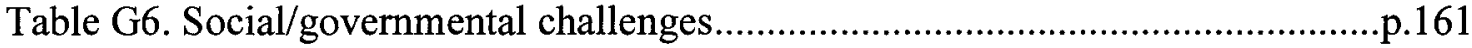

Table G7. Skills and resource challenges.................................... p.161

Table G8. Cultural proficiency for faculty and staff.......................... p.162

Table G9. Cultural proficiency for parents................................ p. 163

Table G10. Cultural proficiency for students.............................. p. 164

Table G11. School leader influence....................................... p.165

Table J1. Essential strategies for development of global leadership............... p.176

Table J2. Strategies for developing cultural proficiency........................ p. 177

Table J3. How school leaders influence cultural proficiency....................... p.178

Table J4. Barriers to cultural proficiency and global leadership................... p.179

Table J5. Success indicators for cultural proficiency....................... p. 180

Table J6. Randomly selected participant quotes.............................. p.181

Table L1. Expert panel member job titles.................................. p. 188

Table L2. Supervisory responsibilities of panel members...................... p.188

Table L3. Participant years of experience in current position...................... p.189

Table L4. Participant experience in international schools........................p.189

Table L5. Participant experience in schools in Latin America......................p.189

Table L6. Panel member gender.......................................... p. 190

Table L7.Student enrollment in panel member schools....................... p.191

Table L8. Reported percents of local/host country students in member schools.... p.191

Table L9. Approximate percent of overseas hire faculty in participant schools...... p.191

Table N1. Rank order of essential strategies for global leadership................... p.199

Table N2. Ranking of essential strategies for school-wide cultural proficiency...... p.203

Table N3. Barriers to cultural proficiency by rank order........................ p.204

Table N4. Reported use of success indicators to measure cultural proficiency..... p.208 


\section{CHAPTER ONE \\ INTRODUCTION TO THE STUDY}

\section{Introduction}

As organizations become increasingly diverse and the world economy more interdependent, leaders must be global-minded and capable of interacting appropriately and effectively with people from a wide variety of national, racial, and ethnic cultures. Schools are in a key position to respond to this demand by creating school cultures that reflect culturally diverse perspectives and encourage intercultural learning among students, teachers, parents, and with outer community members.

American international schools are ideal settings for exploring what schools do or can do to encourage the development of global-minded, culturally- sensitive individuals, since these schools are considered "launching pads" for future leaders (Gillies, 2001; Ketterer \& Marsh, 2001). In general, students who attend American international schools represent an upper socioeconomic class, have influential and well-educated parents, are globally mobile and multilingual, attend top colleges and universities, and go on to hold high-level positions in business and government (International Schools Services [ISS], 2004; Rucci, 1993; U.S. Office of Overseas Schools, 2004). This is also the case in Latin America where a significant number of political and business leaders graduated from American international schools (Ketterer \& Marsh, 2001).

Research in international schools suggests that since students attending these schools are highly likely to hold future positions of power and influence, the development of responsible, "interculturally literate" leaders cannot be left to chance and requires 
schools to consciously create social structures to support this development (Allan, 2002; Heyward, 2002).

The model of cultural proficiency for schools and school leaders proposed by Lindsey, Robins, and Terrell (2003) provides a viable framework for exploring how American international schools in Latin America might identify and create school-wide social structures that enhance global leadership development and intercultural learning. The cultural proficiency model facilitates an analysis of diversity in school cultures and the identification of policies, programs, and practices that address the unique diversity and cross-cultural nature of particular school contexts.

Scholars essentially agree that cultural proficiency involves the ability of individuals, groups, and organizations: (a) to consciously assess attitudes, values, and behavior toward people from diverse cultures; (b) to mediate inevitable intercultural conflicts and tensions; (c) to learn from and adapt to the multiple perspectives, experiences, and values that individuals and groups bring to culturally diverse organizations and situations; and (d) to communicate effectively and appropriately with others who do not share the same culture, ethnicity, language, or other salient variables (Cross, Bazron, Dennis, \& Isaacs, 1989; Lindsey, et al., 2003; Lustig \& Koester, 2002; Lynch \& Hanson, 1998; National Center for Cultural Competence-Georgetown University [NCCC], 2004).

\section{Statement of the Problem}

It is unknown how American international schools in Latin America can consciously develop culturally sensitive, global-minded leaders and what barriers they might encounter. Furthermore, guidelines for determining how school-wide policies, 
programs, and practices reflect diverse perspectives that can enhance intercultural learning among students, teachers, parents, and other community members are limited or non-existent in these schools. At the time of this study, the model of cultural proficiency had not yet been empirically explored in American international schools. There is a general dearth of research on American international schools, in general, and a paucity of research on schools in the Latin American region of the world.

\section{Background to the Study}

American international schools in Latin America are characterized by the fact that they are: (a) accredited by U.S.-based regional accreditation organizations; (b) emulate U.S. educational curriculum, standards, and assessments; and (c) use English as the primary language of instruction. Schools are typically private, non-profit college preparatory institutions serving students from pre-school to grade twelve. Most American international schools are fairly small with fewer than 1,000 students, but some larger schools have student enrollments of up to 3,000 (Office of Overseas Schools, 2004).

A nine to ten member, elected board of directors, usually composed of parents, normally governs these schools and appoints a "head of school" (director or superintendent) to supervise all operations. Since there is no actual legal authority that requires schools to conform to U.S. standards, American international schools seek accreditation from U.S. based regional accreditation organizations to set standards and hold schools accountable to them. Schools that cater to children of overseas U.S. diplomats, often receive a degree of "advisory" or financial support from the U.S. State Department's Office of Overseas Schools Advisory Council; however, the U.S. State Department does not directly finance or govern these schools. 
Finally, constant flux and change has been noted as a general characteristic of international schools around the world. Frequent turnover in staff, administrators, parents, board of directors, and student populations, can potentially affect the continuity and stability of school programs (Hawkins, 2002; Mannino, 1992; Paulsen, 2002; Russell, 1990).

For purposes of this study, it is important to highlight how American international schools in Latin America are both cross-cultural and culturally diverse. Like U.S.-based multinationals, U.S.-accredited, "American style" schools are cross-cultural because they must respond to the influences of the host country cultures in which they operate and maintain smooth relationships with local, national, and international communities in order to survive (Willis, 1991). American international schools are legally obliged to obey all country laws and regulations, including curriculum requirements by the host country ministries of education, which require schools to offer both U.S. and host country high school diplomas.

Challenges can arise from this cross-cultural situation. American international schools are often accused of inappropriately "importing" an American style ethos into the school culture and community, without sufficient regard for the influences of the host country cultures in which they operate. On the other hand, in many schools in Latin America where the majority of students represent the local culture, host country customs, values, and even language may dominate within the school culture. In this case, there is sometimes a sense of moving too far away from the principles of an "American-style" education. 
Challenges also arise in community outreach efforts. Differences in language, cultural norms, and social status sometimes create barriers or make it difficult to establish relationships with local community contacts and organizations. In most Latin American countries, where only poor children attend public schools, there is normally minimal interaction between public and private schools. The foreign nature of international schools in developing countries can sometimes contribute to perceptions of "imperialism" by local host country communities.

In addition to the cross-cultural nature of American international school settings, diversity within schools also creates intercultural challenges and opportunities. Diversity is most reflected in student enrollment and faculty composition. Students attending American international schools tend to fall into three general categories including: (a) international students who come from a variety of countries around the world and usually attend schools from one to four years; (b) local host country students who often attend a school from preschool through high school graduation; and (c) third-culture kids (Useem, 1993) who may not readily identify with a particular culture because they have moved a great deal or come from bi-cultural families.

Some American international schools in Latin America (e.g., The Lincoln School in Buenos Aires, Argentina) reflect high levels of international diversity among students and staff. However, more than any other region of the world, most schools in the Latin American have majority percentages of students and faculty from the host country (ISS, 2004). In some schools in Latin America, percentages of host country students and faculty may be as great as $60 \%-85 \%$. Increases in the number of local, host country 
students has led to new challenges and opportunities related to second language instruction, culture, curriculum, classroom practices, and parent and community outreach.

Staffing policies and practices in American international schools also impact

cultural diversity and school culture. Native English speakers are highly valued in international schools. Top administrators (e.g., school heads and principals) and at least a quarter of the teaching faculty is normally recruited from North America (the United States and Canada) and possesses U.S. or Canadian credentials (ISS, 2003). Teachers who are not recruited from North America are typically hired locally and represent the host country culture.

In comparison to other regions of the world, recruiting and retaining highly qualified teachers is a major concern for schools in South and Central America (Gillies, 1992; Canterford, 2003). Teacher and administrator salaries are lowest in the Latin American region, while schools in other regions (e.g., Europe, Asia) pay higher teacher and administrator salaries (ISS, 2004). Differences in culture, ethnicity, training, classroom management, pedagogical approaches, and pay and benefits between local-hire and overseas hire administrators and teachers can be great.

Cultural differences among students, faculty, parents, administrators, and members of the outer community can either fuel intercultural tensions or provide opportunities for intercultural exchange and learning. However, it is often assumed in international school circles, that the mere mixing of students and faculty from different cultures naturally cultivates culturally sensitive, global-minded, and linguistically proficient people. While some studies in the international school literature support this notion (Hayden, Rancic, \& Thompson, 2000; Rucci, 1993; Straffon, 2001), extensive 
seminal research suggests that exposure to different cultures may not be sufficient to alter attitudes and behaviors toward others who are different (Allport, 1954; Oberg, 1960; Ting-Toomey \& Oetzal, 2001). In fact, without sufficient and appropriate organizational supports, diverse settings often contribute to negative inter-group behavior in the form of group segregation, conflict, resentment, marginalization, hostility, isolation, alienation, culture shock, and identity confusion between different cultural groups (Henze, Katz, Norte, Sather, \& Walker, 1998; Kim, 1995; Ting-Toomey \& Oetzal, 2001).

Moreover, research in schools suggests that organizational supports and skilled, culturally proficient teachers and school leaders greatly enhance the likelihood that students and other school members develop the skills and abilities needed to interact consciously, appropriately, and effectively with others who are culturally different (Banks, 1999; Henze, et al., 1998; Merryfield, 2002; Salvaggio, 2003). This idea is increasingly stressed in recent international school literature as well (Allan, 2002; Heyward, 2002; Popinchalk, Cordeiro, \& Kasan, 2001) and is supported by the model of cultural proficiency for schools (Lindsey, et al., 2003). Chapter two will further elaborate some of these ideas and review relevant literature and empirical studies supporting the notion of cultural proficiency in schools.

\section{Purpose of the Study}

The purpose of this study was to explore what school leaders in American international schools in Latin America, would consider essential features of and barriers to school-wide cultural proficiency as a means of enhancing intercultural learning and global leadership development of students, teachers, and other school community members. The study also aimed to identify how school leaders might influence cultural 
proficiency, what skills and training school leaders need, and potential measures and success indicators of cultural proficiency. The Delphi method was selected to address the research questions in this study, because "Delphi studies are generally designed to map complex, poorly- defined issues or areas of inquiry by systematically collecting the opinions of experts" (Adler, 1983, p.10).

\section{Research Questions}

1. How, if at all, do school leaders in American international schools in Latin America believe that school-wide cultural proficiency might contribute to the development of global leadership abilities among students and other members of the school and outer school community?

2. How do school leaders in American international schools in Latin America characterize a culturally proficient school in terms of essential features (e.g. policies, programs, practices, or others) that involve all school community members, directly impact students, or reach extended audiences (or outer communities)?

3. How do experts believe that school leaders can influence cultural proficiency and global leadership development in American international schools in Latin America?

4. What are the perceived barriers to developing cultural proficiency in American international schools in Latin America? How do these identified barriers relate to the general challenges of managing American international schools in Latin America? 
To better inform practice and the potential application of the model of cultural proficiency in American international schools, this study was guided by the following sub-questions:

1. What skills, training, and experiences do school leaders believe would enhance their abilities to develop and sustain cultural proficiency and global leadership in American international schools in Latin America?

2. How do school leaders think that cultural proficiency might be measured and monitored in America international schools in Latin America? What do they perceive to be potential success indicators?

\section{Limitations and Assumptions}

This study has three major limitations. First, panel participants were limited to formal school leaders (administrators) that served on the administrative leadership teams American international schools in Latin America during the Fall 2004 semester. This limits the extent to which the results of this study may be generalized to other school leaders, other school members, other international schools, other time frames, and other countries and world regions.

Second, the data obtained in the study was based solely on the written, reported perceptions the 35 participants represented on the Delphi panel. Underlying values, beliefs, attitudes, and time availability may have limited the objectivity and plausibility of the topics explored in this study. Generalizations and interpretations must, therefore, be made with caution.

Third, while the researcher tried not to over-specify the structure of the Delphi study to allow for greater input from participants, participants may have been influenced 
by the researcher to the extent that the researcher framed the problem for them and made choices about how to thematically categorize compiled responses that were fed back to panel participants.

Various assumptions were made at the onset of the study. The researcher made an overall assumption that American international school leaders would report opportunities and challenges related to the cultural diversity and cross-cultural settings of U.S.accredited international schools in Latin America. It was also assumed that the terms global leadership and cultural proficiency were positive, desirable descriptors when applied to the American international school setting. It was assumed that having representation from similar international schools throughout the Latin American region would allow for comparison of school leader perceptions and provide a general picture of similarities within the region. Finally, the assumption was made that panel participants would take the time to honestly and thoroughly respond to the questionnaires for each round of Delphi process.

\section{Background of the Researcher}

The background of the researcher contributed to this study endeavor and should be noted here as a potential source of bias for research topics related to race and culture. The researcher was raised in a multiracial family and attended multicultural public schools in a large Mid-Western city in the United States during the era of school desegregation. The researcher has worked as an educator in American international schools and bi-national centers in Panama, Colombia, and Brazil and has a particular interest in the Latin American region of the world. The researcher is married to a Colombian and has two children who have attended American international schools in 
Brazil for more than five years. Based on a strong background in social sciences and education, the researcher believes that a global and interdisciplinary approach to the study of culture and diversity would avoid duplication of theories and provide for a more comprehensive view of how to enhance intercultural understanding.

\section{Definition of Terms}

1. American International Schools: Private U.S. accredited, overseas schools that offer an "American-style" curriculum, based on U.S. curriculum standards and practices, and teach academic subjects in English.

2. Cross-Cultural: Comparative study of multiple cultures (Asante \& Gudykunst, 1989).

3. Cultural Proficiency: Values and behaviors that enable individuals and organizations to respond effectively and appropriately to others from diverse cultures.

4. Host country: The overseas country in which an international school is located.

5. Intercultural: Interaction of people of differing cultures.

6. Latin America: Spanish and Portuguese speaking countries in South America, Central America, and the Caribbean, including Mexico and Brazil. American international schools located in French, English, and Dutch speaking countries in the region were not included in this study.

7. Organizational culture: Shared experiences, norms, rituals, espoused values, artifacts, and underlying assumptions of those who work in an organization (Schein, 1985).

8. School Culture: The organizational culture of schools. 
9. Third Culture Kids: Children who do not strongly identify with a "home culture" or a "host culture" because they are globally mobile and have never lived in one country or culture for very long (Langford, 1997; Pollack \& Van Reken, 1999; Useem, 1993). 


\section{CHAPTER TWO}

\section{REVIEW OF THE LITERATURE}

\section{Introduction}

An interdisciplinary approach to a review of literature was considered essential to this study to provide ample support for application of the cultural proficiency model in American international schools in Latin America. Theories and studies from the fields of anthropology, intercultural communication, cultural competence in health care and human services, organizational theory, multicultural education, global education, and international schools were reviewed to obtain an integrated view of the literature informing the idea of cultural proficiency.

This literature review is divided into five sections. Section one provides seminal definitions of culture as a basis for understanding the concept of cultural proficiency explored in this study. Section two describes theoretical development of the model of cultural proficiency as derived from the constructs of individual intercultural competence and organizational cultural competence. Section three describes some empirical studies on organizational diversity and cross-cultural organizations that inform the idea of cultural proficiency in organizations. Section four gives an overview of the model of cultural proficiency in schools, proposed by Lindsey, Robins, and Terrell (2003), which serves as the theoretical framework for this study. This section also includes a review of relevant literature from the fields of multicultural education, diversity and school leadership, and global education. Finally, section five summarizes studies conducted in international schools that help illustrate the cultural challenges and opportunities in American international schools in Latin America. 


\section{The meaning of Culture}

In order to understand what is meant by cultural proficiency, a basic description of the meaning of culture is essential to this study. Culture is a learned meaning system of shared beliefs, values, norms, symbols, customs, behaviors, and artifacts that members of a society use to make sense of their world and one another, as well as foster a sense of shared identity and community among group members (Bates \& Plog, 1990, Gudykunst, 1998; Hall, 1976; Pierson, 1996; Samovar \& Porter, 1995; Triandis, 1994). Culture is historical and transmitted across generations (Brislin, 1993; Ting-Toomey, 1999). Much of culture is not so much taught as unconsciously experienced (Lustig \& Koester, 1999). Ting-Toomey and Oetzal (2001) compare culture to an iceberg; the deeper layers (e.g. beliefs, values, and traditions) are hidden from view and the uppermost layers (e.g., artifacts, behavior, and verbal and non-verbal symbols) are observable (p. 9).

Gudykunst (1998) emphasizes that cultures are not homogeneous and subgroups or subcultures exist within larger cultures. While culture is an attribute of individuals, groups, organizations, and nations, a single person can belong to a multiplicity of cultures (Brislin, 1993). People may identify with more than one ethnic, racial, or national culture depending on situations and points in time (Casmir, 1999; Cox, 1993; Kim, 1995; Loden, 1995).

In this study, culture refers to ethnic/racial/national culture and acknowledges that people may identify with more than one culture or sub-culture at any given time. Intercultural refers to the interaction between people of differing cultures (Asante \& Gudykunst, 1989; Kim, 2001) and implies that 'cultures have a reciprocal influence on each other within society' (Leeman, 2002). The term intercultural, as used in this study, 
represents what the Brazilian education scholar, Candau (2002) calls, "a permanent, never-ending process, marked by a deliberate intention to promote a democratic relationship between groups and not just passive coexistence in the same territory" (p. 99).

In exploring the concept of organizational cultural proficiency, this study also makes some reference to organizational culture defined as the shared experiences, norms, rituals, espoused values, artifacts, underlying assumptions of those who work in an organization (Schein, 1985; 1992), and, more specifically, school culture as the organizational culture of schools (Deal, 1993).

Theoretical Development of the Concept of Cultural Proficiency

Cultural proficiency involves the ability of individuals, groups, or organizations: (a) to consciously assess attitudes, values, and behavior toward people from diverse cultures; (b) to mediate inevitable intercultural conflicts and tensions; (c) to learn from and adapt to the multiple perspectives, experiences, and values that individuals and groups bring to organizations and situations; and, (d) to communicate effectively and appropriately with others who do not share the same culture, ethnicity, language, or other salient variables (Cross, Bazron, \& Issacs, 1989; Lindsey, et al., 1999, 2003; Lynch \& Hanson, 1998).

The cultural proficiency concepts appear to have emerged from decades of empirical work on the construct of individual intercultural competence in the fields of intercultural communication and cross-cultural psychology and a more recent focus on the idea of organizational cultural competence in healthcare and human services. 


\section{Individual Intercultural Competence}

Since the early 1960's communication scholars have tested the concepts of intercultural communication competence (ICC) or cross-cultural competence of individuals (Gudykunst, 1994; Gudykunst and Hammer, 1983; Gudykunst and Kim, 1992; Kim, 2001; Wiseman \& Koester, 1993). ICC, or now most commonly referred to as intercultural competence, is used to describe individuals who have an ability to understand and communicate appropriately and effectively with people from a variety of cultures (Bender, 1996; Lustig \& Koester, 1999). The term cross-cultural competence has been synonymously used by Lynch and Hanson (1998) to describe "the ability to think, feel, and act in ways that acknowledge, respect, and build upon ethnic, socio-cultural, and linguistic diversity" (p. 50).

Original empirical work on the construct of intercultural competence was derived from the need to cope with practical problems encountered by individuals living and working overseas and was stimulated by the post WWII boom in student exchange and international development work, the Peace Corp movement of the 1960 's, overseas military and diplomatic corps, and an expansion in international trade by multinational corporations (Hammer, 1989, 1987; Oberg, 1960; Ruben, 1989; Wiseman \& Koester, 1993; Yershova, Dejaeghere, \& Mestenhauser, 2000). Within the United States, research on intercultural communication, human relations, and multicultural education was stimulated by an end to legal racial segregation of schools and other public institutions in the 1960's and 1970's. 
Communication literature reflects the consensus that intercultural competence generally involves, but is not exclusive to: communicative and linguistic abilities; empathy; attitudinal openness; tolerance for ambiguity; multiple perspective-taking; display of respect; ability to perceive cultural similarities and differences; descriptive, non-evaluative responsiveness; and an ability to rapidly learn new cultural information (Cui \& Van Den Berg, 1991, pp. 229-231; Dinges 1983, p. 184; Hannigan, 1990, p. 93; Lindsey, et al., 1999, p. 21; Lustig \& Koester, 1999, p.72; Lynch \& Hanson, 1998, p. 50). Lustig and Koester (2002) provide a complete, contemporary description of interculturally competent people:

Interculturally competent communicators integrate a wide array of culture-general knowledge into their behavioral repertoires, and they are able to apply that knowledge to the specific cultures with which they interact. They are also able to respond emotionally and behaviorally with a wide range of choices in order to appropriately and effectively within the constraints of each situation. They have typically had extensive intercultural communication experiences and have learned to adjust to different patterns or thinking and behaving. (p. 171)

\section{Organizational Cultural Competence}

In attempting to understand the concept of cultural proficiency, the idea of organizational cultural competence must be examined. The concept of organizational cultural competence first evolved in the fields of healthcare and human services to respond to the needs of an increasingly culturally and ethnically diverse clientele. Cultural competence essentially refers to an organization or agency's ability to function and perform effectively in cross-cultural situations through a congruent set of behaviors, attitudes, and policies (Cross, et al., 1989; Pederson, 1994; Sue, et al., 1992). The idea of organizational cultural competence presents proactive approaches to assessing and maximizing cultural diversity through analysis, adaptation, and enhancement of 
organizational policies, programs, and practices to reflect the perspectives of diverse cultures (Barrera \& Kramer, 1997; Krajeski-Jaime, et al., 1996; Ponterotto, 1997).

Cross, Bazron and Issacs (1989) provided the first model of cultural competence which presented six developmental levels along a continuum toward cultural proficiency. They proposed that individuals and organizations can be at various levels of awareness, knowledge, and skills along the continuum. Figure 1 illustrates the cultural proficiency dimension proposed by Cross, et al. (1989) and later adapted by Lindsey, et al (1999; 2003) for use in schools:

Figure 1

\begin{tabular}{|cccc|}
\hline Cultural Destructiveness & Cultural Blindness & Cultural Competence \\
\hline Cultural Incapacity & Cultural Precompetence & Cultural Proficiency \\
\hline
\end{tabular}

The Cultural Proficiency Continuum (Lindsey, et al, 1999 adapted from Cross, et al., 1989)

Lindsey, et al. (1999) used the term cultural proficiency rather than cultural competence in their work. These authors distinguish between cultural competence and cultural proficiency by stating that cultural proficiency is, 'more than the esteeming of culture' and involves, "knowing how to learn about individual and organizational culture" (p. 91). Lindsey, et al.'s (2003) model of cultural proficiency for schools and school leaders is described in more detail later in this chapter. In the fields of Healthcare and Human Services; however, cultural competence continues to be the preferred term.

In general, academic research examining organizational level cultural competence is limited. The most tangible indicators for organizational level cultural competence have been developed by practitioners and could potentially be used to empirically examine the construct in schools and other organizations. The National Center for Cultural Competence at Georgetown University (NCCC), for example, supports healthcare and 
human service agencies and bases its organizational assessments on Cross, et al.'s (1989) framework. The NCCC defines cultural competence as: an acceptance for difference, careful attendance to the dynamics of difference, continual assessment and expansion of cultural knowledge, and various adaptations of belief systems, policies, and practices (2004). In assessing cultural competence in client agencies the NCCC looks for:

- A defined set of values and principles, and demonstrated behaviors, attitudes, policies and structures that enable agencies to work effectively cross-culturally.

- The capacity to (a) value diversity, (b) conduct self-assessment, (c) manage the dynamics of difference, (d) acquire and institutionalize cultural knowledge and (e) adapt to diversity and cultural context of communities served.

- Incorporation of the above in all aspects of policy-making, administration, practice, service delivery, including systematic involvement of consumers, stakeholders, and communities.

Other institutions (e.g., U.S. Department of Health and Human Services, 2004; University of San Diego-Irvine Project, 1998, 2001; Ministry for Children and FamiliesGovernment of British Columbia-Canada, 2003) have also identified specific organizational policies, programs, and practices that would be indicative of culturally competent behaviors, including:

- Mission or vision statements that articulate a commitment to cultural diversity and a global perspective.

- Recruitment, retention, rewards, training, mentoring, promotion, and career opportunities offered to culturally diverse groups and individuals. 
- Training and professional development that encourages employees and managers to explicitly explore cultural biases and learn from others' cultural perspectives.

- Greater employee and community participation in policy decisions, as well as community outreach efforts.

- Creation of diverse work teams along with the allowance of multiple ways to accomplish tasks.

- Strategies for addressing and mediating conflicts and tensions.

- Organizational assessments or culture audits designed to gauge cultural sensitivity and monitor efforts toward cultural inclusion.

Culture audits are used to strategically plan future changes by clarifying needs, goals, and objectives to strengthen culturally effective and appropriate policies, programs, and practices. Audits usually involve: document reviews, focus groups, interviews, and surveys with organizational members (NCCC, 2004).

The above strategies and indicators support the model of cultural proficiency for schools and school leaders proposed by Lindsey, et al. (2003) and may be applicable to assessment of cultural proficiency in the international school setting.

\section{Similarities in Constructs}

Several key findings from empirical research on individual intercultural competence closely align with some of the basic tenets of the model of organizational cultural competence and proficiency developed by Cross, et al. (1989) and adapted by Lindsey, et al., (1999). Intercultural competence and cultural competency and proficiency involve: 
- Ongoing developmental processes, not a set endpoints (Lustig \& Koester, 2002; Wiseman \& Koester, 1993; Yershova, et al. 2000).

- Intercultural or cross-cultural engagement (Triandis, 1994).

- An ability to learn to function in a wide variety of cultures (culture general) without specific knowledge of the values and behaviors of a particular culture (culture specific). Individuals and organizations are more capable of adapting to new cultures, regardless of the specific culture encountered (Hofstede, 2002; Kim, 2001; Lindsey, et al., 2003; Lustig \& Koester, 2002; Martin, 1993).

- Effectiveness or "the successful achievement of goals and outcomes in an intercultural interaction" (Koester \& Olebe, 1998, p. 6).

- Appropriateness or behavior that is regarded as suitable and appropriate in a given situation, within a given culture or a "minimization of misunderstandings" (Dinges, 1983; Gudykunst, 1993; Koester \& Olebe, 1998; Kim, 2001, 1991; Lustig \& Koester, 2002).

A panoramic view of the literature related to the notions of cultural competence and proficiency revealed the above factors and provided additional empirical support for the construct outside the traditional areas of healthcare and human services. Additional empirical support for the idea of organizational cultural proficiency can be drawn from research in the areas of cross-cultural organizational theory and diversity in business organizations.

\section{Cross-cultural Organizations and Diversity}

Empirical studies examining the cultural competence and the model of cultural proficiency at an organizational level are limited; however, research on diversity in 
business organizations and cross-cultural organizational theory inform the notion of organizational level cultural proficiency.

\section{Cultural Diversity in Business Organizations}

Research on diversity in business organizations illuminates the concept of organizational cultural proficiency by exploring how diversity impacts organizations. Thomas and Ely $(1996,2003)$, conducted large empirical studies examining paradigms of diversity in U.S. corporations and discovered what three different paradigms for how organizations approach diversity: (a) the discrimination-and-fairness paradigm; (b) the access-and-legitimacy paradigm; and, (c) the learning-and-effectiveness paradigm (later relabeled as the integration-and-learning perspective).

Over a six-year period, Thomas and Ely (1996) studied three organizations that had attained a high degree of demographic diversity, including a community bank, a law firm, and a medium-sized consulting firm to examine the impact of diversity on organizational practices, processes, and performance and explore whether leaders' influence on diversity was an enhancing or detracting element in the organization. Analyses were based on data gathered from interviews, surveys, observations, and archival data.

The researchers discovered that the two paradigms traditionally guided diversity initiatives in organizations: the discrimination-and-fairness paradigm and the access-andlegitimacy paradigm. Leaders who viewed diversity through a discrimination-andfairness paradigm usually had top-down authority, stressed assimilation, strictly complied with equal opportunity requirements for employee recruitment and fair treatment, and instituted professional development programs for women and minorities. Companies 
were often bureaucratic in structure and carefully monitored, measured, and awarded individual performance. Problems for organizations related to the suppression of cultural differences to the extent that the organization did not benefit from innovative, effective ideas and fresh perspectives that a diverse workforce can potentially contribute to the overall organization. The U.S. Army is given as an example of an organization that operates within a discrimination-and-fairness paradigm.

The access-and-legitimacy paradigm was predicated on the notion of "valuing diversity" and the acceptance and celebration of differences. Companies with this paradigm usually operated in a business environment had experienced an increase in demographic diversity among customers, clients, markets, or employees and emphasized cultural differences without analyzing how these differences actually affected or influenced the work that needed to be done. Companies had a tendency to "pigeonhole" employees to fit certain market niches sometimes leaving employees feeling exploited (e.g., an African-American lawyer hired solely to take on the growing African-American client base).

Based on this research, Thomas and Ely $(1996,2003)$ discovered an alternative paradigm, the integration-and-learning perspective. This perspective was revealed in companies that recognized employees frequently make work decisions based on their cultural background or identity-group affiliation. These organizations not only valued cultural differences among people, but were able to incorporate diverse employee perspectives into the organizational culture in a way that allowed for learning and growth by rethinking primary tasks, and redefining missions, markets, products, business strategies in ways that enhanced overall organizational effectiveness. 
According to Thomas and Ely (2003), the integration and learning perspective, like the model for organizational cultural proficiency, represents the integration of diverse perspectives into organizational culture. While awareness of paradigms provides a starting place for organizations to begin to assess how diversity is manifested in the organizational culture, a limitation to these studies include the need to know how organizations could go about effectively integrating diverse perspectives

Other key studies on diversity in organizations also inform the notion of organizational cultural proficiency by analyzing the value of incorporating culturally diverse perspectives. A research consortium, called the Diversity Research Network, gathered organizational theory scholars from six major universities, including Harvard, MIT, Wharton, and UC-Berkeley to empirically examine relationships between cultural diversity, business performance, and organizational effectiveness (Kochan, et al., 2003). The consortium study has been considered one of the largest field-based studies on the effects of race and gender diversity on business performance (Kwak, 2003).

Consortium research was carried out in four large firms to test the 'business case for diversity' or the popular 1990's view that diversity benefits businesses by enhancing team performance and improving a company's ability to serve a diverse customer base. Results of the four studies concluded that the diversity of a demographically diverse workforce can have positive or negative direct effects, depending on whether or not there is some purposeful intervention on the part of the organization that goes beyond the classic "business case" for diversity and/or fears of discrimination suits (Kochan, et al., 2003; Kwak, 2003). One of the studies showed that gender diversity positively affected team output while racial diversity had a negative effect on group processes, unless 
diverse teams were supported by intensive career development training and diversity management strategies (Kochan, et al, 2003). These consortium studies confirm the necessity for organizational strategies and interventions to maximize the benefits of diversity in organizations.

While many other organizational theorists have published books on the values of organizational diversity, much of this work lacks a sound empirical base that allows for realistic and measurable application of diversity strategies in organizations (e.g., Cox, 1997; Loden, 1995).

\section{Cross-cultural Organizational Theory}

Some cross-cultural organizational theories also inform the idea of cultural proficiency in overseas American international schools by examining the complexities of culture in multinational corporations. Most of the empirical work found in the crosscultural organizational literature focuses on cultural values or value dimensions and examines the extent to which countries (national cultures) commit to and express these values.

Empirical research suggests that cultural values play an important role in controlling and directing social behavior, including organizational behavior (Kluckhorn \& Strodbeck, 1961; Rokeach, 1973; Schein, 1985). Hofstede's (1980) seminal work on cultural value orientations is frequently referenced and offers a valuable theoretical and methodological approach to measuring, comparing, and understanding differences and similarities between national cultures. Hofstede surveyed over 100,000 employees working in offices of the large multinational company, IBM. The surveys were conducted in IBM offices in seventy-one different countries. Through statistical analyses and 
theoretical reasoning, Hofstede identified five predominant cultural dimensions which help describe cultural expectations for a range of social behaviors including: individualism/collectivism (expected behaviors toward the group); power distance (perceptions of higher or lower status of others); uncertainty avoidance (people's sense of truth and certainty); masculinity/femininity (beliefs about achievement and gender differences); and time orientation (individual's search for virtue and lasting ideals oriented to past, present, future time). Hofstede's work is enduring and has formed the basis for extensive research by other scholars. The value dimensions serve as a basis for conducting organizational assessment and identifying areas of need to policy changes and training needs, among many others. In more recent work, Hofstede (2001) has emphasized a need for leaders and managers to be trained in cultural competence based on cultural value dimensions.

Using six of the cultural dimensions originally identified by Hofstede (1980), along with an additional three, nine core cultural dimensions are applied to societies and organizations in a research program called Global Leadership and Organizational Behavior Effectiveness (GLOBE). GLOBE explicitly focuses on organizational practices and leadership attributes in 61 different nations by exploring cultural values and practices. The additional value dimensions added by GLOBE researchers include: future orientation, performance orientation (extent to which an organization encourages and rewards group members for performance improvement), and humane orientation (encouragement of altruism). GLOBE is a multi-phase, multi-method project in which close to 150 researchers from around the world are engaged in examining the interrelationships between societal culture, organizational culture, and organizational 
leadership (see House, Hanges, Javidan, Dorfman, \& Gupta, 2004). Nine cultural core dimensions are applied to societies and organizations in studies at GLOBE. Using these dimensions as culture construct definitions, GLOBE researchers employ quantitative and qualitative methods to conduct various cross-cultural studies on leadership and organizational processes. By building on previous studies and their own extensive empirical research, GLOBE researchers attempted to develop an integrated theory of cross-cultural leadership and organizations (House \& Aditya, 1997; House, et al., 2004). International collaborative research of this nature provides empirical approaches for assessing and understanding cultural values and leadership influences in cross-cultural organizations and might illuminate issues of culture, leadership, and cultural proficiency in overseas American international schools.

Several other theorists have extended the work of Hofstede by using metaphors such as the family or sports teams to describe how organizational members orient to their organizations (e.g., Trompenaars and Hampden-Turner, 1998; Gibson \& Zellner-Bruhn, 2001). Few theories, however, have been as applicable to cross-cultural organizational research and theoretically enduring as the work of Hofstede (1980).

While organizational theory illuminates the idea organizational cultural proficiency, schools are a particular type of organization. Therefore, theories and research that inform the phenomenon of culture in schools must be explored.

Cultural Proficiency in Schools

Model of Cultural Proficiency for Schools as a Theoretical Framework

The model of cultural proficiency for schools and school leaders proposed by Lindsey, Robins, and Terrell $(1999,2003)$ served as the theoretical framework for this 
study. These authors endorse cultural proficiency as an approach to responding to and addressing differences in schools for several reasons including: (a) it is proactive; (b) provides tools that are applicable to any setting; (c) is behavioral in focus; and, (d) can be applied to both organizational and individual behavior. The authors further propose that cultural proficiency is, "a model for shifting the culture of a school (or district)-a model for individual transformation and organizational change" (p. 5).

The model of cultural proficiency proposed by Lindsey, et al. (2003) has four basic components: (a)a continuum for understanding levels of development toward culturally proficient policies, practices, and individual behaviors; (b) five essential elements or behavior standards for measuring and planning growth toward cultural proficiency; (c) guiding principles or underlying values; and (d) two identified barriers to change.

Lindsey, et al $(1999,2003)$ generally describe the six points along the cultural proficiency continuum as follows. Hypothetical examples are given to demonstrate how attitudes and behaviors might play out in an international school setting:

- Cultural destructiveness: elimination or denial of other cultures (e.g. "This is an American school; they should be adapting to us.");

- Cultural incapacity: belief in the superiority of one culture over another along with disempowering behavior (e.g., "Bolivian teachers just don't have the right profile to be promoted to principal positions.");

- Cultural blindness: no recognition of cultural differences among and between cultures or behaving as if they do not matter (e.g., "As I walk 
around the school, I do not see color or different nationalities; I only see children);

- Cultural pre-competence: awareness of the limitations of an organization's practices in interacting with various cultural groups (e.g., "We really need a Japanese counselor to help us out with the adjustment of our Japanese students.");

- Cultural competence: standards for individual and organizational practices reflect attention to the dynamics of cultural differences and the adaptation of values, behaviors, policies, and practices (e.g., "For our new teacher orientation, let's create culturally diverse work teams to have teachers explore their beliefs about and experiences with teaching and learning.").

- Cultural proficiency: respond positively and affirming to differences; esteeming culture, knowing how to learn about individual and organizational culture, and interacting effectively in a variety of cultural environments (e.g., "Conflict is normal and I'm glad we are looking for ways to approach conflicts and tensions when they occur.").

In addition to the six-point continuum toward cultural proficiency, Lindsey, et al., $(1999,2003)$ also propose five "essential elements" of cultural proficiency that provide standards for individual behavior and organizational practices. These five essential elements include:

- Assess Culture

- Value diversity

- Manage the dynamics of difference 
- Adapt to diversity

- Institutionalize cultural knowledge

Assessing culture relates to the analyzing, describing, and understanding of individual and school culture such as organizational-level culture audits. Teaching and staff development that encourage attitude assessment would also classify as cultural assessment. Valuing diversity involves recognizing, accepting, and encouraging cultural differences. The valuing of differences may be reflected in school policies, curriculum, staffing, and promotion structures. Managing the dynamics of difference essentially applies to the way that schools acknowledge and mediate intercultural conflicts and tensions. Institutionalizing cultural knowledge is often reflected in the physical layout, allocation of time and resources, training, program development, and the establishment of school traditions. Adapting to diversity includes change strategies designed to adapt to cultural differences, as well as the incorporation of various cultural perspectives and expertise in improving organizational practices.

As part of their model, the authors delineate some core values or guiding principles upon which their approach to cultural proficiency is built. They call these core values, "guiding principles" (p. 6). These guiding principles include the following values or beliefs:

- Culture is a predominant force; you cannot NOT be influenced by culture.

- People are served in varying degrees by the dominant culture.

- It is important to acknowledge the group identity of individuals.

- Diversity within cultures is important; cultural groups are neither homogeneous nor monolithic. 
- Respect the unique cultural needs that members of the dominated groups may have.

Finally, Lindsey, et al (2003) identify and describe what they believe to be two predominant barriers to developing cultural proficiency: (a) the presumption of entitlement and (b) an unawareness of the need to adapt. Presumption of entitlement is defined as the belief that the personal achievements and societal benefits that one has accrued are based solely on merit and quality of character. However, the authors attribute much of the resistance to change in an organization to an "unawareness of the need to adapt" (p. 218). They argue that many people do not recognize the need to make personal and organizational changes to respond to the diversity of the people with whom they and their organizations must interact. Rather, the belief is frequently that others need to change and adapt to them instead.

Aside from the qualitative cases studies on two schools presented in Lindsey, et al.'s (2003) book, searches revealed limited research examining the model of cultural proficiency in schools.

In one dissertation study, Salvaggio (2003) empirically tested the model of cultural proficiency in schools by administering a written questionnaire of twenty-nine items featuring a six-point Likert scale to eighty formal and informal school leaders in eighteen high-achieving, highly culturally diverse elementary schools in California. School leaders in the study reported that all five of the elements of cultural proficiency from the Lindsey, et al. (1999) model existed at high levels in their schools. Elements included: (a) school cultures that reflected shared vision; (b) programs that addressed the needs of a culturally diverse community with opportunities for input and feedback; (c) 
systems for managing the dynamics of difference (conflicts); and (d) organizational cultures that were influenced by cultural assessment and valued of a wide range of viewpoints.

Recommendations from the study included the need for school leaders to be trained in how to develop shared visions and manage the dynamics of difference. Study conclusions stressed that school leaders would greatly benefit from receiving graduate level coursework that focuses culturally proficient leadership and staff development skills. Results also suggested that small school size and a core staff of experienced, fully credentialed teachers and administrators are important factors to developing cultural proficiency in high-achieving, highly diverse elementary schools. The results of this study clearly support the applicability of the model of cultural proficiency to the international school setting.

\section{Multicultural Education}

While much of the educational literature that supports the notion of cultural proficiency in schools was originally based on theories and research in multicultural education (Lindsey, et al., 1999), few studies were located that actually illuminated the questions posed in this study. In extensively reviewing literature on multicultural education for this study, two major limitations were noted. One limitation noted was that multicultural education focuses primarily on issues of inclusion, power, and dominance within national school systems and; two, much multicultural education theory is based on the philosophical approaches of critical pedagogy (e.g., Gladson-Billings, Nieto, McLaren, Sleeter) but does not reflect adherence to empirical inquiry. While some of the tenets of multicultural education have implications in other nations, their applicability to 
the international school setting is limited. The ideas of critical pedagogy are essential to issues of diversity in any school setting, but do not form much of a basis for pragmatic day-to-day solutions in schools.

James Bank's $(1994,1999)$ theoretical and empirical work on the 'school as a social system' does closely mirror the notion of cultural proficiency in schools and is referenced by multicultural education scholars around the world (see Bartolome-Pina, 1997; Candau, 2002a, 2002b). Based on research in schools, Banks and McGee (2001) presented a model for a culturally inclusive school that contained several domains of analysis at the organizational level including: school policy, school culture and the 'hidden curriculum,' school languages and dialects, instructional materials, etc. (p.24). Banks (1994) notion of the "hidden curriculum" was defined as "the curriculum that is not explicitly taught, but all students learn." According to Banks and McGee (2001) a school's attitude toward cultural and ethnic diversity is reflected in many subtle ways in the school culture, such as the kinds of pictures on the bulletin boards, the racial composition of the school staff, and patterns of student discipline (p. 21). These findings support the elements of the cultural proficiency model for schools.

\section{School Leadership and Diversity}

Extensive educational research confirms that school leaders play a large role in influencing school culture (Bolman \& Deal, 1997; Deal \& Peterson, 1990; Fullan, 2001; Leithwood, 1994; Sergiovanni, 2000), as well as enhancing the benefits of cultural diversity and encouraging positive intercultural relations in schools (Reihl, 2000).

In a major comparative, multi-method study titled, Leading for Diversity (Henze, Katz, Norte, Sather, \& Walker, 1998), documented the approaches of school leaders who 
proactively addressed intercultural and inter-racial tensions in U.S. schools and encouraged positive inter-racial and intercultural relationships. Using a nomination process, twenty-one schools, elementary and secondary, in various regions of the U.S., were selected for the study. To participate, the schools had to meet certain criteria: (a) a significant representation of at least three ethnic groups; (b) a tangible record of interethnic conflict in the school or surrounding community; and (c) leadership committed to implementing innovative approaches to prevent inter-ethnic conflict and improve interethnic relationships.

Case studies were conducted in each school to document and describe approaches used by school leaders. Data collection methods included interviews, observations, and document analysis. Analysis of data collected revealed: (a) school leaders do have the power to influence inter-ethnic relations in a positive direction; (b) schools and schools leaders may face more barriers and fewer contextual supports to promote positive intercultural relations, depending on pre-existing contextual conditions; (c) proactive school leaders attend to underlying as well as overt intercultural conflicts; (d) other role groups (informal leaders), besides administrators, can lead efforts to improve inter-ethnic relations; and (e) a strong school-wide vision of community building and democracy that exhibits a unique blend of multiple approaches enhances unity among school members.

Results of the study suggested a need to define success indicators to track improvements in positive intercultural/inter-ethnic relations in schools. Henze (2000) reported that while most school leaders and teachers in the study said they could tell whether ethnic relations had improved or worsened, none of the schools in the study had a system in place to track progress in intercultural relations. This study confirms that lack 
of assessments and success indicators for monitoring intercultural relations in schools is common. Assessment, however, is an essential component of the cultural proficiency model and points to the need to identify potential success indicators to assess the influences of culture in schools.

Results from the Leading for Diversity study mirrored many of the elements of culturally proficient school leaders described by Lindsey, et al. (2003) and supported by other organizational theory researchers (Cox, 2001; Kochran, et al., 2003; Thomas \& Ely, 1996). Many of the approaches identified by Henze, et al. (1998) such as, "strong school vision," "strategies for managing intercultural conflict" also parallel many of the culturally proficient strategies for schools and school leaders described by Lindsey, et al., $(1999,2003)$.

\section{Global Education and Cultural Proficiency}

A school's academic curriculum typically guides school policy, academic goals and expectations, and teaching and learning practices. School leaders consider curriculum an essential part of the overall organization strategy of a school. Educational scholars argue that global curriculum is a twenty-first century necessity for all students (Daniel, 2002; Diaz, Massias, Xanthopoulos, 1999; Gliozzo, 2002; Smith \& Czarra, 2003). Spring (1998) explains that increasing global interdependence, as well as global threats such as terrorism and environmental destruction, may explain the re-emergence of global education, since the 1980 's.

Tye and Tye (1992), based on the work of Alger and Harf (1986), provided a working definition of global education as part of their research on global education and 
the dynamics of educational change (p. 6). The definition involves two essential concepts, which relate to the idea of cultural proficiency and global competence:

1. The study of problems and issues that cut across national boundaries, and the interconnectedness of the systems involved-economic, environmental, cultural, political, and technological;

2. The cultivation of cross-cultural understanding, which includes the development of a skill of perspective-taking that involves being able to see life from someone else's point of view.

Collins, Czarra, and Smith (1996) conducted a study to examine how global topics related to pre-collegiate education. They identified objectives, content, approaches, skills, methods, and values presented in global and international education, by evaluating 75 documents, from around the world, covering a 50-year span. Data were compiled and organized around three common themes of: (a) global issues and challenges, (b) culture, and (c) global connections. From these themes, ten specific categories emerged that provide one possible framework for policymakers and school leaders to support global learning.

Based on the work of Collins, et al. (1996), Czarra (2002) created a Global Education Checklist to assist schools and school systems in assessing and monitoring how well they are "teaching about the world." The checklist contains questions about student knowledge (e.g., "Do students have general geographical, cultural, and historical knowledge?") and questions about schools for principals, teachers, and community members (e.g., "Do individuals and groups representing different ethnic and racial groups have a voice in planning your school community activities or assist in teaching and 
learning about other cultures?"). While no studies were located that empirically tested the Global Education Checklist, the checklist appears to be a useful tool for determining how schools might approach the challenge of providing a global education.

In addition to a global curriculum, research confirms that teacher education and professional development is essential to students' global learning. Diaz, et al., (1999) in their book, Global Perspectives for Educators, reviewed surveys and case studies done in various school to identify influences, overlaps, and shortcomings of both multicultural and global education on learning. The researchers found that to effectively influence global learning, educators must be cognizant of the contemporary forces that require students to have an education that is global in nature. They also discuss results from a survey on global education conducted by the National Council of Social Studies (NCSS) which found that, "while a provincial understanding of global studies by high school graduates is no longer acceptable, $95 \%$ of elementary and secondary teachers have had no academic preparation in international topics or issues" (p. 19).

Smith and Czarra (2003) stress that prospective teachers need more emphasis on global education within their content areas, as well as continuous training throughout their careers, as part of regular in-service programs. Merryfield, Jarchow, and Pickert (1997) also emphasize the key role that teachers play in influencing the global knowledge and citizenship of students and point to the need to develop teachers with global perspectives. While empirical research in the area of global education is limited, literature in the field does provide some guidelines for curriculum development and overall organizational strategy in schools. It also points to the need to examine the global education and training needs of teachers. Overall, global education literature informs the 
notion of cultural proficiency and global leadership development in the American international school context by providing guidelines for curriculum development and emphasizing the essential role of teachers in promoting global-mindedness.

The literature on diversity and school leadership and multicultural and global education have some clear implications for international schools and inform the notion of cultural proficiency in schools. Nonetheless, a review of the academic literature specifically focused on international schools is essential to an understanding of how cultural proficiency might be applied in the international school setting and add to the growing body of knowledge on international education.

\section{Cultural Proficiency in International Schools}

At the time of this study, the model of cultural proficiency had not been explicitly explored in the international school literature. However, some studies in international schools have been conducted which relate strategies to enhance diversity and global leadership development in these schools.

One interpretive organizational case study conducted by Popinchalk, Cordeiro, and Kasan (2001) uncovered some school-wide strategies related to the idea of cultural proficiency by exploring perceptions of the term international school with various constituency groups at the International School of Port of Spain, an U.S. accredited school located in Trinidad. Data collection involved a 16-item survey of teachers, administrators and staff; interviews with twenty-one staff members and nine parents, observations in a wide variety of school settings, and document analysis. Various themes emerged from the case study, along with recommendations as to how the school could become "more international." Themes included the beliefs that: teachers and staff should 
have diverse cultural backgrounds and experience; the school mission should have a global focus; the school should be integrated with the host country community; and the school culture should enhance tolerance and understanding. Curriculum emerged as a major focus in the study. Participants stressed that international school curriculum should include a global focus, integrate diverse perspectives, and tap into local, host culture resources. This study (Popinchalk, Cordeiro, \& Kasan, 2001) comes closest to reflecting how cultural proficiency might be applied to the American international school setting.

Other studies in international schools also relate to the idea of cultural proficiency. Based on international school research and extensive literature reviews, Heyward $(2002 ; 2000)$ stressed that international schools must examine their school cultures, structures, curriculum, and local communities to seek ways to develop intercultural literacy. Heyward (2002) described an interculturally literate person as one who "possesses the understandings, competencies, attitudes, and identities necessary for successful living and working in a cross-cultural or pluralist setting" (p.10). This idea mirrors the construct of intercultural competence researched by communication scholars.

Allan (2000) carried out an ethnographic case study of 171 students, ages 11-18 years, in an international school in the Netherlands to investigate the process of intercultural learning and attempted to identify the factors involved. Allan (2000) used the narrative analysis method to examine student intercultural experiences using Hayden and Thompson's (1996) model of cultural borderlands or the physical and intellectual crossing of 'cultural frontiers' within the international school context. Students were asked to write a story about the experiences of a new student coming to that school. Stories were written in two sessions of one hour each over a three-week period. The study 
found that students, especially of Japanese and East Asian cultures, experienced considerable cognitive dissonance and culture shock within the school culture. While Allan (2002) described that study outcomes, in some cases revealed levels of ethnocentrisms, adaptation, and cultural assimilation, he claimed intercultural learning was determined not to progress beyond an awareness of other cultures. Seven domains of cross-cultural interactions emerged from the study and were considered essential to intercultural learning: individual student factors, peer group interaction, national host culture, teacher/student interactions, academic curriculum, institutional school factors, and home/school interaction. Some of these factors are included in the Lindsey, et al. (2003) cultural proficiency model for schools.

A major limitation with the majority of studies that may have some relevance to the examination of cultural diversity and global leadership in international schools is their focus on "what it means to be international." In most cases, studies seem to reveal superficial findings that do little to inform school-wide strategy and day-to-day practices in international schools. Another limitation is the fact that studies were conducted with individuals, primarily students and some teachers and parents) and did not explore overall school-wide strategies and school leadership (e.g., Hayden, Rancic, \& Thompson, 2000; Hayden \& Thompson, 1998; Hayden and Wong, 1997; Heyward, 2000; Langford, 1997; Pollack \& Van Reken, 1999; Schaetti, 1998, Straffon, 2001; Useem, 1966, 1973). Finally, many of the studies appear to rely primarily on one-time surveys as their research methodology. Examples of some of these studies follow:

Hayden, Rancic, and Thompson (2000) administered a questionnaire to a large sample of 18-year-olds studying in international schools worldwide. The study suggested 
a number of characteristics that students considered relevant to "being international." Characteristics included: open-mindedness and the idea that one can "be international" and maintain their own cultural identity. The study revealed little about school factors that might have influenced these student perceptions.

In another study, Hayden and Thompson (1998) surveyed three thousand 16-18 year olds, attending schools in the European Council of International Schools (ECIS) and a sample of 226 teachers from secondary ECIS schools around the world on the meaning of an international education. Five themes were identified and ranked by level of importance. Students and teachers reported that 'exposure to students from different cultures' was the most important characteristic of an international school education, and secondly, a balanced formal curriculum with internationally-minded teachers as role models. Informal aspects of the school organization and contact with the local community were ranked as less important to an international education.

MacKenzie (2000) polled international school students, teachers, and parents to understand how they perceived the term international and what they considered to be characteristics of an international education. Parents emphasized the importance of student interaction with people of other cultures and English language instruction most important to being "international." Interaction with the local host culture community was reported as important to teachers and students, but was not highlighted by parents.

Burleigh (1994) interviewed K-12 teachers at an international school in Berne, Switzerland to identify practical recommendations for culturally and linguistically diverse student bodies in these schools. Teachers reported a need to emphasize world history and a global attitude in the curriculum. With the exception of the IB curriculum, 
which is not accessible to all students, high school teachers claimed that the examcentered emphasis of the curriculum limited its international breadth. Teachers stressed a need to create unity within the school community, as well as reach out to the local host country community. Finally, teachers reported that multicultural awareness and sensitivity were essential for all school members.

Straffon's dissertation study (2001) assessed the intercultural sensitivity levels of 336 high school students, from over 50 countries, at an international school in Southeast Asia by conducting surveys, gathering demographic characteristics, and interviewing 13 selected students. Results showed that $97 \%$ of the students in the study were operating high levels of cultural sensitivity. Sensitivity levels were positively correlated with the length of time a student had attended an international school and lived outside of the home country. While this study supported the potential of international schools in developing intercultural sensitivity in students, it provided limited information on other school-related factors that may have influenced international student cultural sensitivity levels.

Few studies in international schools have examined the experiences of teachers working in international schools even though tensions among teachers from different cultures can be readily observed. Host country, local-hire teachers, may spend their entire teaching career at one American international school, while expatriate, foreign-hire teachers, are recruited from overseas on two-year cycle contracts and are often faced with the challenges of living and working in new country (Remington, 2002; Richards, 1997). Beyond cultural differences and adaptation difficulties, tensions are often fueled by a 
disparity in pay and benefits between the two groups (see Cambridge, 1998; Canterford, 2003; Richards, 1997; Schwindt, 2003).

Remington (2002) explored factors that influence culture shock of North American teachers in international schools in Latin America. A total of 155 North American teachers from thirty-eight American international schools completed a fiftyeight item survey related to experiences of culture shock. Results indicated that gender, age, prior overseas experience, and living with a partner had statistically significant effects on reported levels of culture shock.

Richards (1997) did a case study of local-contract teachers in an international school in Africa to explore teacher perceptions of the intercultural climate at that school. Results from several teacher interviews suggested a failure to recognize and respond to the unique problems and needs of teachers from developing and non-Western countries that work in international schools. Study participants reported facing administrative, classroom, and psychological challenges that were very distinct from those faced by teachers hired overseas.

Recent dissertation studies on American international schools suggest that school leader perceptions and behavior impact school climate (see Hawkins, 2002) and school "reculturing" (see Mathews, 2003), and that certain leadership competencies are required to confront the cultural challenges of managing American international schools (see Paulsen, 2002). However, few studies on international schools have examined overall leadership and organizational factors that might enhance diversity, develop global leadership, and promote intercultural learning. 
Overall, there is a dearth of studies examining leadership and organizational practices that promote cultural diversity and global competencies in the international school setting. For the most part, literature on cultural diversity, internationalism, and intercultural issues at an organizational level of analysis have been limited to theoretical models or reviews of existing literature, with little added empirical knowledge to inform scholars and enhance practice in international education (e.g., Cambridge, 1998; Hayden and Thompson, 1996; Pasternik, 1998; Pearce, 2001; Sylvester, 1998; Thompson, 2002; Wilkerson, 1998).

Furthermore, as the above studies indicate, very little research has been done in American international schools. Most studies have been done in Europe in international schools belonging to the European Council of International Schools (ECIS) rather than in U.S. accredited, American international schools. There is a great need for more research on American international schools in developing regions of the world, such as Latin America, where very limited empirical work has been done.

\section{Summary}

This review of the literature provides theoretical and empirical support for the model of cultural proficiency applied to American international schools in Latin America from diverse fields and sets the foundation for this study. Chapter three describes the methodology applied in this study. 


\section{CHAPTER THREE \\ RESEARCH DESIGN AND METHODOLOGY}

Purpose of the Study

An interdisciplinary review of the literature suggests that the idea of organizational cultural proficiency provides a comprehensive, proactive approach to addressing cultural diversity in schools. The primary focus of this study was to explore how school leaders in American international schools, in Latin America, would characterize cultural proficiency in these schools as a means of enhancing the global leadership abilities of students, teachers, and other school community members.

The research questions posed in this study were designed to meet the purpose stated above and reflect adherence to many of the elements of Lindsey, Robbins, and Terrell's $(1999,2003)$ model of cultural proficiency in schools, which served as the theoretical framework for this study. Relevant theories and research from a variety of fields, as discussed in chapter two, also informed this research design.

The primary research questions for this study were:

1. How, if at all, do school leaders in American international schools in Latin America believe that school-wide cultural proficiency might contribute to the development of global leadership abilities among students and other members of the school and outer school community?

2. How do school leaders in American international schools in Latin America characterize a culturally proficient school in terms of essential features (e.g., policies, programs, practices, or others) that involve all school community 
members, directly impact students, or reach extended audiences (or outer communities)?

3. How do experts believe that school leaders can influence cultural proficiency and global leadership development in American international schools in Latin America?

4. What are the perceived barriers to developing cultural proficiency in American international schools in Latin America? How do these identified barriers relate to the general challenges of managing American international schools in Latin America?

To better inform practice and the potential application of the model of cultural proficiency in American international schools, this study was guided by the following sub-questions:

1. What skills, training, and experiences do school leaders believe would enhance their abilities to develop and sustain cultural proficiency and global leadership in American international schools in Latin America?

2. How do school leaders think that cultural proficiency might be measured and monitored in America international schools in Latin America? What do they perceive to be potential success indicators?

This study aimed to explore how school leaders would characterize cultural proficient American international schools in Latin America and how their ideas might compare to existing models and theories of cultural proficiency and diversity in schools and other organizations. This research was also designed to inform the practice of international school leaders and associations that support international schools by 
exploring possible ways to enhance intercultural learning and develop global leadership skills among school members, while also alleviating some of the inevitable cultural challenges to operating U.S.-accredited, "American-style" schools located in Latin America.

\section{The Delphi Method}

The Delphi method was selected as the most appropriate method to address the research questions proposed in this study. The strength of this research technique is based on the adage that "two heads are better than one" or, in the case of Delphi, that "several heads are better than one," particularly when the best information obtainable is based on the judgment of a knowledgeable group of individuals (Dalkey, Rourke, Lewis, \& Snyder, 1972, p.4). Levary and Han (1995) state that the objective of the Delphi method is to combine expert opinions to obtain a reliable response to a problem or question on a particular topic. Reliability is enhanced by giving a series of questionnaires that reiterate the same questions to individual participants, while providing cumulative group feedback from previous rounds (Helmer, 1983). The technique allows experts to deal systematically with a complex problem or question. Delphi studies tend to produce a convergence of opinion - not just toward the mean but also toward the true value (Helmer, 1983, p. 153).

The Delphi technique is essentially a structured process for collecting and distilling knowledge from a group of geographically dispersed, pre-selected "experts" by means of a series of questionnaires (Adler\& Ziglio, 1996). In a Delphi study, the participants in the group of experts are referred to as the Delphi panel. The panel members do not actually interact with one another and responses are anonymous. The 
technique uses written responses from group members rather than bringing individuals together for face-to-face interaction. Group results are fed back to the participants in cumulative form and are most often given in terms of means, medians, or standard deviations. Once participants have received the group feedback, individual participants are given the opportunity to reconsider their responses in subsequent questionnaires. The process of iterative questioning, feedback of summarized responses, prioritizing, and elaborated responses continue until group consensus is reached or determined by the researcher. After the last round of questions is analyzed, panelists are provided with a final summary of their ratings. Armstrong (1989) emphasizes that the Delphi technique is based on qualities of 'anonymity, statistical analysis, and feedback."

\section{Development of the Delphi Method}

The Delphi method originated in 1953 when Olaf Helmer, of the Institute for the Future, and Normal Dalkey, of the Rand Corporation, used the technique to address a specific military problem by obtaining consensus from a group of experts on U.S. military capabilities (Helmer, 1983). The name "Delphi" was derived from the Delphi Oracle of ancient Greece, which was used to look into the future. However, Dalkey (1968) explains that rather than "something oracular," Delphi is primarily concerned with "making the best of a less that perfect kind of information." This kind of information is usual not factual and involves value judgments. Linstone and Turoff (1975) emphasize that Delphi is particularly useful for studies that call for subjective judgments rather than precise statistical analysis.

In the 1960 's, research conducted using the Delphi technique originally focused on assessing long range trends by making future forecasts and predictions about science 
and technology and their probable impacts on society (Adler \& Ziglio, 1996; Delbecq, Van de Ven, \& Gustafson, 1975; Gordon \& Helmer, 1968; Linstone \& Turoff, 1975).

Since the 1970's; however, the technique has been increasingly used in business, education, and social science for a number of different purposes including management decision-making, program planning, policy evaluation, and prioritizing issues (Delbecq, et al., 1975; Dunham, 1998). Based on a recent on-line search, the Delphi method has become an increasingly frequent choice for educational research projects (UMI Proquest Digital Dissertations, 2004).

\section{Strengths and Limitations of the Delphi Method}

Scheele (1975) supported the Delphi method because of its ability to be sensitive to the social construct of reality by providing rich context-specific data. The Delphi technique offers some key strengths or advantages. First, most applications of the Delphi method have the objective of stimulating reliable and creative exploration of ideas or the identification of suitable information for decision-making. The method is appropriate for exploring broad or complex problems and research questions that require subjective, value judgments and opinions and do not lend themselves easily to precise analytical and strictly statistical analysis (Linstone \& Turoff, 1975). Second, a high degree of anonymity of the expert panel members is maintained throughout the process. The belief is that participants will respond more freely to the questions posed and there is the advantage of group response without the persuasive and dominating group dynamics of face-to-face discussion that frequently influence opinion forming (Helmer, 1983). Third, the technique allows for the attainment of group consensus among a geographically 
dispersed panel of experts, especially when more individual experts are needed than can effectively interact in a face-to-face exchange.

The Delphi technique also has some limitations or disadvantages. Many researchers remain skeptical about the credibility and experimental validity of the Delphi method because it involves facilitation of group information by a researcher and lacks the control of scientific methodology (Sackman, 1975). Some critics also question the reliability of the method since results are based on the opinions of a group of experts, making Delphi studies difficult to replicate (Helmer, 1983). One of the major criticisms of the method relates to the potential for researcher bias. Since the researcher serves as the facilitator for group perspectives, the researcher may intentionally or un-intentionally over-specify the structure of the Delphi and, therefore, limit the range of participant input (Linstone \& Turoff, 1975). Sackman (1975) also argued that Delphi studies rarely explain why a group moved toward consensus on certain ideas and often lack explanations for divergent opinions. As in all studies, there is also always a potential for bias that can occur as a result of poorly worded questionnaires, unclear evaluation scales, or faulty interpretations of results (Lang, 1998; Linstone \& Turoff, 1975). In general, the level of skills and expertise of the researcher and the participants is difficult to ascertain and may affect study results (Uhl, 1983). One of the greatest disadvantages to the Delphi method relates to the high degree of motivation needed to offset the tendency for participant dropout as the study progresses. Linstone and Turoff (1975) observed that after three or four rounds of a Delphi study, an acceptable consensus is normally reached and the Delphi cycle begins upsetting participants to the point of diminishing responses to questionnaires. Delbecq, et al. (1972) estimated that a minimum of forty-five days is 
required to carry out a Delphi study and complete three to four rounds. Delbecq, et al., (1972) also emphasized that three critical conditions need to be present in order to offset some of the disadvantages of the method and successfully apply a Delphi technique. These included: adequate time, high participant skill in written communication, and high participant motivation (p.84).

\section{Selection of the Delphi Method for this Study}

Even considering the limitations of the Delphi method, this method was deemed most appropriate for this study for several reasons. First, the concept of cultural proficiency has not been explicitly explored in U.S.-accredited, American international schools and it was not clear how "experts," or in this case, school leaders (administrators) working in schools in Latin America, might interpret the complex concept of cultural proficiency and apply the theory in actual and potential day-to-day policies, programs, and practices in schools. Use of the Delphi method allowed for an initial exploration of expert opinions about what cultural proficiency might mean to school leaders in U.S. accredited, American international school settings and how experts believed that cultural proficiency might be manifested. The method also helped reveal how some formal school leaders might view and interpret such nebulous concepts as culture, intercultural communication and learning, global leadership, and cultural diversity in American international schools in Latin America. Second, to obtain diverse opinions from schools located in various Spanish and Portuguese-speaking countries throughout Latin America, expert panel members were selected from schools in countries throughout the region.

The Delphi method allowed for the anonymous gathering of opinions from geographically dispersed panel members. Third, the Delphi Method allowed for 
"discussion" between experts without permitting the social interactive patterns of normal group discussions or focus group interviews that can influence opinions and increase the potential for bias of the data collected.

This study was considered exploratory in nature since the concept of cultural proficiency applied to the American international schools context had not yet been examined. The exploratory nature of the research project made the Delphi method a logical technique to begin to uncover perceptions of a geographically dispersed group of school leaders on the idea of school-wide cultural proficiency.

\section{Participant Selection}

Participants selected to serve on the expert panel for this Delphi study were drawn from the administrative leadership teams of U.S.-accredited international schools located in Spanish or Portuguese-speaking countries throughout Latin America, including schools located in the countries of: Bolivia, Brazil, Chile, Colombia, the Dominican Republic, Guatemala, Mexico, Nicaragua, Panama, Paraguay, Peru, Uruguay, and Venezuela. U.S.accredited international schools located in English, Dutch, or French-speaking countries, such as Trinidad-Tobago, Suriname, Jamaica, etc. were not approached for participation in this particular study.

Administrative leadership teams in American international schools are usually composed of school administrators in formal positions of authority (e.g., directors, principals, etc.). Administrative leadership teams typically work together to implement school policy, ensure integration between various school divisions or departments, and oversee strategic planning for school improvement. Administrative leadership teams usually vary in size from four to eight members. In addition to the school head and 
division principals, remaining leadership team members usually a host country director, who serves as a liaison with the host country's national ministry of education, and often a business manager, school counselor or psychologist, or a curriculum coordinator. The composition of members on the administrative leadership team usually depends on the size of the school.

All the schools contacted for participation in this study were schools accredited by the U.S.-based accreditation agency, the Southern Association for Colleges and Schools (SACS). At the time of this study, Southern Association of Colleges and Schools had a total of 101 accredited American international schools throughout Latin America and fourteen schools in the initial accreditation process (Anderson, 2004).

To recruit school leaders to serve as experts in this study, thirty-one of the largest, SACS-accredited American international schools were identified through the U.S. State Department's Office of Overseas Schools Latin American Caribbean Office. Using statistics and school descriptions provided by the Office of Overseas Schools, the researcher first selected schools located in Spanish or Portuguese-speaking countries and then identified schools that had a current enrollment of 350 students or more in grades $\mathrm{K}$ 12 in the year 2004. Only one school, the American School of Uruguay, had slightly less than 300 students but was contacted to nominate a school leader anyway, since only one American school exists in Uruguay. The majority of the schools approached for participation in the study, however, ranged in enrollment from 400 to 1,500 . One school leader participant represented a school with an enrollment of 2,500 students.

Once the researcher identified the target schools, a personal cover letter was sent via electronic mail to the heads of school or directors from each of the 31 identified 
schools. The cover letter (Appendix B) explained the study, stipulated criteria for participation, and invited each school to nominate one or two administrators from its administrative leadership team who could provide expertise on how American international schools approach the cultural challenges and opportunities facing them. The researcher then personally contacted each school head by phone to answer any questions and confirm participation in the study.

The pre-determined criterion for selection of expert participants included:

1. At least two years experience working in a formal administrative position in an U.S.-accredited international school, in a Latin American country. For purposes of this study, formal administrative positions included: head of school/director/superintendent, school principal, coordinator, counselor, lead teacher, or department director/manager.

2. Active participation on the school administrative or leadership team.

3. At least two years of experience living and working in a country different than one's home country of national origin.

Application of these criteria in selecting experts for this Delphi study were justified, based on the academic literature, as follows:

Criterion one and two are justified by the fact that formal school leaders influence school culture and policy-making (Fullan, 2001; Leithwood \& Jantzi, 2000; Peterson \& Deal, 1998, 2002; and Sergiovanni, 2000). While influential leaders in a school may not necessarily hold positions of formal leadership authority (Manasse, 1986), it was generally assumed that administrative team members have the positional power to impact policies, programs, and practices in schools. It was assumed that experience working in 
American international schools in the Latin American region would facilitate one's ability to identify potential cultural challenges and opportunities that may be present in schools in this region.

In reference to criterion three, research in intercultural communication confirms that experience living in different countries and exposure to a variety of other cultures tend to make one more conscious of and sensitive to issues of culture (Bennett, 1993; Kim, 2001; Wiseman \& Koester, 1993). While intercultural experiences do not necessarily ensure individual cultural proficiency, it was considered essential that "experts" had enough personal intercultural experiences to be able to seriously reflect on cultural and intercultural issues and realities of the American international schools under study.

While some school heads declined participation in the study for a variety of reasons, many of those contacted enthusiastically agreed to participate themselves or nominated another member from their administrative leadership team. The majority of expert participants were school heads and elementary, middle school, and high school principals. In a few cases, school leaders from additional U.S. accredited international schools, not originally identified by the researcher for participation in the study, were recommended by the SACS Director for Latin America and invited to participate on the expert panel. Those recommended school leaders who met the criteria for panel participation were also approached and invited to participate in the Delphi study.

All recruited participants were personally contacted by electronic mail, formally asked to provide their expertise in this study, and asked to complete an informed consent form (Appendix C). A total of forty school leaders initially agreed to participate in the 
study. Of these forty school leaders, thirty-seven submitted the consent form for participation, thirty-five completed the Round One questionnaire, and thirty-four completed all rounds of the Delphi process. A description of demographics and background information on expert panel participants is provided in the data analysis section of chapter four.

In reference to the size of an expert panel, Linstone and Turoff (1975) suggested a Delphi panel size of anywhere from 10 to 15 participants. Delbecq, et al., (1975) reinforced this number range, as long as experts form a homogeneous group representing the same general discipline. In studies examining error related to participant numbers, Dalkey, Brown, and Cochrane (1969) found error to stabilize in Delphi groups using 13 to 25 people. The objective of this research was to begin the study with a larger number of panel participants to allow for the inevitable natural attrition in the participation level of Delphi panel participants throughout the rounds of questioning (Delbecq, et al., 1975), while still stabilizing the final results. It was determined that 13 to 25 experts would be a sufficient number to complete all rounds of questionnaires throughout the Delphi process, without severely affecting study results. In actuality, a total of 34 panel members completed all four rounds of questionnaires for this Delphi study.

\section{Institutional Review Board}

This study received approval from the Institutional Review Board (IRB) of the University of San Diego on September 24, 2004. 


\section{Data Collection}

Since the Delphi process involves iterative questioning of a panel of participants using a series of questionnaires, each administration of a questionnaire was considered one "round" of the process. Through the questionnaires, panelists indirectly collaborated to identify essential features for the development of cultural proficiency in American international schools in Latin America, as well as explore other related issues including: relations between global leadership development and cultural proficiency; the role of school leaders in influencing cultural proficiency; barriers to cultural proficiency; and potential success indicators. Participant responses were analyzed and summarized by the researcher who then prepared subsequent rounds of questionnaires based on participant responses to previous questionnaires and the research questions for this study. In some cases, questions for Round Two and Three questionnaires were designed to elicit more in-depth information on ideas presented by participants and allow for a sense of ownership regarding the strategies presented.

All data were collected using an on-line survey system. The researcher designed questionnaires using the on-line system and then embedded links to the various openended questionnaires in personalized electronic mail letters sent to individual Delphi panel participants for each round.

To encourage expert panel participants to remain motivated, the researcher analyzed and compiled participant responses and returned compiled summaries to panel members for their review within one week of questionnaire submission for each round. Questionnaires for the sequential round were then distributed within the following week 
of distribution of the compiled results from the previous round. Appendix A outlines the phases of the study and indicates dates and time frames.

Advantages of Electronic Mail and On-line Questionnaires

Since all panel participants had Internet access, the study was conducted using electronic mail correspondence and on-line questionnaires that could be accessed by clicking on links embedded in electronic mail letters. Use of the Internet in this study allowed for the participation of a widely geographically disbursed group of busy school administrators, who juggle numerous priorities on a day-to-day basis. On-line questionnaires were determined to be the most efficient way to collect data because participants could easily access and submit information. Participants appeared were highly motivated by the on-line process based on the amount of written information they provided, the low attrition rate for the study, and the fact that many participants expressed that they enjoyed having a "forum" for ideas related to culture.

Electronic distribution of correspondence and questionnaires had many advantages for both the study participants and the researcher. Electronic messages between the researcher and participants could be read and responded to quickly. Respondents could access questionnaires easily by simply clicking on a given link. Questionnaires could also be read and responded to on a computer at the convenience of the participant, allowing for reflection and revision. Participants were not asked to complete any handwritten forms or send anything by regular mail. The global nature of the worldwide web made it possible to coordinate data from over ten different countries. The researcher could more easily access, sort, collate, and analyze data collected in cumulative form without having to analyze each questionnaire one at a time. Electronic 
questionnaires were also less expensive than paper questionnaires due to savings in printing costs and postage for mailing. The convenience of the on-line questionnaires and the immediacy of the feedback received in using electronic mail may have increased the likelihood that school administrators responded to questionnaires in a timely and efficient manner. Some research suggests that respondents to electronic surveys answer more honestly than participants who respond to paper questionnaires or interviews (Walsh, Kiesler, \& Sproul, 1992).

\section{Disadvantages of Electronic Mail and On-line Questionnaires}

The primary disadvantage to using electronic mail and on-line questionnaires related to the potential for technical difficulties due to total reliance on computer systems and servers for all communication and data collection. Both the researcher and participants were susceptible to problems with Internet servers and computers. In some cases, differences in participant levels of proficiency in using computers and the Internet may have impacted the study. In a few cases, participants contacted the researcher because they had received error messages from the on-line system or firewall systems did not allow attachments to be opened. The potential for miscommunication may have also increased in depending on electronic mail for written communication. In some cases, there was initial uncertainty about who actually received electronic mail correspondence, as many school administrators have general electronic mail addresses that filter correspondence through an administrative assistant.

To assure anonymity and avoid potential communication problems, the researcher confirmed a precise electronic mail address list prior to the distribution of the Round One 
questionnaire. The researcher also risked losing vital electronic data if the information was not consistently backed up and saved.

To alleviate the above risks, pretest messages were done before emailing any correspondence, on-line questionnaires, attachments, or links to Delphi panel participants. Every attempt was made to maintain an accurate, updated list of the direct electronic mail addresses of all consented panel participants to ensure smooth and efficient communication. Throughout the study, the researcher focused on writing clear messages that conveyed a positive, personalized tone to enhance communication with all panel participants.

\section{Researcher Role}

The researcher acted as a facilitator or "knowledge engineer" for this Delphi study. The researcher/facilitator carried out several steps including, but not exclusive to: setting criteria for selection of expert panel members, making contacts and recruiting school leaders to serve on an the expert panel, developing four Internet surveys for each round of questioning, including a background questionnaire; analyzing data from each round of questionnaires to identify themes and determine consensus; analyzing final data for implications and recommendations, and determining appropriate follow up, and writing up and presenting findings of the study.

To enhance trustworthiness and subjectivity, Peshkin (1988) recommended using a "subjectivity journal" or a notebook in which a researcher actively and honestly notes thoughts, feelings and perceptions as they go through the research process. In this study, a subjectivity journal was maintained throughout the research in an additional effort to enhance reliability and objectivity and reduce bias. 


\section{Pre-Delphi: Pre-test of Round One Questionnaire}

Prior to designing and distributing the Round One questionnaire for this study, an initial questionnaire was pre-tested and reviewed with a group representative of the expert panel to check for face validity, clarity of questions, and relevance to the concept of cultural proficiency. This representative group consisted of eight American international school leaders who worked in overseas schools located outside the Latin American region. Creswell (1994) emphasized the importance of conducting a pretest of the first Delphi questionnaire in order to improve questions, format, and scales and to increase overall validity. Modifications to the first questionnaire were made based on feedback from those formal school leaders who participated in the pre-test.

\section{Data Collection: Round One}

To begin to identify what experts might believe to be essential features (e.g., programs, policies, practices, etc.) of culturally proficient U.S.-accredited, American international schools in Latin America, the initial questionnaire (Appendix E) presented questions that related to the general literature on cultural proficiency in schools such as: how schools promote global leadership, what challenges school leaders encounter in managing American-style schools in Latin America, how cultural proficiency could be enhanced for various groups in a school; and how school leaders might influence cultural proficiency in schools. Participants were asked to give their opinions in response to the above questions.

The questions were designed to be broad enough to allow participants to provide descriptions that indicated how they first might perceive, define, and link the ideas of global leadership and cultural proficiency. The questions also solicited lists of factors 
(e.g., policies, programs, practices, beliefs, values) that panelists believed developed global leadership abilities and cultural proficiency in schools for different constituency groups (e.g., students, parents, teachers, outer community members), as well as a list of challenges related to managing American-style schools in Latin American. The final question on the Round One questionnaire encouraged leaders to share ways that they believed that school leaders influence the development of school-wide cultural proficiency and global leadership abilities in schools.

On October 4, 2004, the Round One questionnaire was sent to the thirty-seven participants who had submitted their informed consent forms. Access to the on-line questionnaire was made possible via a link embedded in electronic mail cover letters to all participants. Participants were given ten days to complete the Round One questionnaire and asked to respond and submit the questionnaire by October 17, 2004. Thirty-five participants submitted their questionnaires by this deadline. The two remaining consenting panel members represented the same school and asked to be removed from participation in the study due to time pressures related to an upcoming school accreditation process.

As questionnaires were received, the researcher contacted each panel member to thank them for their response and indicated an estimated timeline for when they would receive feedback on Round One and receive the Round Two questionnaire. Compiled data from Round One (Appendix G) was distributed to all thirty-five panel members, along with a cover letter (Appendix F), on October 23, 2004. The purpose was to provide feedback for participants to review, reflect upon, and compare information with the responses of other panel members in preparation for the next round of questioning. 


\section{Data Collection: Round Two}

The goal of the second round of iterative questioning in this Delphi process was to encourage expert panel members to reflect on their own responses to the Round One questionnaire in comparison to the responses of other panel participants and, then, begin to move the panel toward consensus on how essential participants believed the previously reported items (strategies) were. Questions one through three on the Round Two questionnaire (Appendix I) listed the strategies named by participants in Round One including: strategies for promoting global leadership abilities, strategies for developing school-wide cultural proficiency, and ways that school leaders might influence the development of global leadership abilities and school-wide cultural proficiency. For each item listed, participants were asked to rate how essential each of the named strategies were to American international schools in Latin America, on a scale of 1 (not at all essential) to 5 (very essential).

Question four asked participants to name some perceived barriers to developing the strategies they had reported in the Round One questionnaire. This question aimed to address one of the primary research questions for this study. Question five then aimed to ascertain how school leader participants thought that cultural proficiency and global leadership development might be measured and monitored in American international schools in Latin America, and asked participants to name some potential success indicators. This question was based on one of the sub-research questions for this study, which aimed to explore how these schools might go about measuring and monitoring cultural proficiency development, since the literature suggests that measurement is a general challenge. Finally, question six asked participants to express agreement or 
disagreement with the idea that school-wide cultural proficiency might encourage the development of global leadership abilities in students and other school members and help alleviate the cultural challenges previously named by the panel. The goal of this question was to provide an opportunity for the expression of any dissident opinions and not assume participant agreement with the various ideas discussed and presented thus far in the study.

On October 29, 2004 thirty-five Round Two questionnaires (Appendix H) were sent via electronic mail links to all panel participants, with a request to complete and submit the questionnaire by November 14,2004 . Thank you notes were sent to participants as they submitted their questionnaires. One week prior to the submission date, an electronic mail reminder was sent to those panel participants whose names did not indicate 'responded' on the researcher's on-line tracking list. Twenty-nine of the participants submitted their questionnaires by the November 14, 2004 submission date. Five additional panel members apologetically contacted the researcher within a few days following the submission deadline to ask if they might still complete the Round Two questionnaire. Although the researcher had begun analyzing the data submitted by the initial 29 participants, the responses of these additional panel members were analyzed and included, bringing the total response rate for Round Two to 34 . Compiled data from Round Two was sent to participants on November 19, 2004, via electronic mail along with a cover letter providing a timeline for the next rounds.

\section{Data Collection: Round Three}

The goal of the Round Three questionnaire (Appendix $\mathrm{O}$ ) was to further refine participant agreement on the perceived importance of the features or cultural proficiency 
and global leadership presented by the Delphi panel. Additional questions were asked of the panel to add depth to the data gathered in the study so far, as well as provide a basis for related future research. For questions one and three, participants were asked to rank, in order of importance, from most important to least important, those strategies for global leadership and cultural proficiency that they had previously rated as essential or very essential on the 1 to 5 scale.

Question two asked participants to provide real-life examples for three of the seemingly less tangible strategies previously presented including: "emphasizing tolerance and acceptance of diverse cultures;" "teaching and role modeling value of diversity;" and "demonstrating democratic process." While the majority of panel participants initially named these items in Round One, many participants expressed a need to better define the three features because they seemed vague and were difficult to visualize in everyday practice.

Question four asked participants to describe why they decided to rank the top three most important strategies for cultural proficiency the way they did. The goal here was to enhance the richness of the data collected and check for consistency in responses. Question five asked participants to rank the six barriers to implementing school-wide cultural proficiency, previously cited by a majority of panel members, from the greatest barrier to the least great barrier to find out if participants viewed certain barriers as more serious than others. Then, question six asked participants to share some possible strategies for handling the top three barriers they cited. The objective of this question was both to inform actual practice and evaluate how strategies for confronting barriers to cultural proficiency might relate to strategies for developing cultural proficiency. 
To ascertain school leader perceptions of how cultural proficiency and global leadership development in American international schools in the Latin American region could be measured, question seven required participants to check which of the potential success indicators reported in Round Two were being used, if at all, in their schools. Question eight then prompted participants to describe how their school used these indicators to measure and monitor success. These questions aimed to uncover any relationship to the literature on success measures for cultural competency and proficiency described in chapter two.

In reference to questions on school leader influence explored in previous rounds, question nine, asked participants to list specific skills, training, and experiences that might help school leaders be more effective in influencing and sustaining cultural proficiency and global leadership development in American international schools in Latin America. The objective was to add to a growing body of information on the training and education needs of international school leaders. Finally, participants were prompted to comment on anything else they would like to say related to the topics discussed. The objective of this was to maintain participant ownership over the ideas explored in the study by allowing for any additional, open-ended comments or opinions.

Links to the Round Three questionnaire (Appendix M) were included in electronic mail cover letters sent to all 35 panel participants on November 29, 2004, with a submission deadline of December 12, 2004 Thank you letters were sent to participants as questionnaires were submitted. Thirty-four questionnaires were received by December 12,2004 . One participant from the panel did not complete the questionnaire or submit it within the time period, despite a reminder letter. 
Since the initiation of Round One, no participant formally contacted the researcher to withdraw from the study. Overall, participants were timely in their responses and appeared motivated and committed to completing all rounds of this Delphi process. Results of the study, in the form of an executive summary, were sent as an Email attachment to all expert panel participants on December 22, 2004 along with a letter of thanks.

\section{Data Collection: Background Questionnaire}

The researcher decided to collect background information on expert panel participants and their representative schools to obtain a basic profile of the expert panel. The questionnaire was distributed between Rounds Two and Three of the Delphi process, rather than at the beginning of the study, to gather information from participants who were already consistently participating in the study.

Questions for the participant profile portion of the background questionnaire were developed based on models used in other Delphi studies. Since exact demographic information on institutions could be obtained by other means, questions on participant schools were designed to get a sense of panel member perceptions of percentages of host country and international populations of faculty and students. Correlations between institutional demographics and school leader perceptions were not the focus of this study so extensive school profiles were determined unnecessary. Future research may warrant a closer look at the exact demographic breakdowns of diversity in schools examined.

The background questionnaire (Appendix L) contained a total of 15 closed item questions about participants and their schools and one open-ended question asking study participants to briefly discuss how they would describe their cultural identity and the 
cultural influences in their lives. The background questionnaire was sent to panel members on November 22, 2004 and 34 surveys were returned.

\section{Data Analysis}

In a Delphi study, the researcher is required to compile, analyze, and summarize data from each round of questionnaires to provide feedback to the group of participants following each round of questioning and to use this data as a basis for designing questionnaires for subsequent rounds. After each round of questioning, emerging patterns or domains (e.g., community service) were identified from participants' written responses and tallied to determine how many participants mentioned each item. Complete summaries of all responses given were then sent to each expert panel participant, along with the number and percentage of panel members who reported each item following each round of questionnaires. In some cases, direct quotes from participants were also included in the summaries to enhance a dense of ownership. Summaries were sent to expert panel members, via electronic mail, for their review and reflection at least one week prior to the mailing of each subsequent questionnaire. Items selected for inclusion in each questionnaire were items either reported by at least four panel members or items that received a panel consensus of $75 \%$ or more in the preceding round of questioning. For purposes of this study, consensus was set at $75 \%$; however, literature on the Delphi technique confirms that more than $60 \%$ of panel agreement indicates a great degree of consensus, implying that even strategies rated as less essential, in this study, may prove to be useful in some school contexts, depending on the needs of a school. On questionnaires where participants were asked to rate items in terms of degree of 
essentialness, rating percentages of the participant group for each item were calculated by the on-line survey system and shared with expert panel participants.

First Round Data Analysis

For the first round of the Delphi process, the researcher tallied all participant responses given for each question on the Round One questionnaire. The researcher tried to ensure that all responses were recorded to maintain credibility and avoid researcher bias. Once all responses were listed, the researcher looked for broad themes or categories, where possible and tallied the number of responses for each emerging theme (Appendix G).

For question one, participants reported strategies for promoting global leadership development among students, teachers, and other community members. Results revealed a list of several policies, programs, and practices to be implemented school-wide. For question two, all possible challenges related to managing American international schools in Latin America reported by the participants. These challenges were then grouped into the following categories: academic challenges, attitudinal/behavioral challenges, demographic challenges, societal/governmental challenges, skills and resources challenges, and challenges related to school mission and policies. These challenges were then presented to participants in the form of a pie graph to reflect the percentage of challenges reported for each category. The pie graph was sent to participants as part of the Round One summary.

Suggested strategies for cultural proficiency for question three were tallied under the categories of potential school constituency groups originally presented in the questionnaire: faculty and staff; parents; students; and outer community members. The 
number and percentage of panel participants who reported each item, under each category, were determined and indicated on tables for participant review (see Appendix G). For question four, on ways that school leaders might influence cultural proficiency and global leadership development, the researcher also tallied the responses of participants and indicated the number and percentage of participants who reported each item.

\section{Second Round Data Analysis}

By completion of Round Two, the expert panel had reached a consensus of $75 \%$ or over on the most essential strategies (those rated a 4 or 5 on the rating scale) for developing global leadership and school-wide cultural proficiency in American international schools in Latin America. Panel consensus was also revealed in items related to ways that participants thought school leaders influenced the development of global leadership and school-wide cultural proficiency. The compiled summary of Round Two responses (see Appendix K) contained matrixes that displayed the degree of panel consensus on each rated item. Columns 4 and 5 on the rating scale were combined to determined the degree of consensus on those items rated high on the scale toward very essential. Round Two results also generated a list of potential barriers to cultural proficiency, as well as potential success indicators and measures. Finally, panel members expressed overwhelming agreement with the relationship between school-wide cultural proficiency and the development of global leadership skills and alleviation of cultural challenges. Numerous participant quotes were included in the compiled results summary sent to panel members regarding their perspectives on the ideas discussed up to this round of the Delphi study. 
Third Round Data Analysis

Data analysis for Round Three was found to be the most challenging because of the breadth and depth of data gathered. For three of the questions, the percentage of total participants who rank ordered each item was calculated to obtain a sense of perceived priority on the part of the group. The percentage of panel members who reported using certain success indicators to measure cultural proficiency was also calculated.

All other data was analyzed through a process of tallying responses and creating and collapsing domain categories and sub-categories for strategies given for: developing global leadership, handling barriers to school-wide cultural proficiency, and measuring success of cultural proficiency development. The same approach was used to determine what skills and formal training participants reported were needed by school leaders to influence and sustain cultural proficiency, as well as analyze participant explanations for choices and responses to previous questions. Comments given in response to the opportunity to freely comment on "anything else you would like to say about the topics discussed in this study," did not reveal any particular pattern. Only ten participants responded to this final question, primarily using it as an opportunity to express how they found the topic stimulating, important, and informative. Dissident or negative opinions were not expressed.

\section{Background Questionnaire}

Data from the background questionnaire was summarized according to actual numbers and percentage of panel members who reported each item. The question on cultural influences and identity (see Appendix L) was open-ended to allow participants the opportunity to describe their cultural identity rather than check a box. This 
information was reviewed for patterns or trends. Responses revealed that the panel represented a diversity of cultures, ages, experiences, and gender. At the end of the survey, participants were given the option to reveal their identity or that of their school. About two thirds of the participants agreed to reveal their name or the name of their school in association with this study, while others opted to have their participation in the study remain anonymous. Participants were also asked if they would be willing to participate in follow-up research on the topics explored in the study. A majority of study participants agreed to do so.

Background information reported on schools, experience levels, etc. was based on participant perceptions rather than actual hard data. In some cases, two participants may have worked at the same school and reported differently, however, the purpose of the background survey was to give a general profile of the expert panel participants and their perceptions of their position and work environment, not provide precise demographic data.

This data was shared with panel participants in a final executive summary that also included the results of Round Three and was distributed as an Email attachment to all expert panel members at the completion of the study, on December 22, 2004.

\section{Evaluation of the Delphi Method for this Study}

\section{Advantages of the Delphi Method for this Study}

The advantages of applying the Delphi method in this study closely reflected those indicated in the literature. Advantages to using the Delphi process to address the research questions in this study, combined with the opportunity to use on-line questionnaires, were numerous. First, the method allowed for participation of a group of 
widely geographically disbursed American international school leaders, from Mexico to the Dominican Republic, and from Venezuela to Argentina. Second, the level of anonymity provided by the method, allowed for free and uninhibited expression on the part of participants led to generation of a diverse range of responses. In general, participants wrote a great deal in response to each question posited on the questionnaires and appeared to freely express their concerns and dissident opinions. No particular group was able to dominate and each participant was free to express their own opinions and perceptions of the topics presented.

Third, Judd (1972) described the Delphi method as an educational tool. This proved to be the case of in this study as determined by the positive, enthusiastic comments and responses of participants on the Round Three questionnaire, as well as feedback received from individual participants and others in the field upon completion of the study. During the study, some participants expressed that they planned to implement some of the strategies suggested by the expert panel in their schools.

Fourth, the opportunity to provide participants with feedback throughout the study appeared to keep panel members highly motivated as evidenced in a more than expected response rate throughout all rounds of the study. Fifth, the method was versatile enough to allow for an initial exploration of the complex and seemingly nebulous concept of school-wide cultural proficiency applied to schools (American international schools) that receive little empirical attention, in a Latin American region of the world that is frequently overlooked by scholars. Finally, high quality ideas were produced that may both inform practice and be used as a basis for further more in-depth future research. 
The opportunity to use an on-line survey system and electronic mail had many advantages as well. The use of this technology may have contributed to the low attrition rate of panel members throughout the study because of fast transmission time and quick turnaround time in the receipt of questionnaires, feedback, and compiled group responses. Participants could complete their on-line surveys at their own convenience and submit them at any time of day or night. This allowed time and space for participants to reflect on the ideas discussed as well. The researcher was able to closely monitor questionnaire submission and easily send thank you notes and reminders to participants via list serve based on a master submission list. The researcher was also able to download data and cut and paste data in most cases.

Overall, use of the Delphi method allowed for the opportunity to obtain rich qualitative data through the use of open-ended questionnaires. Purely quantitative methods would not have elicited the in-depth opinions needed to begin to understand how the complex idea of cultural proficiency might to apply to American international schools in Latin America. Furthermore, the Delphi process of iterative questioning enhanced validity and allowed for group consensus to be reached on the ideas expressed. This data can be shared with practitioners to inform practice, forms a basis for further research on the idea of cultural proficiency applied to the American international school setting, and adds to a severely limited body of knowledge on international schools that operate in the Latin American region of the world.

Disadvantages of the Delphi Method for this Study

Some disadvantages to using the Delphi method for this study naturally emerged. The expert panel recruiting process was found to be arduous due to the timing of the 
study which occurred at the beginning of the school year. The amount of follow up required to line up panel members in so many different countries and schools was extensive. Frequent and consistent communication with participants was also required throughout the study.

While the researcher tried to maintain a tight timeline in the distribution, collection, and summarizing of data, the Delphi study still took a long time to conduct when compared to a one-time survey distribution for example. Even though, attrition is common in Delphi studies, only one initial panel participant did not complete the final two rounds and two school leaders who initially submitted consents forms, did not go one to complete the Round One questionnaire.

Other disadvantages became apparent through the researcher's maintenance of a subjectivity journal where the researcher attempted to note biases, concerns, and questions throughout the research process. On the one hand, the 'open' nature of the process sometimes brought about concerns related to tightness, validity, applicability to specific school cultures, and relationships between the questions and the ideas presented by the participants. While the researcher attempted to maintain a sense of participant ownership in the questionnaire format, at times, some of the initial questions and domain categories may have been over-specified by the researcher. Maintaining objectivity in the facilitator role was also sometimes challenging because participants would personally contact the researcher to enthusiastically compliment the ideas presented and, in some cases, request further information. Likewise, it was difficult to protect the anonymity of participants as some insistently requested to know which other schools and administrators were participating in the study. Anonymity was maintained until the end of the study. In 
all cases, the researcher tried to maintain a neutral demeanor and respond professionally by stating that further information could not be revealed until the end of the study.

Overall, however, the subjectivity journal helped the researcher monitor biases and more objectively analyze and summarize the entire range of participant responses.

There were some inevitable disadvantages to using an on-line survey system and electronic mail communications as well. On a few occasions, participants contacted the researcher because they were uncertain if their questionnaire had actually been submitted because the last page jumped to the website of the on-line service provider. On other occasions, participants did not receive information or could not open attachments due to firewalls and spam prevention software. Occasionally, technical difficulties or computer problems hampered the process by delaying communications. In general, however, the advantages of electronic mail outweighed the disadvantages of electronic mail in this study.

\section{Summary}

This study was designed to begin to explore how formal school leaders working in American international schools in Latin America might characterize school-wide as a means of enhancing global leadership development. The study specifically aimed to uncover possible essential features of and barriers to proficiency in these schools. The Delphi process was selected as the most appropriate method to address the research questions in this study because the study participants were widely geographically disbursed and the complex notion of cultural proficiency had not yet been explored in Latin America. Thirty-five selected school leaders representing twenty-five schools in fourteen different countries participated in the study. The Delphi process involved three 
rounds of open-ended questionnaires, along with ratings and ranking of previous response items, and one background questionnaire to gather information on panel participants and their institutions. The complete study took approximately four months to complete.

Chapter four summarizes the key findings of this Delphi study by research question. Findings reflect expert panel consensus on ideas explored through the three rounds of Delphi questionnaires and the background questionnaire. 


\section{CHAPTER FOUR \\ FINDINGS OF THE STUDY}

\section{Introduction}

The purpose of this study was to explore what school leaders in American international schools, in Latin America, would consider essential features of and barriers to developing school-wide cultural proficiency as a means of enhancing the global leadership abilities of students, teachers, and other school community members. The study also examined how school leaders believed they might influence cultural proficiency and acquire the skills and success indicators necessary to develop and sustain school-wide culturally proficiency and global leadership development in their schools. Participating school leaders also identified unique challenges to operating American international schools in the Latin American region. The Delphi method was selected for this study because it allowed for an initial exploration of perspectives from a geographically dispersed panel of school leaders on a concept that had not yet been examined in American international schools in Latin America.

This chapter highlights the key findings of this study. These findings reflect the group consensus of an expert panel of 35 formal school leaders who were working in American international schools throughout Latin America in 2004. The findings presented in this chapter are organized by the four major research questions and two subquestions that guided this study. The data presented reflects information distilled through three rounds of participant questioning. This process involved identification and categorization of emerging themes from written text, rating of these items to determine group consensus on the essential features of and barriers to school-wide cultural 
proficiency and global leadership development, further inquiry into why participants reported certain information the way they did, and a final participant ranking of the importance of each item to cultural proficiency and global leadership development. Quotes by individual panel participants are presented throughout this chapter to illustrate the varied opinions provided by the study participants and provide support for the themes that emerged in the Delphi process.

Following these key findings, some background information on the panel participants and their institutions is provided. This information was gathered by a demographic questionnaire that was administered to panel participants between Rounds Two and Three. The background questionnaire was conducted near the end of the study after participant 'buy-in' and rapport with the expert panel had been well established.

\section{Key Findings}

Research Question \#1: How, if at all, do school leaders in American international schools in Latin America believe that school-wide cultural proficiency might contribute to the development of global leadership abilities among students and other members of the school and outer school community?

Throughout this Delphi process, expert panel participants expressed a consistent consensus that school-wide cultural proficiency could enhance global leadership development in American international schools in Latin America. The extensive data collected, in the form of written text, confirmed this idea and was consistent with many of the elements presented in Lindsey, et al.'s (2003) model for cultural proficiency in schools. No panel members expressed dissenting opinions related to this research question. One participant quote, in particular, embraced the potential benefits of cultural proficiency by stating: 
The higher the cultural proficiency is in an organization, the more successful it can be as it can encourage any and all members to take a leadership role. If all members of the school feel supported and equally valued in the school, more emphasis will naturally be placed on developing excellence rather than finding excuses and focusing on problems and barriers. A culturally proficient school environment can be a model for all school members to learn from and emulate within a more global context. Students will grow to expect a culturally proficient community and will have high expectations of larger communities they may become a part of. They, due to their experiences in a culturally proficient environment, can become models within larger global communities.

Data revealed that most participants believed that the students attending their schools were destined to become future global leaders. They also emphasized the importance of involving all stakeholders or constituency groups in strategic decisionmaking processes and stressed the essential tasks of building community and enhancing community outreach as indicative of school-wide cultural proficiency in American international schools operating in the Latin American region. These ideas reflect adherence to the academic literature supporting the idea of organizational cultural proficiency presented in the review of the literature presented in Chapter Two.

The following participant ideas reflect panel perceptions of the role of schools in preparing competent future global leaders:

As the world moves steadily toward a more interconnected and interdependent economic, political, and social environment, the next generation will be required to have increased cultural proficiency and global leadership skills. I have always believed that schools mirror society. As such, schools are obliged to incorporate the understanding, skills and concepts necessary for the reality of our everincreasing global world.

We are teaching the future decision makers. They may be involved in a variety of fields, such as manufacturing, development, finance, government or education, yet they will be leaders of those fields. We need to give our students voice and expose them to other voices.

If the purpose of education is to prepare our students to lead the world of tomorrow, then developing school-wide cultural proficiency is not only a sound school principle, but also a necessary obligation to our host nation and wider society. 
Some expert panelists emphasized how culturally proficient strategies allow for a wider array of "voices" to be considered in decision-making. Participant data supporting this idea focused on the essential involvement of all stakeholders and constituency groups in a school, along with a greater allowance for participation by students in determining school-wide strategies:

If all of the stakeholders know and understand the mission and accept the policies, then the school can move forward educating the students and helping the host country understand the benefits of a global education. The students will graduate knowing the value of service, inclusiveness, and being well educated for all global societies.

Cultural proficiency promotes inclusion and addresses the importance of student "voice" in school strategy as well. This way students can really learn the necessary leadership skills to be truly effective leaders.

Other panel participants stressed the how cultural proficiency in American

international schools could foster more positive outer community relationships with the host country culture in which schools operate, for example:

The perception of the local community of what our school is tends to be negative (a symbol of foreign power). Unwittingly, we contribute to that perception by seeming to be detached from events around us. By fostering school-wide cultural proficiency, members of the school community will be more likely to participate, appreciate, or even embrace some of the cultural norms of the country. As it becomes apparent that this is the case, the community may see us in a more positive light while at the same time allowing us to reach out and provide expertise in the areas where that aid may be required.

This idea reflects participant awareness of the cross-cultural nature of an American school placed within the setting of a developing nation and the connotations of "imperialism" that this may represent.

In Round Three, participants were asked to rank order (by level of importance) five strategies for developing global leadership in schools. These strategies had been 
previously identified and rated according to how essential they were perceived to be by participants in Rounds One and Two. Participants ranked these five strategies for enhancing global leadership development in schools by level of importance, from 1 (most important) to 5 (least important). Strategies were ranked as follows based on panel consensus.

1. A school mission that reflects culturally diverse perspectives.

2. Global curriculum with learning outcomes.

3. Cultural awareness training.

4. Community service.

5. Traditional cultural celebrations and events.

In previous Rounds One and Two of the Delphi, participants considered eight items to be essential to enhancing global leadership abilities in students, teachers, and other school community members.

1. Active teaching and role modeling of the value of diversity.

2. Emphasis on tolerance and acceptance of diverse cultures.

3. A school mission that reflects culturally diverse perspectives.

4. Community service.

5. Demonstration of democratic process.

6. Cultural awareness training.

7. A global curriculum with learning outcomes.

8. Traditional cultural celebrations and events.

The item "Model United Nations program for students," originally cited by the Delphi panel in Round One, was not included in the Round Three questionnaire because 
it was not rated essential or very essential by the majority of panel participants in Round Two. This indicated a distinct shift from Round One, where the majority of the panel participants mentioned "Model United Nations program for students" as a key way to promote global leadership. This shift can be observed in comparing the Round One (Appendix G) and Round Three (Appendix N) results.

The two top-rated items, (1) "teaching and role modeling of the value of diversity" and (2) "tolerance and acceptance of diverse cultures" were separated from the list of items in the Round Three questionnaire, along with item (5) on "demonstration of democratic process." These items were separated from the other emerging features for closer examination, because some panel members expressed that these three ideas seemed vague and intangible and were difficult to visualize in actual day-to-day practice. Participants asked for more concrete examples of what these features looked like in terms of behaviors, policies, or programs. The following panel member quote exemplifies this concern:

I think we give a lot of lip service to tolerance and value of diversity, but what does that actually mean in terms of actual practices and policies in our schools?

Another participant stated:

What do we mean by teaching and role modeling the value of diversity and democratic process?

To address these concerns, in Round Three, participants were asked to provide examples of how these strategies of role modeling and teaching value, tolerance, and acceptance of diverse cultures could actually be carried out in American international schools. Expert panel examples for both: (a) "teaching and role modeling the value of diversity" and (b) "tolerance and acceptance of diverse cultures" were combined based on 
similarity of responses. Appendix $\mathrm{N}$ contains a complete list of participant suggested strategies. The strategies listed below were indicated by four or more participants and are ordered from the most frequently mentioned to the least frequently mentioned:

- Hold international day/week/month celebrations and activities that are linked to the curriculum and more than a "food fair."

- Create an integrated curriculum that reflects global cultures, religions, history, and geography, including host culture.

- Hire people who value cultural diversity and represent diverse backgrounds.

- Require school-wide community service programs (e.g., service learning, Habitat for Humanity project).

- Clearly state expectations for adult and student behavior (e.g., handbooks) to emphasize zero tolerance for exclusionary or discriminatory behavior.

- Use literature and drama from different cultures to enhance empathy and understanding.

- Ensure administrators and teachers model a value for diversity by using accountability measures in performance appraisals.

- Provide "real-life" opportunities to learn from and about others who are culturally different (e.g. experiential education, simulations).

- Create culturally diverse teaching and project teams.

- Have a character education program that incorporates cultural acceptance and learning.

When asked to elaborate on what was meant by, "demonstration of democratic process," panel participants expressed overwhelming consensus on two main points. First, panel members agreed that democratic process was best promoted by student programs normally sponsored in most American international schools including: Model United Nations, Student Council, and other student government organizations. However, 
panel members emphasized a greater need for authentic student "voice" and input into decision-making so students could truly learn from and experience democratic process.

Second, panel members emphasized the importance of considering more ways to encourage collaborative, consensus making throughout the school (with all school members) and ensure greater, yet balanced, input from the various cultural groups and stakeholders in a school.

Research Question \#2: How do school leaders in American international schools in Latin America characterize a culturally proficient school in terms of essential features (e.g. policies, programs, practices, or others) that involve all school community members, directly impact students, or reach extended audiences (or outer communities)?

Through the three rounds of questioning, expert panel participants identified and reached a consensus on seven essential features of culture proficiency. These seven essential features included:

- Student community service.

- Integration of curriculum to reflect global perspectives and cultural diversity.

- Diversity in staffing and leadership positions.

- Orientations on local culture for overseas (international) staff.

- Encouragement of intercultural interactions and dialogue between students.

- Language acquisition and cultural orientations for faculty.

- Staff development/training on cultural awareness and the value of diversity.

In Round Three, participants were asked to rank these essential features of cultural proficiency in order of perceived importance. Some panel members commented 
said they would have given all strategies equal weight of importance, if possible, as in the following quote:

Ranking these essential features is tough, as I would actually place many of them at the same level of importance.

Appendixes $\mathrm{J}$ contains all participant rating percentages on the essentialness of each identified feature. Appendix $\mathrm{N}$ contains rank ordering percentages for each of these items and indicates that consensus was not reached on a precise ranking of importance.

While nearly all panel identified items were agreed to be essential to cultural proficiency, "integration of curriculum to reflect global perspectives and global diversity" was the only feature clearly ranked as more important than the others in developing school-wide cultural proficiency in American international schools in Latin America. Participants reported ranking this feature as one of the most important for some of the following reasons:

A school is what it teaches and does not teach. The curriculum is a written commitment of what, how, and when children are taught and what educators should be accountable for.

A curriculum that focuses on international understanding, as opposed to a more focused, strictly "American" curriculum is more in keeping with today's realities and needs.

The curriculum is the most important expression of what is valued at a school.

If the curriculum does not reflect global perspectives, then teachers will not find the time for this focus.

Cultural proficiency has to be part of the day-to-day functioning of a school, not just a one time classroom, activity, etc. The best way to accomplish this is to integrate the concept into the curriculum.

The following strategies were given equally middle rankings (fourth) of importance by the majority of panel participants: 
- Orientations on local culture for overseas (international) staff.

- Encouragement of intercultural interactions and dialogue between students.

- Staff development/training on cultural awareness and diversity.

Panel participants were polarized at two extremes on the dimension of most important to least important in their rankings of the feature, "diversity in staffing and leadership positions." These extremes in ranking clearly indicated disagreement on the importance of this item. While some participants described why they ranked the importance of hiring diverse staff and leadership as one of the most important features, as demonstrated by the following quotes, no panel members gave explanations for giving this item a low ranking:

It is essential to find outstanding school leaders who can professionally improve the organization but also add to diversity. It seems a little naïve to preach tolerance and respect for different races, religions, genders, etc. and hire all male, Caucasian, Christian administrators.

Diversity at the 'decision making' level sends a strong message and ensures culturally wise decisions. Predominance of one section of the community results in culturally wise decisions.

Diversity in staffing is a must in overseas schools in Latin America. It's the only way to insure multiple perspectives are represented in decisions, curriculum and activities.

Participants were also split in their rankings of the importance of "language acquisition and cultural orientations for faculty." Twenty-one percent of the group considered this strategy relatively important, by ranking it third, while another twentyone percent of the group considered language acquisition and cultural orientations for faculty one of the least important essential features of cultural proficiency. This disagreement may be influenced by the degree of cultural diversity in individual school contexts and the needs that arise as a result. It also may reflect differing levels of 
consciousness regarding language and culture or differing opinions regarding the value of language and culture training programs in schools.

Since the Round Three questionnaire asked participants to explain why they ranked the top three items the way they did, another key finding emerged. After exploring the notion of school-wide cultural proficiency, a primary focus on students was stressed by many expert panel participants who expressed that policy, programs, and practices which develop community responsibility, global awareness, cultural sensitivity, and leadership abilities in students were the most essential. The following participant quotes from Round Three reflect these sentiments:

As I have completed the surveys, I have found myself going back and forth between developing cultural proficiency in staff and in students. My answers to this round have focused more on the student domain, where I believe the development of school wide cultural proficiency can be more easily fostered and have greater impact.

The three I ranked the highest are opportunities for students to experience and express their opinions.

The literature on change and inclusion in schools also supports the importance of including diverse student "voices" in leadership development (Fullan, 1991).

Research Question \#3: How do experts believe that school leaders can influence cultural proficiency and global leadership development in American international schools in Latin America?

Six major themes emerged from panel participant responses to this question in Round One. In Round Two, participants were asked to rate these six items according to how essential they were to the development of global leadership and cultural proficiency. All six items were rated essential or very essential by $80 \%$ of more of the study participants. 
The six major ways participants reported that American international school leaders could influence cultural proficiency and global leadership in Latin America include the following. Items are listed in order of how essential they were rated by the majority of Delphi panel participants from the most essential to those items perceived to be slightly less essential:

1) Modeling/setting an example through culturally proficient values, attitudes, and behaviors (both overt and subtle).

2) Demonstrating value for local host country cultures in both attitude and behavior.

3) Incorporating cultural proficiency and global leadership into everything the school is and does, both curricular and extracurricular (from mission statement to classroom decorations).

4) Sponsoring community service and citizenship projects that actually build relationships with the outer community.

5) Prioritizing objectives of intercultural understanding in the mission statement and school vision.

6) Ensuring culture and language training sessions are conducted for various groups in the school.

Many expert panel participants emphasized the importance of school leaders modeling behaviors that exemplify cultural awareness and sensitivity as evidenced in the following quotes:

School leaders provide the vision and guide the resources and staff of the school. They determine the agenda and create the channels of communication...They must be open to the voices of all constituency groups, but also encourage and guide these groups to better understand one another. 
School leaders are the KEY catalysts in a school moving towards a level of cultural awareness and sensitivity.

School leaders set the tone...(and) influence through their actions and words in both overt and subtle ways.

Effective leaders create an environment where it is clear to all that global leadership and cultural proficiency are important, that these characteristics will be modeled by the administration and staff and incorporated into the daily life of the school, and that a means of assessment will be implemented to monitor reality with the ideal.

Since most top administrators are hired from North America, many panel members focused on school leader attitudes toward the host country culture in which an American international school operates and the importance of local community outreach programs. Examples of this sentiment include:

School leaders should first learn the language of the country and quickly learn what s/he likes or dislikes about the local culture. If s/he dislikes many things, $\mathrm{s} /$ he should move on ...to avoid becoming bitter about the local environment and passing this bitterness on to others.

Leaders cannot belittle the local culture no matter how frustrated they are personally with certain aspects. Leaders should encourage staff to learn the language and local customs to avoid offending local citizens.

The history of American involvement in Latin America is not enviable. American schools must present an alternative to the traditional view of U.S. led interventions or support for dictatorships in the area by sharing resources, training, and knowledge with the local community by offering training sessions on modern educational techniques to teachers in the public school system... and by promoting social service programs that may make a valuable contribution to the future of these countries by reducing the pervasive social segregation that tends to exist in Latin America...

For some Delphi panel members, the notion of "community" also involved developing stronger ties to other American international schools around the topics of cultural proficiency and global leadership development: 
Leaders must develop better modes of communication with other American international schools...(cultural proficiency) cannot be achieved in isolated learning communities, but rather must be done in concert with others.

Some participants stressed the importance of an overall school-wide strategy that involves the participation of stakeholders in articulating and working towards a school mission/vision that move schools toward cultural proficiency:

...Every stakeholder should have a role in articulating the school mission/vision and practices that ensure the school works toward this mission. Every stakeholder should have a role in the process and be held accountable.

Other participants emphasized the importance of going beyond the school mission/vision, for example:

It is not enough to put global leadership comments in the mission statement; rather schools must actively pursue these goals on an ongoing basis. International schools must also recognize that 'leadership' is viewed in different ways in different cultures. There is a tendency to nurture an American leadership perspective...schools need to be more aware of this at a conscious level and be more transparent (in differentiating) traits that are more global from those that are more American.

A few of the school leaders on the expert panel appeared to have some prior familiarity with the idea of school-wide cultural proficiency as revealed by comments that directly addressed elements of the cultural proficiency model for schools, for example:

School leaders must be aware that cultural proficiency is enhanced in a myriad of ways. Not only through activities and programs, but also through communications, curriculum, training workshops, etc. Culture (like values) is not something you 'teach,' it is something you have to experience and model. Everything a school is and does reflects our values: from classroom decorations to the celebrations we decide to include in the calendar. Cultural proficiency is reflected in the 'hidden curriculum' as well. 
Responses by expert panel participants in the Round One survey indicated that the idea of school-wide cultural proficiency was salient to some school leaders at the beginning of the Delphi process and supported the literature reviewed in chapter two.

Research Question \#4: What are the perceived barriers to developing cultural proficiency in American international schools in Latin America? How do these identified barriers relate to the general challenges of managing American international schools in Latin America?

In Round Two of the Delphi process, expert panel participants were asked to identify potential barriers to developing school-wide cultural proficiency and global leadership. Six primary barriers emerged from these responses as named by four or more panel members. Appendix $\mathrm{J}$ provides a complete list of all identified barriers based on a total of 34 participant responses for Round Two. In Round Three, panel members were asked to rank the top six reported items from 1 (greatest barrier) to 6 (least great barrier). A majority of panel members ranked the barriers to developing school-wide cultural proficiency and global leadership as follows (see Appendix $\mathrm{N}$ for ranking percentages):

1. Exclusive (elite) values of student and parent populations.

2. Demographic/cultural makeup of student population.

3. Ethnocentric attitudes and behaviors of host country and international groups.

4. Resistance to change.

5. Frequent faculty turnover.

6. Time constraints.

The primary barriers listed above can be defined as follows, based on the comments provided by panel participants in Round Two. These barriers emerged from participant comments. 
"Exclusive, elite values of student and parent populations" refers primarily to the high socioeconomic status of most of the students who attend American international schools in Latin America and, in some cases, the attitudes, values, and behaviors that elite societal status may represent. Panel member comments related to this identified barrier include:

It is more about status that acquiring a quality education and an appreciation of other cultures.

Parents may say they value global leadership and cultural proficiency, but when it comes down to it, they are more concerned about whether their child will get into the university of their choice or learn English.

Values of diversity and community outreach threaten the lifestyles and elite values of the wealthy host country nationals that attend American schools in Latin America.

The demographic/cultural makeup of the school population was considered a barrier by the Delphi panel because each school has to address particular cultural challenges that depend on variations in the percentages of international versus local students and faculty members. Tensions often occur in attempting to meet the various needs and interests of culturally diverse groups. As discussed in chapters one and two, local students and teachers often represent the majority in international schools in Latin American countries, yet the schools are U.S. accredited and considered "American." Diversity percentages in student enrollment and faculty makeup often impact language instruction, school policy, cultural events, and the overall school culture. One participant confirms this in saying:

It is difficult to satisfy all constituencies...strategies are not necessarily viewed as compatible by parents and students representing different cultures.

With such a large percentage of host country nationals, it is really difficult to enforce that English be spoken throughout the school and the school day. 
Study participants noted ethnocentric attitudes by both host country and international populations as a major barrier. Conflict in values and expectations of students, faculty, and parents representing different culture groups was reported common. This barrier is confirmed in the extensive academic literature on intercultural relations referred to in chapter two. "Resistance to change" was noted as another barrier and has proven to be an evident part of any change process in schools (Fullan, 2001).

"Frequent faculty turnover" and "time constraints" were ranked the least great barriers to cultural proficiency. As discussed in chapter three, overseas hire teachers tend to have the greatest faculty turnover due to the temporary nature of their typically twoyear contracts. Local hire faculty in Latin America; however, often have long-term stability and may spend a career in these schools (ISS, 2004). While the majority of participants in Round Two listed 'time constraints' as a barrier, it was ranked the least great barrier in Round Three.

\section{Expert Panel Suggestions for Approaching Primary Barriers}

To inform practice and identify potential solutions to the barriers to cultural proficiency cited by expert panel members, in question six of Round Three, participants were asked to give examples of potential strategies for handling the three barriers they ranked as greatest in question five. Panel participant suggestions for confronting the named barriers to school-wide cultural proficiency are listed below and reflect a groupranking consensus. The information was elicited from the study participants to further inform practice and set a basis for future research.

1. Exclusive (elite) values of student and parent populations. 
- Require community service and service learning to help overcome elite, sheltered upbringing of students.

- Purposeful parent education and dialogue about cultural issues.

- Social opportunities for parents to interact.

- Help parents understand the importance of global understanding by allowing it to come from them (those in the community that express this value or interest) so it does not seem imposed.

- Have equitable and consistent policies and the integrity to truly practice democratic values. Don't be bullied by powerful, influential families.

- Get commitment to school-wide cultural proficiency at the Board of Director level and then work down.

2. Demographic/cultural makeup of student population.

- With more homogeneous populations (e.g., large percentages of local students), create a strong marketing campaign to diversify student population, limit number of dominate culture students, and promote different types of cultural exchanges.

- Ensure appropriate and high quality English as a Second Language support.

- Provide more "real life" opportunities to interact with other culture groups through school-to-school partnerships with the U.S. or other countries and include on-line (electronic communities) as an outlet/opportunity in culturally homogeneous schools.

- Emphasize the importance of speaking English throughout the school using incentives, modeling, and positive reinforcement, not punishment. 
3. Ethnocentric attitudes and behaviors of host country and international groups.

- Directly influence student attitudes (future global and country leaders) by creating a culturally proficient and sensitive school culture.

- Seek numerous ways to encourage intercultural interactions and foster relationships.

- Build common vision and involve all potential stakeholders.

- Sensitize and educate people in the school community.

- Diversify the leadership body at the board, administrative, faculty, and student levels.

- Parent volunteer groups to stimulate intercultural interactions.

4. Resistance to change.

- Rotate local hires in administrative positions.

- Train top staff to handle change.

- Work out proposed changes bottom-up by slowly working with individual segments of the community and slowly integrating larger groups.

- Celebrate "small victories" toward desired change.

- Teach and learn about the change process (Board, administrators, teachers, parents).

- Practices can be imposed in a school, even if points of view cannot. Sometimes resistance is only broken down by doing, learning, accomplishing.

- Strategic planning.

- Open and continuous communication.

5. Frequent Faculty turnover. 
- Stagger foreign hire renewal.

- Create a school culture and curriculum that survives staff turnover. Newcomers should fit the fundamental philosophy of the school culture.

- Create a school climate that makes quality staff members want to stay.

- Create incentives and attractive professional development opportunities.

- Have longer contracts.

- Create supports for staff (e.g., Personnel Officer) to handle "life stuff."

6. Time constraints.

- Develop inter-disciplinary study units.

- Have a strategic plan for organizational level cultural proficiency that should naturally be integrated into all other programs and activities targeted to various school groups. Not a separate, additional task.

General Challenges of Managing American international schools in Latin America

In Round One (Appendix E), participants were asked to list what they perceived to be three major challenges to managing these schools to obtain school leader perceptions regarding general challenges experienced by school leaders working in American international schools in the Latin American region. Participants reported a total number of 105 responses to this question. Same items were tallied and then grouped into six emerging challenge categories, as follows:

- Academic challenges (e.g., curriculum and instruction).

- Behavioral/attitudinal/value challenges (e.g., needs, expectations, perceptions).

- School mission and policies.

- Demographic challenges (e.g., diversity breakdown). 
- Society/government challenges (e.g., political turmoil).

- Skills and resource challenges (e.g., money, time, resources, professional skill levels).

These panel-cited challenges were then referred to in future questionnaires to stimulate reflection on the other ideas explored in the study.

In examining the relationship between the general challenges of managing American international schools in Latin America and the barriers to cultural proficiency, overlap was apparent in nearly all area but one, societal/government challenges. Societal and government challenges included political turmoil, violence, and fluctuations in the world economy. Overall, panel participants expressed consensus that culturally proficient school-wide strategies would help alleviate most of the general challenges of managing American international schools by providing an approach to assessing cultural impacts in these schools and creating potential solutions through school-wide strategies.

Research Subquestion \#1: What skills, training, and experiences do school leaders believe would enhance their abilities to develop and sustain cultural proficiency and global leadership in American international schools in Latin America?

Expert panel members identified several skills, training, and experiences that they believed enhance school leaders' abilities to effectively influence and sustain cultural proficiency and global leadership development in American international schools in Latin America. Study participant responses are listed below beginning with the most frequently mentioned ideas:

1. International/cross-cultural work experiences.

2. Language abilities (incentive package for proficiency). 
3. University coursework in intercultural communication and cross-cultural management for administrators and teachers.

4. University level required exchange programs (to and from the U.S.).

5. Collegial contact with other school leaders through associations, conferences, workshops.

6. Training in Change Management.

7. Greater involvement of relevant associations in these topics (e.g. SACS, Association of American Schools in South America (AASSA), Academy of International School Heads (AISH), The Tri-Association, Association for International Education (AIE), etc.) to better support school leaders.

8. Conflict resolution training.

9. More thorough understanding of cultures and subcultures in Latin America, as well as other world cultures.

10. Forums for board members and school heads to address global leadership issues.

11. Understanding of organizational (school) culture and how to incorporate and address diversity.

12. Knowledge of action research methods for gathering organizational level data.

13. Skills in strategic planning and vision building.

14. Team building and facilitation skills.

15. School-to-school partnerships.

16. Personal qualities of openness, ethics, culturally competent values and behaviors.

17. Stakeholder integration and community outreach abilities. 
Research Subquestion \#2: How do school leaders think that cultural proficiency might be measured and monitored in American international schools in Latin America? What do they perceive to be potential success indicators?

The potential measures and success indicators listed in Table 1 illustrate items identified by the majority of panel members in Round Two. Table 1 also shows the percentage of total panel members who indicated that these success indicators were currently being used at their schools.

Table 1

Reported Use of Success Indicators to Measure School-wide Cultural Proficiency $n=34$

Indicator \% of Participants \# of Participants

Measured attitudes of all stakeholder groups. $\quad 73.5 \% \quad 25$

$\begin{array}{lll}\text { Student-initiated community service. } & 73.5 \% & 25\end{array}$

Participation levels of various cultural groups $\quad 70.6 \% \quad 24$

in school-wide events.

Observed intercultural (social) integration. $\quad 58.8 \% \quad 20$

$\begin{array}{lll}\text { None of these. } & 8.8 \% & 3\end{array}$

Panel participants reported various ways that they believed these success indicators could be used to monitor and assess cultural proficiency and global leadership development in American international schools in Latin America. The following measurement strategies emerged from the participant data collected:

- Strategic planning process that includes data collection and analysis.

- SACS re-accreditation process.

- Attitudinal surveys of various groups in the school including: teacher and student surveys; anonymous parent surveys; community climate surveys to 
address questions related to diversity and leadership; an NSSE survey with all school members including students in grades 3 and up.

- "Building a Better Community Council" with stakeholders representing various school community members, including students.

- Tracking of stability of enrollment and staff, positive comments from families, teacher, and students.

- Exit surveys and interviews for families and teachers.

- Documented disciplinary action related to lack of cultural tolerance.

- Informal sessions (coffees, meetings, etc.) with various groups, including new students and international families.

- Number of student community service organizations, student initiated projects, sustainability of these projects, and participation in them.

- Assessment of curriculum standards for diversity and global understanding.

- Counting actual numbers of participants who participate in a school activity. Hourly participation recorded.

- Amnesty International club.

- Focus groups.

- Informal observations around the school.

While the majority of panel participants confirmed that their current schools used some kind of measures to monitor programs and attitudes of various constituency groups toward the school, most expressed that cultural issues were not directly addressed, even though they reported challenges and learning opportunities related to the culturally diverse and cross-cultural settings of their schools. No panel participants mentioned that "cultural audits" were conducted in their schools. 


\section{Background Information on Expert Panel Participants}

The background questionnaire contained a total of ten background questions. The questionnaire was sent as an electronic mail link to the 35 expert panel participants who responded to the Round One questionnaire. Of these 35 participants, 34 returned the background questionnaire. Tables displaying specific percentages and numbers reported for each question item are displayed in Appendix L.

Formal school leaders from American international schools in fourteen different countries participated in this study including: Argentina, Bolivia, Brazil, Chile, Colombia, Dominican Republic, Ecuador, Guatemala, Mexico, Nicaragua, Panama, Paraguay, Uruguay, and Venezuela. There was a fairly equal distribution of school leaders representing small, medium, and large schools. Schools varied in the degree of faculty diversity and demographic enrollment of students. Some were highly international, while others had large percentages of host country national students and faculty.

The expert panel included eleven heads of school (e.g., directors), seventeen principals, two country directors, five curriculum coordinators/lead teachers, and one counselor. Of the seventeen participating principals, eight were secondary principals; six were elementary principals; two were K-12 principals; one was an early childhood principal; another was a middle school vice principal; and another was an elementary vice principal.

Participant gender was closely distributed between men and women. Of the thirtyfour respondents to the demographic questionnaire, sixteen were women and eighteen were men. 
Based on participant self-descriptions, the expert panel was culturally and ethnically diverse. While most participants were from the U.S. or Canada, others were born and raised in Latin America and some were raised in bi-cultural/multicultural families. Panel members also grew up in both rural and urban settings and most had considerable experience living and working in different countries and cultures. Some school leader participants permanently reside in the countries where they work because they are either country nationals or North American citizens married to host country nationals.

\section{Summary}

This chapter presents the key results of this Delphi study by research question. There was a clear consensus by expert panel participants that school-wide cultural proficiency provided a potential framework for enhancing global leadership development and alleviating some of the cultural challenges of managing American international schools in Latin America. Panel participants identified seven essential features of cultural proficiency for these schools and six potential barriers to cultural proficiency development in these schools. Findings also included: how leaders can promote cultural proficiency and skills and training need by leaders; strategies for confronting barriers to cultural proficiency; and potential measures and success indicators for monitoring cultural proficiency development.

In chapter five, the study and key findings are summarized. Implications of these findings are discussed in relation to the theoretical framework of cultural proficiency applied in this study. Limitations to the study are then presented, along with recommendations for practice and future research. 


\section{CHAPTER FIVE}

\section{IMPLICATIONS, LIMITATIONS, AND RECOMMENDATIONS}

\section{Introduction}

This exploratory study examined how the model of cultural proficiency for schools and school leaders (Lindsey, et al., 2003) might serve as a framework for American international schools in Latin America to develop policies, programs, and practices that reflect culturally diverse perspectives and promote the global leadership development of students, teachers, and other school community members.

This chapter begins with a summary of the study and its key findings. Implications of findings are then discussed in reference to the theoretical framework of cultural proficiency for schools and school leaders applied in this study. Implications specifically address: (a) the primary essential features or strategies for cultural proficiency identified in the study; (b) school leadership; and (c) barriers to developing cultural proficiency in these schools. The limitations to the study are discussed, followed by recommendations to school leaders, supporting international education associations, and graduate programs in teaching and educational administration. The chapter concludes with recommendations for future research on the topics explored in this study and a few final words.

\section{Summary of the Study}

American international schools in Latin America educate future leaders and, therefore, can play a vital role in preparing people to effectively interact with people of diverse cultures. This study was designed to explore how formal school leaders, working in American international schools in Latin America, would characterize school-wide 
cultural proficiency as a means of enhancing intercultural learning and global leadership development in these schools. The study also explored barriers to cultural proficiency development and potential strategies to confront these barriers. The influence of school leaders in promoting school-wide cultural proficiency was also explored, along with identification of the skills, training, and experiences needed by school leaders to carry this out. Study participants also proposed possible success indicators to assess and monitor cultural proficiency development in American international schools in Latin America.

The Delphi technique was selected as the most appropriate method to address the research questions in this study for two main reasons. One, study participants were widely geographically disbursed in fourteen countries throughout Latin America, and two, the complex notion of cultural proficiency had not yet been examined in American international schools in Latin America. The model of cultural proficiency required initial subjective exploration by experts to determine how it might be applied in these schools and operationalized for future research.

Based on set criteria, thirty-five formal school leaders were selected to serve on an expert panel to examine the research questions posed in this study. Selection criteria included: a formal administrative title (e.g., principal), active membership on a school administrative or leadership team, and at least two years of experience living and working outside of a one's home country.

The Delphi process involved three rounds of open-ended, questionnaires distributed on-line to expert panel participants. Questionnaires required participants to respond in writing or, in some cases, rate or rank order previously reported items to 
determine group consensus. Written text was analyzed to identify and categorize emerging themes. Tallies were made for each emerging theme to record how many panel participants mentioned each item in their written responses. Items reported by four or more participants on the Round One questionnaire were included in matrixes on the Round Two questionnaire for participants to rate how essential they perceived each item to be on a Likert scales. Group consensus for rated items was determined at seventy-five percent or above for each item. Questionnaire Three asked participants to further rank order these items in terms of their perceived levels of importance to the development of global leadership and school-wide cultural proficiency to determine if certain features took priority over others. In all rounds, additional open-ended questions were included to elicit more in-depth information, illuminate participant perspectives and proposed strategies, and address the research questions proposed in this study. To obtain a profile of the expert panel, a background questionnaire was administered between Rounds Two and Three to gather general information on participants and their institutions.

After each round of questioning, expert panel participants were sent a copy of compiled group results to review and reflect upon in preparation for the next round of questioning. Anonymity of all group members and their institutions was maintained throughout the study. The entire study took approximately four months to complete.

\section{Summary of the Findings}

A breadth of data was collected in this study that may inform practice and form a basis for future research. The essential features of cultural proficiency and global leadership development revealed in this study provide tools for assessing school culture and developing cultural proficient policies, programs, and practices in American 
international schools in Latin America. Essential features included: (a) a shared vision that reflects culturally diverse perspectives; (b) a global curriculum with learning outcomes; (c) consistent modeling and teaching of value of diversity; (d) cultural awareness training and workshops for various constituency groups; (e) community service that builds relationships; (f) traditional cultural celebrations; (g) democratic decision-making process; (h) culturally proficient leadership; (i) diversity in staffing and leadership; (j) and assessments to monitor cultural proficiency development.

Major barriers to cultural proficiency identified in this included: (a) elite values of students and parents; (b) ethnocentric values of cultural groups; (c) the cultural makeup of the student population; (d) resistance to change; (e) faculty and administrative turnover; and, lastly, (f) time constraints. The expert panel suggested numerous strategies to confront these barriers in schools.

Participants reached consensus on essential ways that school leaders influence cultural proficiency and global leadership development in American international schools in Latin America, such as: (a) modeling culturally proficient values, attitudes, and behaviors; (b) valuing host country cultures; (c) strategizing for culturally proficient school-wide policies, programs, and practices; (d) supporting community service that builds relationships with the outer community; (e) integrating intercultural understanding objectives into school mission/vision; and (f) ensuring culture and language training for various school groups. The Delphi panel suggested skills, training, and experiences required by school leaders to enhance their abilities to effectively influence and sustain cultural proficiency and global leadership development in American international schools in Latin America. 
Finally, study results revealed potential success indicators to monitor and assess school-wide cultural proficiency and global leadership development in American international schools, including: (a) attitude measures of various constituency groups; (b) number of student-initiated community service projects; (c) degree of culturally diverse representation in school events; and (d) observed intercultural group interaction/integration. Some suggested measurement tools were: (a) strategic assessment and planning processes (e.g., culture audits); (b) attitudinal surveys and focus groups; (c) accreditation processes; (d) statistical tracking of enrollment and turnover; (e) exit interviews; (f) number and sustainability of community service projects; (g) curriculum standard reviews of global and diverse content; and (h) informal meetings with various constituency groups.

The findings from this exploratory study provide a basis for developing and examining potential outcome measures of cultural proficiency for practical use in schools. Study results also suggest a need for more in-depth research, using alternative research methods, to further examine the findings of this Delphi study.

\section{Implications of Findings}

The findings from this study have both theoretical and practical implications. Overall, study results suggested that the school leaders in this study were indeed aware of the impact of cultural diversity and the cross-cultural challenges in managing American international schools in the Latin American region. Nonetheless, few school leaders reported that their schools used comprehensive school-wide strategies that specifically focused on implementing and assessing cultural proficiency and global leadership development. 
Key findings generally supported the theoretical framework for cultural proficiency in schools (Lindsey, et al., 2003). Most of the findings were also consistent with the academic literature on schools, school leadership, global education, and diversity in organizations discussed in chapter two. In particular, the literature supports the importance of leader influence, shared vision building, global and diverse curriculum, community outreach, and intercultural learning and conflict resolution in promoting an inclusive and global-minded education.

\section{Essential Features of Cultural Proficiency and the Theoretical Framework}

The essential features for cultural proficiency in American international schools in Latin America, identified in this study, can be integrated into the five essential elements (or guiding principles) for cultural proficiency outlined by Lindsey, et al. (2003) in their model for schools and school leaders as follows. These elements are meant to serve as an overall guide for developing general objectives, standards, and behavior markers for cultural proficiency in schools. Many essential features from this study apply to more than one element of the Lindsey, et al. model, so categories should not be considered mutually exclusive.

- Adapt to Diversity: Encouragement of intercultural interactions and dialogue between students; language acquisition and cultural orientations for faculty; orientations on local culture for international staff.

- Institutionalize Cultural Knowledge: Community service that builds relationships; global curriculum with learning outcomes; traditional cultural celebrations and events; student-initiated community service. 
- Assess Culture: Cultural awareness training; success indicators and measures.

- Value Diversity: Active teaching and role modeling of value of diversity; mission/vision reflecting diverse perspectives; diversity in staffing and leadership positions; staff development/training on cultural awareness and the value of diversity.

- Manage the Dynamics of Difference: Tolerance and acceptance of differences; demonstration of democratic process.

\section{Leadership Implications}

Participants in this study expressed several ways that they believed school leaders can influence cultural proficiency and global leadership development in schools. The following quote reflects these sentiments:

School leaders are the KEY catalysts in a school moving towards any level of cultural awareness and sensitivity.

These findings are confirmed by research on leadership and organizations that suggests organizational leaders influence organizational culture (Argyris, 1990; Deal \& Kennedy, 1999; Schein, 1992) and can positively affect diversity in organizations (Adler, 1997; Cox, 1993; Kochran, et al., 2003; Thomas \& Ely, 1996). This idea is also supported by literature on schools and school leadership (Fullan, 2001; Leithwood \& Jantzi, 2000; Peterson \& Deal, 1998; and Sergiovanni, 2000). Studies further suggest that when school leaders provide the necessary school-wide supports for diversity, global education, and leadership development, intercultural learning is enhanced and positive intercultural relations are more likely to develop (Banks \& McGee-Banks, 2001; Henze, et al., 1998; Lindsey, et al., 1999, 2003; Reihl, 2000; Salvaggio, 2003). Studies on school 
leadership in American international schools have also pointed to the potential of leaders to influence school change in culturally complex environments (Hawkins, 2002;

Mathews, 2003; Paulsen, 2002). Consequently, the essential role of formal school leaders in promoting and sustaining cultural proficiency cannot be overlooked.

Implications from this study include the importance of considering the roles of informal leaders and students in developing school-wide cultural proficiency and global leadership development. Many panel participants discussed this in the first round of the Delphi process as illustrated in the following quote:

From the gardener to the schoolteacher, once he or she knows their opinion is heard and valued, and begins to see that they too are considered leaders; the whole institution has reached a new level of proficiency.

Not every influential leader in an organization is going to have in a formal position of power and authority. These leaders need to be consciously identified at all levels and encouraged to formally participate in decision making. This idea is also stressed in the model for cultural proficiency for schools:

Leaders come from all sectors of the school and community it serves, and student leadership is vital to culturally proficient schools (Lindsey, et al., 2003, p. 193).

The importance of consciously developing student leaders in schools and seeking ways to give students an "authentic voice" in policy making was also emphasized by many of the study participants and is supported in the literature on school change. Fullan (1991) discussed the importance of student participation in school change as "central to any school improvement effort" (p. 183) emphasized that students must have the necessary skills, understanding, and motivation to make a significant contribution; otherwise, they might actually impede change. 
Finally, when examining leadership for cultural proficiency and global-

mindedness, it is key to explore how different cultures may view and define "leadership." As one participant stated:

International schools must also recognize that leadership is viewed in different ways in different cultures. There is a tendency to support and nurture an American leadership perspective... differences between global traits and American traits must be made more transparent.

An effort to create more "transparency" between what these schools define as global and "American" would be indicative of movement toward greater cultural proficiency.

\section{Barriers to Cultural Proficiency}

Most of the six barriers to cultural proficiency identified in this study support the two major barriers discussed by Lindsey, et al. (2003): (a) the presumption of entitlement and (b) an unawareness of the need to adapt.

The number one reported barrier of "exclusive (elite) values of student and parent populations" relates to the barrier of entitlement, defined as "the accrual of benefits solely because of membership in a dominant group" (Lindsey, et al., 2003, p.246). This sense of entitlement is apparent in many ways in American international schools in the Latin American region.

"Elite," entitled attitudes may be prevalent in these schools as a consequence of the tremendous economic disparities apparent in Latin American countries. While host country students, and their parents, tend to represent the wealthy class of their countries, forty-four percent of the total population of Latin America live in extremely precarious conditions of poverty and inequity (United Nations Commission on Economics for Latin America and the Caribbean [CEPAL], 2004). This disparity in wealth and privilege maybe reflected in the attitudes and behaviors of parents and students who may 
intimidate teachers and school personnel because they perceive them to be of lower social status.

In this study, participants emphasized that schools should not allow themselves to be "bullied" by influential parents. Displays of entitlement can make teachers and schools feel "impotent" in carrying out inclusive policies and programs, because they fear student and parent reactions and risk negative consequences in confronting powerfully political and economically influential parents.

Elitist attitudes also appear to impede community service and outreach efforts because parents and students may not value personal contact with people and communities of lower classes, other than their maids and drivers, and may not feel any obligation to "give back to the community" through planned, ongoing community service programs with poorer communities.

On the other hand, few schools require students, teachers, and parents to participate in meaningful community service projects that go beyond periodic food or school supply donations. Since many international schools offer the European based, International Baccalaureate diploma, which has a required component called, "community action and service" or CAS, high school students in the IB program must complete a certain number of community service hours. Beyond the CAS requirement, many schools in Latin America appear to do little to proactively engage in meaningful and sustainable community outreach programs.

Interestingly, in proposing strategies to confront barriers to cultural proficiency, no panel members mentioned the idea of offering scholarships to local low-income students from the local community. A few participants did propose, however, that schools 
should share expertise with local public schools and school teachers through training seminars and partnering and exchange programs.

An overall sense of entitlement may be further manifested in international schools in developing countries due to the reality of global dominance of industrialized nations. Teachers, administrators, parents, and students from North America and Europe might look down on host country cultures and distance themselves. Heyward (2002), in characterizing international schools, emphasized this reality:

International schools in developing nations face further obstacles. In being defined by distance, they are also defined by exclusivity and political advantage, by elitism. Genuine attempts to engage with local cultures may unwittingly reinforce attitudes of superiority and paternalism, of cultural chauvinism. (p.27)

In general, overseas hire teachers and administrators are paid more and have greater benefits than local, host country employees. International administrators, teachers, and parents frequently exhibit attitudes of superiority in English language speaking abilities and pedagogical practices. They may openly put down host country values. Even among host country parents and board members, preference is sometimes shown for the hiring of a North American administrator over a more qualified host country national with extensive experience in the school.

The barrier of ethnocentrisms identified in this study might also fit into discussions of the overall barrier of entitlement. For example, some research suggests that Europeans and North Americans tend to look down on Latin American socioemotional relational styles at work as "unprofessional" and off-task (Sanchez-Burks, Nisbett, \& Ybarra, 2000). Ethnocentrisms, however, can take many forms that become evident in exploring the values, attitudes, and behaviors of all cultural groups in a school. For this 
reason, schools must be aware of and seek ways to "manage the dynamics of difference," or the inevitable conflicts and tensions that arise, rather than pretend they do not exist.

"Unawareness of the need to adapt" is the other major barrier to cultural proficiency stressed by Lindsey, et al. (2003, p. 217). While expert participants in this study demonstrated awareness of the need for cultural proficiency, future research is required to determine how aware other international schools leaders are of this need to proactively assess and strategize about the realities of culture and the potential for global leadership development in schools.

Related to "lack of awareness," however, is "resistance to change," which was cited as another major barrier to cultural proficiency in this study. Resistance to the idea of cultural proficiency as a school improvement tool became evident in the comments of one of the expert panel members in response to a Round Two question about potential success indicators:

The need to assure quality in more fundamental aspects of the program such as: curriculum and instruction, valid testing, qualified personnel, facility improvements, etc. is more important. Identifying indicators and measuring successes in the areas of global leadership and cultural proficiency will have to wait.

This school leader obviously viewed cultural proficiency as separate from, rather than integral to, the policies, programs, and practices named in the quote. Ideally, culture would be salient variable in assessing and analyzing all components of school policy and programs. A degree of resistance to the idea of change in this area is evident and would be expected in line with the academic literature on change management.

It is clear that becoming culturally proficient involves change and would require strategies for change management such as those discussed by Fullan (2001). Strategic 
change management might also reveal solutions to the barrier of "frequent faculty turnover" and help confront the realities of flux and change that characterize many American international schools.

The barrier, "cultural demographic makeup of student populations," cited in this study is not addressed in Lindsey, et al.'s (2003) discussion of barriers. Based on expert panel comments, the cultural makeup of the student body can directly impact program development, particularly in the area of English language development and teaching and special services to students with special needs. When a large percentage of the student population is from the host country culture, as is the case in many international schools in the Latin American region, students have fewer opportunities to practice English outside the classroom and require more specialized second language instruction. Furthermore, when the population is more homogeneous, students and teachers have less exposure to students from other cultures, races, and social classes. On the contrary, however, some study participants felt that more diverse schools had more cultural challenges. Regardless of the exact cultural makeup of a school, the cultural proficiency framework allows for the tailored analysis and strategy that addresses the cultural needs and issues of a particular school context.

\section{General Need for a Cultural Proficiency Framework}

Overall, the findings from this study point to an evident need for American international schools in the Latin American region to consciously assess the impact of culture in these schools and proactively seek ways to address the challenges and opportunities presented by culturally diverse and cross-cultural settings. The economic and political survival of American international schools is increasingly contingent upon their ability to move 
toward cultural proficiency. If schools do not pay attention to the "cultural dimension" of school culture, as well as the challenges of operating in a cross-cultural environment, they may risk alienating certain constituency groups and risk losing or attracting students and high quality teachers. In some cases, school security and the facility of visa acquisition for overseas hire employees may be negatively affected. To a certain degree, these issues may depend on whether or not an international school has established a positive image in the local community and smooth relationships with the host country government.

There are numerous reasons why American international schools in Latin America must develop culturally proficient policies, programs, and practices. Reasons include a need to:

- Develop competent future global leaders.

- Maintain healthy student enrollment levels and attract and retain high quality teachers in an increasingly competitive market.

- Facilitate smooth relationships with host country institutions and communities.

- Mediate inevitable tensions and conflicts between various cultural groups within the school setting, while promoting intercultural understanding and learning.

- Respond to demands from parents and the international education community to globalize curriculum to meet the requirements of more national educational systems.

- Improve organizational effectiveness by integrating various cultural perspectives.

- Model community outreach efforts that may positively impact host country communities (e.g., scholarships for academically competent low-income children 
from local communities, sustainable community projects, knowledge exchanges between schools, etc.).

- Enhance intercultural learning and global leadership development among students, and all other school community members, in response to the $21^{\text {st }}$ century realities of globalization, terrorism, technology, travel, migration, and organizational diversity.

\section{Advantages of the Delphi Method and On-line Questionnaires}

The Delphi method appeared to have worked well in this study. Participant awareness of cultural proficiency appeared to have increased through actual participation in the process and the study in general. Several participants stated that they "learned" as a result of participating in the study and desired an ongoing forum to discuss topics related to culture and leadership. Many expressed that they frequently felt a sense of isolation in their individual schools and needed the opportunity to have more contact with other schools around these matters. Participant motivation remained high throughout the study as indicated by very little attrition and the extensive amount of written text provided in response to the on-line questionnaires.

The on-line questionnaires also provided the opportunity for very busy people to efficiently respond and submit their responses. Participants could also answer some questions and come back at a later time to respond to the remaining items. The on-line nature of the study also allowed the researcher to monitor submissions, quickly provide thank you notes to participants as they submitted their questionnaires, and efficiently download data for analysis. The researcher was also able to provide panel members with 
compiled results within a one-week turnaround time, contributing to participant motivation.

\section{Limitations to the Study}

This study was considered exploratory in nature. It was hoped that these findings would inform practice and provide a basis for further research on the impact of culture in American international schools in Latin America; however, several limitations to this study must be noted, some of which were noted in at the outset of the study as outlined in chapter one. Other limitations became apparent during the study and at its conclusion and primarily concern the subjectivity of assumptions and interpretations made by participants and the researcher, questionnaire development and validity, and potential bias in data analysis.

In reviewing the results of the study, it became apparent that the essential features of cultural proficiency and global leadership could have been merged in early rounds of the Delphi process, based on the similarity of the strategies presented. This was not initiated by the researcher nor suggested by the participants during the study.

Despite these limitations, several valuable recommendations can be made based on the implications of the findings. In particular, recommendations to international education associations and graduate programs in education are discussed below.

\section{Recommendations}

International Associations and Accreditation Organizations

Several international education associations directly support American international schools that operate in the Latin American region. Some of these supporting organizations include: 
- Southern Association for Colleges and Schools (SACS)

- Association for American Schools in South America (AASSA)

- The Tri-Association

- Association for International Education (AIE)

- Academy of International School Heads (AISH)

- International Schools Services (ISS)

Since American international schools have no governing agency, schools depend a great deal on these associations to set standards, hold them accountable to these standards, and share information on best practices and school improvement strategies. Associations also provide American international schools with networking and information sharing opportunities in the form of: annual conferences, newsletters, journals, workshops, onsite consulting services, and teacher recruitment and training. Consequently, these associations and accrediting agencies have key roles to play in promoting the development of cultural proficiency and global leadership. The potential influence of these associations was confirmed by the findings of this study.

Findings from this study suggest five identifiable areas in which associations could provide more support for cultural proficiency development. These include: (a) enhancement of on-line network opportunities for school leaders to share ideas and strategies for addressing cultural issues in schools; (b) encouragement of regional conferences and training sessions on topics of intercultural learning, global leadership development, and cultural proficiency; (c) extension of accreditation standards to more directly address diversity; (d) seek ways to modify U.S. standards to more appropriately address the cultural challenges, opportunities, and nuances in overseas international 
schools; and (e) confront the need to examine potential discrimination and gender bias in the hiring and promotion of administrators in American international schools.

First, expert panel participants expressed that they often feel isolated in their schools and have few opportunities to share ideas with other school leaders. Some expressed the desire to have an interactive, on-line forum to address topics related to culture and global issues. This is something that could be sponsored and maintained by a professional association.

Second, "to manage the dynamics of differences," regional association conferences need to hold more panel debates on culture and diversity to identify and "hash out" potential issues in these areas. Association conferences typically rely on keynote speakers and consultants, who are brought in from the U.S. and have little to no knowledge of international schools. This often makes it difficult for conference participants to make meaningful links to their own practice. Teacher volunteer comprise the majority of the presentations. However, little is done to tap into the expertise of existing school leaders around topics related to culture and comprehensive, school-wide strategies for approaching diversity.

Three, in reviewing accreditation standards for SACS (2004), there is little mention of enhancement of diversity, except under curriculum and no mention of "culture" or "global-mindedness." Under the standard "leadership," guidelines are very limited and suggest sole reliance on formal leadership to "control" or "govern," for example:

Controls all activities, including extra-curricular, that are sponsored by the school. (p. 2.19) 
While these documents have standards for citizenship, stakeholder communication, and continuous school improvement, the standards are so generic and limited that they do not appear to address real issues confronting American international schools and do not sufficiently provide guidelines for community outreach, leadership development, global curriculum, shared vision building, and other needed areas of focus.

On the other hand, some U.S. based and oriented standards, like those of the National Association of Elementary School Principals (NAESP) do appear to endorse diversity and leadership, as well as the type of school improvement that might enhance cultural proficiency development. In Standards for What Principals Should Know and Be Able to Do (NASP, 2004), one of the statements under the category of leadership standards says, "seek leadership contributions from multiple sources" (p. 17). In another reference to an "engaged community," NASP standards state:

Engaged parents, business leaders, members of the neighborhood...may not be essential to student success but they sure help!...Thus, school goals must be communicated not just to those who work in schools, but to the community as well. (p.5)

Perhaps accrediting agencies for international schools should thoroughly examine how other U.S. based associations are developing their standards related to culture, community, diversity, and leadership. Then, rather than just importing those standards to the American international school setting, associations could guide and encourage schools to effectively adapt these standards to their unique school cultures and host country circumstances.

Finally, issues of discrimination and gender preference in American international schools are often whispered about, but rarely addressed. While International Schools Services (ISS), who assists with recruiting of overseas hire teachers and administrators, 
has an anti-discrimination policy, it is difficult for potential administrators from non-U.S. countries to be hired (or promoted) to work in formal leadership positions in American international schools, even if they live and work in the host country where the school operates. Sometimes schools overlook in-house promotions in giving preference to the hiring of overseas administrators, who have little to no intercultural or overseas experiences and training or second language speaking abilities. In some cases, school boards of directors show preferences for such hiring practices and risk disruptive consequences for the organization. Furthermore, while the "good old boy network" is known to be alive and well in American international schools in Latin America, the issue has not been formally confronted in any way that may lead to some fundamental change toward more inclusive hiring and promotion practices.

University programs can also be influential in increasing awareness of the importance of cultural proficiency development in international schools by seeking to develop teachers and administrators who are truly prepared to work in diverse environments and by encouraging more research in international schools.

\section{Graduate Programs in Teaching and Educational Administration}

The need for culturally proficient teachers is increasingly evident as solid empirical research in education suggests that teachers are the most essential factors in guaranteeing student learning (Darling-Hammond, 2000) and have a strong capacity to affect intercultural learning and global awareness (Merryfield, 2002; Villegas \& Lucas, 2002). Teachers must be skilled in interacting with culturally diverse groups themselves and possess the global knowledge necessary to effectively prepare students to be global leaders. To be effective models for global leadership, teachers require the education and 
opportunities to develop their own cultural and global competencies (Smith \& Czarra, 2003; Villegas \& Lucas, 2002). Universities must offer teacher education programs that enhance cultural proficiency development. Programs should include rich content and teaching strategies that stimulate self-reflection and transformation, as well as community internships, international exchange programs, and experiential learning programs that immerse teachers in other cultures and give them opportunities to acquire other languages and knowledge of world geography.

Graduate programs in educational administration should also seek ways to better prepare potential international school leaders to address cultural issues and opportunities. Based on strategies identified in this study, programs should include: opportunities to work cross-culturally (e.g., internships); foreign language acquisition requirements; training in intercultural communication and cross-cultural management; international exchange programs (to and from the U.S.); and exposure to international conferences and associations. Course work topics should include: change management; conflict resolution; intercultural communication; school culture and diversity; action research methods; world cultures and subcultures; strategic planning and vision building; team building; stakeholder integration; and community outreach.

\section{Recommendations for Future Research}

This study suggests many areas for future research. First, there is an obvious need to examine how cultural proficiency might be manifested in different schools and school contexts. A comparative case study of two or three relatively similar schools or the comparison of a typical and outlier case may reveal more in-depth information on factors that influence cultural proficiency in individual school contexts. Case studies should 
include the use of multiple methods (e.g., surveys, interviews, observation, and document analysis) with various school constituency groups. This research could explore where schools might fall along the developmental continuum of cultural constituency proposed by Lindsey, et al. (2003) and indicate areas of success and needed improvement.

Second, the essential features of cultural proficiency and the identified barriers to its development, identified in this Delphi study, could form a basis of a large-scale survey of a sample population of American international schools to examine awareness levels and elicit information on what schools are currently doing to move their schools toward cultural proficiency and global leadership development. Sample schools could then be selected for interviews and observations to compare reported practices with actual practices. This would address the need to examine the relationship between what schools report they or doing and what they are actually doing. Argyris and Schon (1974) emphasized the difference between "espoused theory" and "theory in use." To complement reported and observed practice, it would be essential to "cross-check" perceptions of various groups in the school, as well as the outer community, in an attempt to get a complete picture of the cultural phenomena in a school and not just rely on the reports, perceptions, and orchestrations of formal leaders.

Third, careful study of any one of the findings of this study would further inform the field of international education. For example, an in-depth study on the role of "community service" or "global curriculum" on cultural proficiency and global leadership development may reveal a wealth of valuable data to guide practice and contribute to the body of knowledge on international schools. 
Fourth, the barriers identified in this study could be more closely examined. An analysis of the forces both driving and restraining cultural proficiency development in these schools might reveal areas for new focus.

Fifth, this study gathered expert panel opinions about the potential influence of school leaders on school-wide cultural proficiency. More research on the relationship between individual cultural proficiency of school leaders and the development of schoolwide cultural proficiency is needed. Perhaps individual scales of cultural proficiency could be developed and results compared with the presence or absence of identified outcomes in schools, using both quantitative and qualitative methods. This research could also explore the role of non-formal leaders in schools, who are influential individuals, but may not necessarily possess positional power.

Finally, while this study revealed numerous culture-related challenges and opportunities, there is a paucity of research specifically examining the dynamics of culture in American international schools in general, and even less in Latin America. To date, much of the research remotely related to culture in international schools has focused on what it means to "be international."

\section{Final Words}

Culture is a complex phenomenon that requires an in-depth analysis that goes beyond the traditional discussions found in the international school literature. It is increasingly clear that all schools, around the world, need to consciously seek ways to develop cultural proficiency in order to prepare students to be responsible citizens and meet the $21^{\text {st }}$ century demands of a global world. 


\section{REFERENCES}

Adler, N. (1983). Cross-cultural management: Issues to be faced. International Studies of Management and Organizations, 8 (1-2), 7-45.

Adler, N. (1997). International Dimensions of Organizational Behavior. Cincinnati: South-Western College Publishing

Adler, M. \& Ziglio, E. (1996). Gazing into the Oracle: The Delphi method and its application to social policy and public health. London: Jessica Kingsley Publishers.

Alger, C. \& Harf, J. (1986). Global Education: Why? For Whom? About What? In Promising Practices in Global Educations: A Handbook with Case Studies, (pp.113). NY: National Council on Foreign Language and International Studies.

Allan, M. (2000). Border crossings: A study of cognitive dissonance in an international school. Unpublished masters these: Oxford Brooks University, England.

Allan, M. (2002). Cultural borderlands: A case study of cultural dissonance in an international school. Journal of Research in International Education, l (1), 63-90. London: International Baccalaureate Organization and Sage Publications.

Allport, G. (1954). The Nature of Prejudice. Reading, MA: Addison-Wesley.

Anderson, F. (2004). Presentation on Southern Association of Colleges and Schools (SACS) at Principals' Conference for the Association of American Schools in South America (AASSA) on October 21, 2004 in Sao Paulo, Brazil.

Argyris, C. (1990). Overcoming Organizational Defenses. Boston: Allyn \& Bacon.

Argyris, C. \& Schon, D.A. (1974). Theory in Practice. San Francisco: Jossey-Bass.

Armstrong, M.A. (1989). The Delphi technique. Retrieved on March 4, 2004 from http://www.pei.intl.com/Research/MARKETS/DELPHI/HTM.

Asante, M.K. \& Gudykunst, W.B. (1989). Handbook of international and intercultural. Newbury Park, CA: Sage.

Banks, J.A. (1994). An introduction to multicultural education. Boston: Allyn and Bacon.

Banks, J.A. (1999). An introduction to multicultural education. (2 ${ }^{\text {nd }}$ ed.) Boston: Allyn and Bacon. 
Banks, J. \& McGee-Banks, C. (2001) Multicultural education: Issues and perspectives $\left(4^{\text {th }}\right.$ ed.). New York: John Wiley and Sons.

Barrera, I. \& Kramer, L. (1997). From monologues to skilled dialogues: Teaching the process of crafting culturally competent early childhood environments. In P.J. Winton, J. A. McCollum, \& C. Catlett (Eds.), Reforming personnel preparation in early intervention: Issues, models, and practical strategies, (pp. 217-251). Baltimore: Paul H. Brookes.

Bartolome Pina, M. (1997). Diagnostico a la escuela multicultural. [Diagnostic of the Multicultural School], Barcelona, Spain: Cedecs Edit.

Bates, D.G. \& Plog, F. (1990). Cultural Anthropology ( $3^{\text {rd }}$ ed). New York: McGraw-Hill.

Bender, D. (1996). Intercultural competence as a competitive advantage. Retreived online September 10, 2003 at http://alpha.fdu.edu/ bender/culture.html.

Bennett, M. (1993). Toward ethnorelativism: A developmental model of intercultural sensitivity. In M. Paige (Ed.), Education for the Intercultural Experience, (pp. 43-60). Yarmouth, ME: Intercultural Press.

Bolman, L. \& Deal, T. (1997). Reframing Organizations: Artistry, Choice, and Leadership ( $2^{\text {nd }}$ ed.). San Francisco: John Wiley \& Sons.

Brislin, R. (1993). Understanding culture's influence on behavior. New York: Harcourt Brace Jovanovich.

Burleigh, J. (1994). What works: A study of international education in an international school setting: Part 2. The International Schools Journal, 27, 46-52.

Cambridge, J. (1998). Investigating national and organizational cultures in the context of the international school. In M. Hayden \& J. Thompson (Eds.), International Education: Principles and Practice (2 ${ }^{\text {nd }}$ ed.), (pp. 197-211). London: Kogan

Candau, V.M. (2002a). Sociedade, Educação, e Cultura(s): Questões propostas. [Society, Education, and Culture: Questions and Proposals], Petropolis, Brazil: Vozes, 2002.

Candau, V.M. (2002b). Sociedade, Cotidiano Escolar e Cultura(s): Uma Aproximação. Em Educação \& Sociedade, [Society, School Life, and Culture: An Approximation], ano XXIII, no. 79, Agosto/2002. Campinas, Brazil: CEDES.

Canterford, G. (2003). Segmented labour markets in international schools. Journal of Research in International Education, 2 (1), 47-65. London: International Baccalaureate Organization \& Sage Publications. 
Casmir, F. (1999). Foundations for the study of intercultural communications based on a Third-Culture building model. International Journal of Intercultural Relations, 23(1), 91-116.

Collins, H.T., Czarra, F.R., \& Smith, A.F. (1996). Guidelines for global and international studies education. New York: The American Forum for Global Education.

Cox, T. (1993). Cultural Diversity in Organizations: Theory, Research, \& Practice. San Francisco: Berret-Koehler Publishers.

Cox, T. (2001). Creating the Multicultural Organization: A strategy for capturing the power of diversity. San Francisco: Jossey-Bass.

Cox, T. \& Beale, R., (1997). Developing competency to manage diversity: Readings, cases, \& activities. San Francisco: Berrett-Koehler.

Cross, T., Bazron, B. Dennis, K. \& Isaacs, M., (1989). Towards a culturally competent system of care, Vol. I. Washington, D.C.: Georgetown University Child Development Center, CASSP Technical Assistance Center.

Cui, G., \& Van den Berg, S. (1991). Testing the construct validity of intercultural effectiveness. International Journal of Intercultural Relations, 15, 227-241.

Czarra, F.R. (2002). Issues in global education: Global education checklist for teachers, schools, school systems, and state agencies [occasional paper]. New York: The American Forum for Global Education. Retrieved September 13, 2004 from http://www.globaled.org/fianlcopy.pdf.

Dalkey, N.C. (1968). Predicting the Future. Santa Monica, CA: Rand Corporation.

Dalkey, N.C., Brown, B. \& Cochran, S. (1969). The Delphi method, III: Use of self-ratings to improve group estimates. (Publication No. RM-6115-PR). Santa Monica, CA: Rand Corporation.

Dalkey, N.C., Rourke, D.L., Lewis, R., \& Snyder, D. (1972). Studies in the quality of life: Delphi and decision-making. Lexington, MA: Lexington Books.

Darling-Hammond, L. (2000). Teacher quality and student achievement: A review of state policy evidence. Education Policy Analysis Archives, 8 (1), 13-55.

Daniel, J. (2002). A curriculum for peace: A conversation with Sir John Daniel. Educational Leadership, October, Arlington, VA: Association for Curriculum and Instruction. 
Deal, T.E. (1993). The culture of schools. In M.Sashkin \& H.J. Walberg, (Eds.), Educational leadership and school culture (pp. 3-18). Berkeley, CA: McCutchan Publishing Corporation.

Deal, T.E. \& Kennedy, A.A. (1999). ). The New Corporate Cultures: Revitalizing the workplace after downsizing, mergers, and reengineering. Cambridge, MA: Perseus Publishing.

Deal, T.E. \& Peterson, K.D. (1990). The Principal's Role in Shaping School Culture. Washington,D.C.: U.S. Department of Education, Office of Educational Research and Improvement.

Delbecq, A.L., Van de Ven, A.H. \& Gustafson, D.H. (1975). Group techniques for program planning: A guide to nominal and group Delphi processes. Glenview, IL: Scott Foresman.

Diaz, C. Massialas, B. \& Xanthopolous, J. (1999). Global Perspectives in Education. Boston, MA: Allyn \& Bacon.

Dinges, N. (1983). Intercultural competence. In D. Landis \& R. Brislin (Eds.), Handbook of intercultural training, Vol. 1. New York: Pergamon.

Dunham, R.B. (1998). The Delphi technique. Retrieved March 4, 2004 from http://instruction.bus.wisc.edu/obdemo/readings/delphi.htm.

European Council of International Schools/Council of International Schools International School Directory-2005. Retrieved May 20, 2005 from http://www.cois.org/directory.

Fullan, M. (1991). The New Meaning of Educational Change. New York: Teachers College Press.

Fullan, M. (2001). Leading in a culture of change. San Francisco: Jossey-Bass.

Georgetown University, National Center for Cultural Competence (2003). Conceptual Frameworks/Models, Guiding Values and Principles. Washington, D.C. Retrieved on October 15, 2003 from http://www.gucdc.georgetown.edu/nccc.

Gibson, C. and Zellmer-Bruhn, M. (2001). Metaphors and Meaning: AN intercultural analysis of the concept of teamwork. Administrative Science Quarterly, June, v. 46 (2), pp. 274-304.

Gillies, W. (2001). American international schools: Poised for the twenty-first century. Education, Winter 2001, 122 (2), p. 2-17. 
Gliozzo, C. (2002). An agenda for International Education. IIE Networker, Oct., New York: Institute of International Education

Government of British Columbia-Canada, Ministry for Children and Families (2003). Cultural Competency Assessment Tool. Retrieved March 24, 2004 from http://cf.gov.bc.ca/publications/cultural_competency/assessment_tool.

Gudykunst, W., (1998). Applying anxiety/uncertainty management (AUM) theory to intercultural adjustment training. International Journal of Intercultural Relations, 22(2), 227-250.

Gudykunst, W. (1994). Bridging differences, Effective intergroup communication. London: Sage.

Gudykunst, W. \& Kim, Y.Y. (1992). Communicating with strangers: An approach to intercultural communication. NY: McGraw Hill.

Gudykunst, W. \& Hammer, M. (1984). Dimensions of intercultural effectiveness: Culture specific or culture general? International Journal of Intercultural Relations, 8 (1), $1-10$.

Hall, E.T. (1976). Beyond Culture. Garden City, NY: Doubleday.

Hammer, M. (1987). Behavioral dimensions of intercultural effectiveness: A replication and extension. International Journal of Intercultural Relations, 11, 65-88.

Hammer, M. (1989). Intercultural communication competence. In M.K. Asante \& W. Gudykunst (Eds.), Handbook of International and Intercultural Communication, (pp. 246-260). Newbury Park, CA: Sage.

Hampden-Turner, C. \& Trompenaars, F. (2000). Building cross-cultural competencies. New Haven, CT: Yale University Press.

Hannigan, T. P. (1990). Traits, attitudes, and skills that are related to intercultural effectiveness and their implications for cross-cultural training: A review of the literature. International Journal of Intercultural Relations, 14(1), 89-111.

Hawkins, T.L. (2002). Principal leadership and organizational climate: A study of perceptions of leadership behavior on school climate in international schools. Unpublished doctoral dissertation, University of Minnesota.

Hayden, M., Rancic, B., \& Thompson, J. (2000). Being International: student and teacher perceptions from international schools. Oxford Review of Education, 26 (1), 107124. 
Hayden, M. \& Thompson, J. (1996). Potential difference: The driving force for international education. International Schools Journal, 16(1), 46-57.

Hayden, M. \& Thompson, J. (1998a.). International Education: Principles and Practice. London: Kogan.

Hayden, M. \& Thompson, J. (1998b.). International education: Perceptions of teachers in international schools. International Review of Education, 44(5/6), 549-568.

Hayden, M. \& Wong, C. (1997). The International Baccalaureate: international education and cultural preservation. Educational Studies, 23(3), 349-352.

Helmer, O. (1983). Looking forward: A guide to futures research. Beverly Hills, CA: Sage.

Henze, R., Katz, A., Norte, E., Sather, S., \& Walker, E. (1998). Leading for diversity: $A$ study of how school leaders achieve racial and ethnic harmony. Paper presented at American Educational Research Association (AERA) conference, April 14, 1998, San Diego, California.

Henze, R., Katz, A., Norte, E. Sather, S., \& Walker, E. (2002). Leading for Diversity. Thousand Oaks, CA: Corwin Press.

Heyward, M. (2002). From international to intercultural: Redefining the international school for a globalized world. Journal of Research in International Education, 1(1), 9-32. London: International Baccalaureate Organization and Sage Publications.

Hofstede, G. (1980). Cultures Consequences: International differences in work-related values. Beverly Hills, CA: Sage.

Hofstede, G. (2001). Culture's consequences: Comparing values, behaviors, institutions, and organizations across nations. London: Sage.

House, R.J. \& Aditya, R.N. (1997). The social scientific study of leadership: Quo vadis? Journal of Management, 23(3), 409-473.

House, R.J., Hanges, P.J., Javidan, M., Dorfman, P.W., \& Gupta, V. (Eds.) (2004). Culture,leadership and organizations: The GLOBE Study of 62 societies. Thousand Oaks:CA: Sage.

International School Services (ISS), (2004). Statistics provided by ISS for upcoming publication of International Schools Services Directory 2004-2005. Sent via electronic mail by Linda Freeman of ISS on September 24, 2004. 
International Schools Services, (2003). ISS Directory 2002-2003. Princeton, NJ: International Schools Services.

Judd, R.C. (1972). Forecasting to Consensus gathering: Delphi grows up to college needs. College and University Business, 53, 35-43.

Ketterer, J. \& Marsh, G. (2001). Impact of U.S. overseas schools in Latin America on political and civic values formation. Education Policy Analysis Archives, 9(3). Retrieved October 6, 2004 from http://epaa.asu.edu/epaa.

Kim, Y.Y. (1995). Identity development: From cultural to intercultural. In H. Mokros (Ed.) Interactions and Identity, (pp. 347-369). New Brunswick, NJ: Transaction.

Kim, Y.Y. (2001). Mapping the domain of intercultural communication: An overview. Communication Yearbook. 24, 139-157.

Kluckhorn, F. \& Strodbeck, F. (1961). Variations in Value Orientations. New York: Row Peterson

Kochan, T., Bezrukova, K., Ely, R., Jackson, S. Joshi, A., Jehn, K., Leonard, J., Levine, D., \& Thomas, D., (2003). The effects of diversity on business performance: Report of the diversity research network. Human Resource Management, 42 (I), 3-21.

Koester, J. \& Olebe, M. (1998). The behavioral assessment scale for intercultural communication effectiveness. International Journal of Intercultural Communication, 12, 233-246.

Krajeski-Jaime, E.R., Brown, K.S., Ziefert, M. \& Kaufman, E. (1996). Utilizing international clinical practice to build intercultural sensitivity in social work students. Journal of Multicultural Social Work, 4(2), 15-29.

Kroeber, A.L. \& Kluckholn, C. (1952). Culture: A critical review of concepts and definitions. Harvard University Peabody Museum of Archaeology and Ethnology Papers, 47, 181.

Kwak, M., (2003). The Paradoxical Effects of Diversity. MIT Sloan Management Review, Spring 2003, 44(3), 7-8.

Langford, M. (1997). Internationally mobile pupils in transition: The role of the international school. Unpublished masters thesis, University of Bath, England.

Leeman, Y.A.M. (2002). School Leadership for Intercultural Education. Intercultural Education, 14(1), 31-45. 
Leithwood, K. (1994). Leadership for school restructuring. Educational Administration Quarterly, 30(4), 498-518.

Leithwood, K. \& Jantzi, D. (2000). The effects of transformational leadership on organizational conditions and student engagement with school. Journal of Educational Administration, 38(2), 112-126.

Levary, R.R. \& Han, D. (1995). Choosing a Technological Forecasting Method. Industrial Management, 37 (1), 14-18.

Lindsey, R., Robins, K., \& Terrell, R., (1999). Cultural Proficiency: A Manual for School Leaders. Thousand Oaks, CA: Corwin Press.

Lindsey, R., Robins, K., \& Terrell, R., (2003). Cultural Proficiency: A Manual for School Leaders $\left(2^{\text {nd }}\right.$ ed.). Thousand Oaks, CA: Corwin Press.

Linstone, H.A. \& Turoff, M. (1975). The Delphi method: Techniques and applications. Reading, MA: Addison-Wesley.

Loden, M. (1995). Implementing Diversity: Best Practices for Making Diversity Work in Your Organization. NY: McGraw-Hill

Lustig, M.W. \& Koester, J. (2002). Intercultural Competence: Interpersonal Communication Across Cultures ( $4^{\text {th }}$ ed.). Boston: Longman.

Lynch, E.W. and Hanson, M.J. (1998). Developing cross-cultural competence: A guide for working with young children and their families $\left(2^{\text {nd }}\right.$ ed.) Baltimore: Paul $H$. Brookes.

MacKenzie, M. (1998). Going, Going, Gone...Global! In M. Hayden and J. Thompson (Eds.) International Education: Principles and Practice (pp. 242-252). London: Kogan.

Manasse, A.L. (1986). Vision and leadership: Paying attention to intention. Peabody Journal of Education, 63(1), 150-173.

Mannino, E. (1992). Special activities of the office of overseas schools. Washington, D.C.: Department of State, Office of Overseas Schools.

Martin, J. (1993) Intercultural communication competence: A Review. In R. Wiseman and J. Koester (Eds.) Intercultural Communication Competence, (pp. 16-29). Newbury, CA: Sage

Mathews, B. (2003). Leaders' influence on school reculturing: A case study of an international school. Unpublished doctoral dissertation, University of San Diego. 
Merryfield, M. (2002) The difference a global educator can make. Educational Leadership, Oct., Arlington, VA: Association for Curriculum and Instruction.

Merryfield, M., Jarchow, E., \& Pickert, S. (Eds.). (1997). Preparing to teach global perspectives: $A$ handbook for teacher educators. Thousand Oaks, CA: Corwin Press.

National Association of Elementary School Principals (NASP), (2004). Standards for What Principals Should Know and Be Able To Do. Washington, D.C.: NASP/Collaborative Communications Group

Oberg, K. (1960). Culture shock: Adjustments to new cultural environments. Practical Anthropology. 4, 177-182.

Pasternik, M. (1998). Is international education a pipedream? A question of values. In M. Hayden and J. Thompson (Eds.) International Education: Principles and Practice $\left(2^{\text {nd }}\right.$ ed.), pp. 253-275. London: Kogan

Paulson, J.B. (2002). Leadership competencies for United States accredited international schools. Unpublished doctoral dissertation, University of Minnesota.

Pearce, R. (2001). Plural vision for plural schools: How we can disagree yet both be right. International Schools Journal, 20 (2), 39-45.

Peterson, K.D. \& Deal, T.E. (1998). How leaders influence culture of schools. Educational Leadership, 56(1), 28-30.

Peterson, K.D. \& Deal, T.E. (2002). Shaping school culture fieldbook. San Francisco: Jossey-Bass.

Pedersen, P. (1994). A Handbook for Developing Multicultural Awareness (2 ${ }^{\text {nd }}$ Ed.). Alexandria, VA: American Counseling Association.

Pierson, R.M. (1996). The benefits of culturally embedded health messages: Targeting African-American women. Unpublished doctoral dissertation, Stanford University.

Pettigrew, T. (1998). Intergroup contact theory. Annual Review of Psychology, 49, 65-85.

Peshkin, A.(1988). In search of subjectivity---One's own. Educational Researcher, 17(7), 17-21.

Pollack, D. \& Van Reken, R. (1999). The Third Culture Kid experience: Growing up among worlds. Yarmouth, MN: Intercultural Press. 
Ponterotto, J.G. (1997). Multicultural counseling training: A competency model and national survey. In D.B. Pope-Davis \& H.L.K. Coleman (Eds.), Multicultural Counseling Competencies: Assessment, education and training, and supervision, (pp. 111-130). Thousand Oaks, CA: Sage.

Pope-Davis, D.B. \& H.L.K. Coleman (1997), Multicultural Counseling Competencies: Assessment, education and training, and supervision. Thousand Oaks, CA: Sage.

Popinchalk, M., Cordeiro, P. \& Kasan, D. (2001). The multicultural International school: Paradox? Possibility? Or Oxymoron? Paper presented at the Annual Convention of the Association for the Advancement of International Education, March 5-8, Miami, Florida.

Power, C. (2001). UNESCO's Response to the Challenge of Establishing Unity in Diversity. In J. Campell (Ed.) Creating Our Common Future: Educating for Unity in Diversity. UNESCO/Scientific \& Cultural Organization/Berghahn Books.

Reihl, C.J. (2000). The principal's role in creating inclusive schools for diverse students: A review of normative, empirical, and critical literature on the practice of educational educational administration. Review of Educational Research, 70(1), 55-81.

Remington, M.A.G. (2002). Culture Shock of North American educators living and working in international schools in Latin America. Unpublished doctoral dissertation, University of Mississippi.

Richards, N. (1997). A case study of the implementation of change and its effect on the job satisfaction and morale of local-contract teaching staff in an international school. Unpublished masters thesis, University of Bath, England.

Rokeach, M. (1969). The Nature of Human Values. NY: The Free Press.

Ruben, B. (1989). The study of cross-cultural competence: Traditions and contemporary issues. International Journal of Intercultural Relations, 13, 229-240.

Ruben, B. (1976). Assessing communication competency for intercultural adaptation. Group and Organization Studies, 1, 334-354.

Rucci, R. (1993). What makes international schools special?, InterEd, 20 (67), 17.

Russell, W.F. (1990). Staff development needs and practices in isolated Americansponsored overseas schools. Dissertation Abstracts International, DAI-A, 51 (01), 46.

Sackman, H. (1975). Delphi critique. Lexington, MA: D.C. Heath and Company. 
Salvaggio, K.C. (2003). Perceptions of formal and informal school leaders regarding cultural proficiency in high-achieving, highly diverse elementary schools. Unpublished doctoral dissertation, University of LaVerne.

Sanchez-Burkes, J., Nisbett, R., \& Ybarra, O. (2000). Cultural styles, relational schemas, and prejudice against out-groups. Journal of Personality and Social Psychology, 79 (2), pp. 174-189. American Psychological Association.

Samovar, L.A. \& Porter, R.E. (1995). Communication Between Cultures $\left(2^{\text {nd }}\right.$ ed.). Belmont, CA: Wadsworth Publishing Company

Schaetti, B. (1993). The Global Nomad Profile. Paper presented at a conference entitled, "The Global Nomad: The Benefits and Challenges of an Internationally Mobile Childhood." Regents College, London, April 23.

Scheele, S. (1975). Reality construction as a product of Delphi interaction. In H.A. Linstone, \& M. Turoff (Eds.) The Delphi Method: Techniques and Applications. Reading, MA: Addison-Wesley.

Schein, E. (1985). Organizational culture and leadership. San Francisco: Jossey-Bass Publishers.

Schein, E. (1992). Organizational culture and leadership (2 ${ }^{\text {nd }}$ ed.). San Francisco: Jossey-Bass Publishers.

Schwindt, E. (2003). The development of a model for international education with special reference to the role of host country nationals. Journal of Research in International Education, 2 (1), 67-81.

Sergiovanni, T.J. (2000). The lifeworld of leadership: Creating culture, community, and personal meaning in our schools. San Francisco: Jossey-Bass

Smith, A. \& Czarra, F. (2003). Teaching in a Global Context. [Electronic Version] Global Education, 32, Downloaded October 13, 2004 from American Society for Curriculum Development, Infobrief, January 2003.

Southern Association of Colleges and Schools/Council on Accreditation and School Improvement (SACS/CASI), (2004). Accreditation and School Improvement: The Handbook for the Next Generation.

Southern Association of Colleges and Schools/Council on Accreditation and School Improvement (SACS/CASI), (2004). Accreditation Standards for AmericanInternational Schools.

Spring, J. (1998). Education and the Rise of the Global Economy. Mahwah, NJ: Lawrence Erlbaum Associates. 
Straffon, D. (2001). Assessing intercultural sensitivity levels of high school students in an international school. Unpublished doctoral dissertation, University of Minnesota.

Sue, D.W., Arredondo, P., \& McDavis, R.J. (1992). Multicultural counseling competencies and standards: A call to the profession. Journal of Multicultural Counseling and Development, 20, 64-88.

Sylvester, B. (1998). Through the lens of diversity: inclusive and encapsulated school missions. In M. Hayden and J. Thompson (Eds.) International Education: Principles and Practice (pp. 184-196). London: Kogan.

Thomas, D. \& Ely, R. (1996). Making differences matter: A new paradigm for managing diversity. Harvard Business Review, September-October.

Thompson, J. (2002). International education: Towards a shared understanding. Journal of Research in International Education, 1(1), 5-8. London: International Baccalaureate Organization and Sage Publications.

Ting-Toomey, S. (1999). Communicating across cultures. New York: Guilford.

Ting-Toomey, S. \& Oetzel, J., (2001). Managing Intercultural Conflict Effectively. Thousand Oaks, CA: Sage.

Triandis, H. (1994). Culture and Social Behavior. NY: McGraw-Hill.

Trompenaars, Fons and Charles Hampden-Turner (1998). Riding the waves of culture: Understanding cultural diversity in global business. $\left(2^{\text {nd }}\right.$ ed.) New York: McGraw-Hill.

Tye, B. and Tye, K. (1992). Global Education: A Study of School Change. New York: State University of New York Press.

Uhl, N.P. (1983). Using the Delphi technique in institutional planning. In N.P. Uhl (Ed.) New Directions for Institutional Research, (pp. 81-93). San Francisco, CA: Jossey-Bass.

UMI Proquest Digital Dissertations (2004) accessed September 12, 2004 from http://www.lib.umi.com.sally.sandiego.edu.

United Nations, Comision Economica para America Latina (CEPAL), (2004). [Economic Commission on Latin America] Estudio Economico de America Latina y el Caribe 2002-2003, [An Economic Study of Latin American and the Carribbean 2002-2003], LC/G.2209-P/E, Santiago:Chile. 
United States Department of Health and Human Services (2003). Linguistic and Cultural Competence Standards for Developing a Research Agenda for Cultural Competence in Health Care: Organizational Supports. Document retrieved on October 14, 2003 from http://www.diversityrx.org.

United States Department of Health and Human Services, Agency for Healthcare Research and Quality (AHRQ) (2004). Strategies for Improving Minority Healthcare Quality. Baltimore, MD: AHRQ Publications

United States Department of State, Office of Overseas Schools, 2004. Retrieved on March 18, 2004 from http://www.state.gov/m/a/os/1522.htm.

University of San Diego, Cultural Competence Project Team (1998). Creating Cultural Competence. Document available from Dr. Sue Zgliczynski at http:/ www.sandiego.edu.

Useem, R.H. (1993). Third Culture Kids: Focus of a major study. Newslinks, 12(3), 1-29.

Villegas, A.M. \& Lucas, T. (2002). Educating Culturally Responsive Teachers: A Coherent Approach. Albany, NY: SUNY.

Walker, G. (2001). Learning to live with others. Speech to the conference of Nordic International Baccalaureate Schools in Denmark, September 14. Retrieved on August 8, 2003 from http://www.seei.qc.ca/Conference.

Walker, G. (2002). International education: An idea whose time has come. Education Week, Nov., 3-5.

Wilkerson, D. (1998). International education: A question of access. In M. Hayden \& J. Thompson (Eds.) International Education: Principles and Practice, (pp. 227234). London: Kogan.

Willis, D. (1991). International and overseas schools: A research synthesis and bibliography. Educational Management, 1-30.

Wiseman, R. \& Koester, J. (Eds.), (1993). Intercultural Communication Competence. Newbury Park, CA: Sage.

Yershova, Y., DeJaeghere, J., \& Mestenhauser, J. (2000). Thinking not as usual: Adding the intercultural perspective. Journal of Studies in International Education, 4, 3978. 
Appendix A

Delphi Process: Schedule of Activities 


\section{Appendix A}

\section{Delphi Process: Schedule of Activities}

Delphi process: schedule of activities

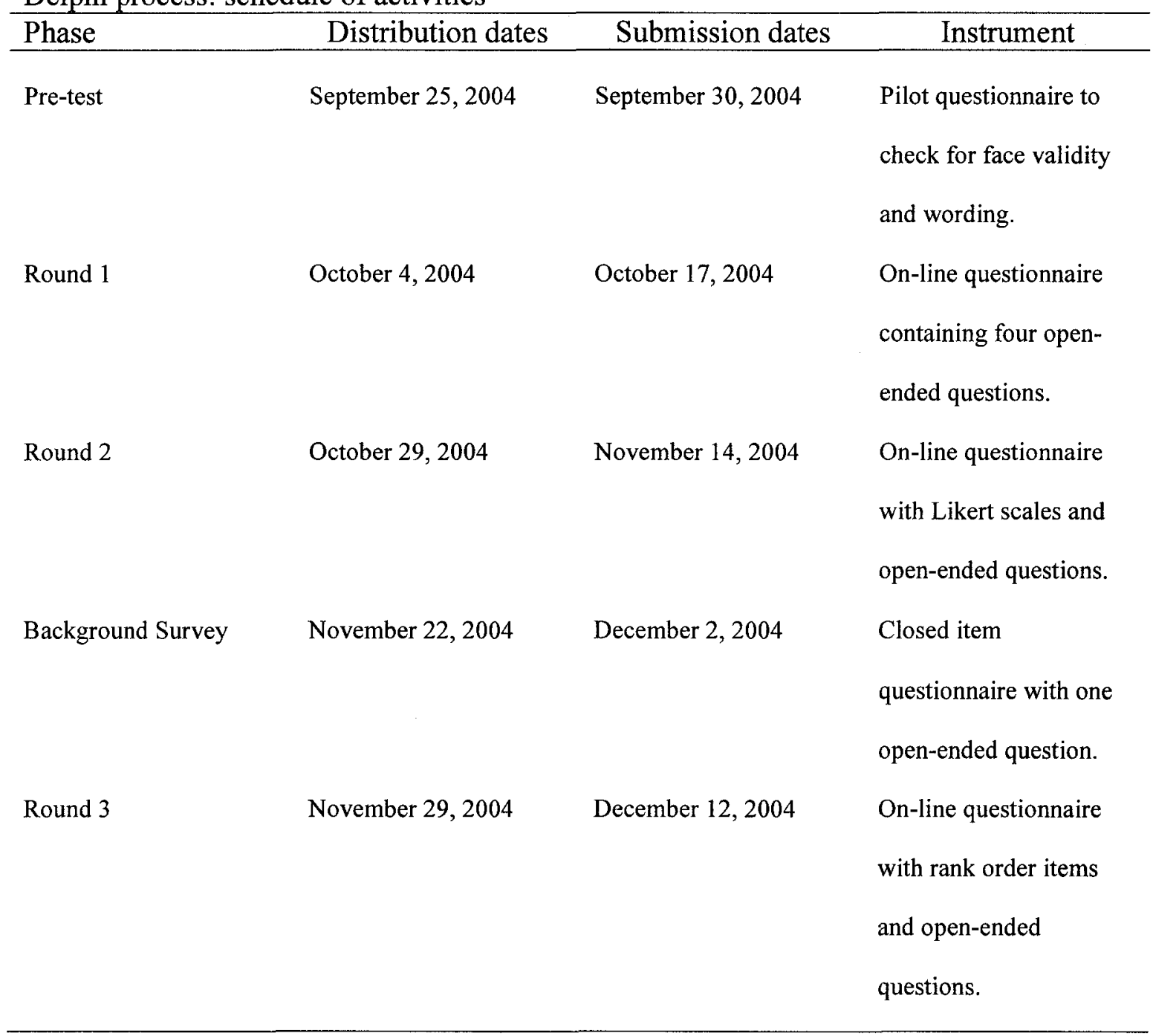




\section{Appendix B}

Expert Panel Recruitment Letter 


\title{
Appendix B
}

\author{
Expert Panel Recruitment Letter
}

September 25, 2004

Dear Mr. Smith:

I would like to invite school leaders from the American School of Lima to participate in an important dissertation study involving a panel of experts from the most renowned U.S.-accredited, American international schools in the Latin American Region.

As an international school educator with administrative experience in American schools in Latin America and a doctoral student at the University of San Diego, I am well aware of the opportunities and challenges we face in managing American international schools due to both the unique diversity and crosscultural settings of our schools. To date, there is a lack of information on school leadership strategies that address these issues in schools in the Latin American region.

For my dissertation research, I am recruiting school administrators from U.S. accredited American international schools throughout Latin America to share and compare their experiences and beliefs regarding policies, programs, and practices that contribute to a school's proficiency in managing the challenges and opportunities that arise from operating a culturally diverse American-style school within a cross-cultural setting.

The study is titled, Essential Features of Cultural Proficiency in American International Schools in Latin America: A Delphi Study. Expert participation will involve responding to a series of short, web-based questionnaires distributed via electronic mail about every 2 weeks for a period of approximately three months beginning the end of September 2004. After each questionnaire, participants will receive feedback on how their comments compared with other panel experts (American international school administrators in other schools). Panel participation promises to be stimulating.

Participation is anonymous in that specific comments will not be associated with an individual or a participating school. Experts are given the opportunity, however, to allow their name or school to be associated with this study. This option will be indicated on a questionnaire near the end of the study.

Please nominate up to two administrators (local or overseas hires) from your school who could provide expertise on cultural issues in American international schools in Latin America for participation in this valuable study. To meet the criteria for panel participation, nominated experts should meet the following three criteria: 
1) Have at least two years of experience in an administrative leadership position (e.g. superintendent, principal, coordinator, department

director, lead teacher, counselor/psychologist) working in U.S. accredited international schools in Latin America.

2) Serve on the school's leadership or administrative team.

3) Have experience living and working in at least one other country, outside their country of origin.

Superintendents and Heads of School are encouraged to participate. I look forward to your school's active participation in this valuable study.

Please feel free to contact me by phone at 55-21-2523-9762 (in Brazil) or my committee chairperson, Dr. Johanna Hunsaker, at hunsaker@sandiego.edu and/or (619) 260-4858 with any questions or concerns about this study.

Sincerely,

Rebecca McBride Bustamante

rebeccab@sandiego.edu 
Appendix C

Informed Consent Form 


\section{Appendix C}

\section{Informed Consent Form}

The Institutional Review Board (IRB) at the University of San Diego requires that all study participants provide informed consent before participating in any type of research Please review the information listed below and click on the link at the end of the page to give your consent to participate on this expert panel of leaders from U.S.-accredited schools in the Latin American Region. Thank you.

\section{Purpose of this Study}

The purpose of this study is to explore how school leaders in U.S.-accredited, international schools in Latin America believe that development of global leadership skills and cultural proficiency can be reflected in a school's policies, programs, practices, and/or other indicators. The study also aims to uncover some of the perceived opportunities and challenges to managing a culturally diverse, American-style school in a Latin American country.

This study is dissertation research in partial fulfillment of the requirement for a doctoral degree in Leadership Studies in International Education at the University of San Diego in California.

\section{$\underline{\text { Research Methodology and Time Frame }}$}

This study will employ the Delphi technique. Delphi methodology involves the use of a panel of experts on the particular topic to be explored. The nature of Delphi process allows for anonymous group communication between geographically dispersed panel participants. Literature on the Delphi process recommends that the researcher pose initial questions in the broadest terms on the first questionnaire to allow for rich responses from the participants. The researcher will then summarize panelist responses and feed these responses (in cumulative form) back to the panel in a second round questionnaire in which participants may be asked to rank priorities and add any additional ideas to the topic of discussion.

Panel participants will respond to three to four rounds of electronic, mini-questionnaires dispersed over a two to three-month period, depending on the timeliness of panel responses, until group consensus is reached. The first on-line mini-questionnaire will be sent the end of September 2004. In pretests, participants reported an average time of 15 minutes to complete the mini-questionnaires, however, panel members may choose to take more time in writing their responses.

Participation in this study involves completing all rounds of mini-questionnaires sent via electronic mail links, along with a final demographic form to provide basic background information near the end of the study. 


\section{Anonymity and Confidentiality}

Participant anonymity will be enhanced in this study by using on-line links to questionnaires. By using electronic mailing lists, the researcher will be able to track which panel members submitted questionnaires throughout the Delphi process. However, the researcher will not be able to link actual questionnaire responses to individual participants. The researcher will summarize group responses and feed back this information to the panel members in a cumulative form.

Only the researcher will know the name, institution, and Email address of each panel participant. This information will not be made available to other participants in the study. After completion of the Delphi process, panelists will be given the option to affiliate their names and/or institutions with this study if they choose.

\section{$\underline{\text { Benefits and Risks }}$}

Benefits for participation in this study include the opportunity to share ideas on best practices with other school leader colleagues in similar positions in U.S.-accredited, international schools throughout the Latin American region. Personal satisfaction may arise from contributing to the growing body of knowledge on leadership and culture in American international schools, U.S.-accredited schools in Latin America, and the concept of cultural proficiency applied to schools.

No major risks are anticipated in this study beyond those encountered in daily professional life. The researcher will make every effort to ensure that computer viruses are not received or transmitted through use of the on-line surveys or any other electronic correspondence related to this study.

\section{Participant Questions}

Panel participants may ask questions about this research at any time and the researcher will make every effort to clarify any aspects of the study at any time.

The researcher, Rebecca McBride Bustamante, may be contacted in Brazil at (55-212523-9762) or by email at rebeccab@sandiego.edu or rebecca.bustamante@terra.com.br. Her dissertation advisor, Dr. Johanna Hunsaker, may be contacted at the University of San Diego, California at (619) 260-4858 or hunsaker@sandiego.edu.

\section{Voluntary Participation}

Participation in this study is voluntary and the participant may withdraw from this project at anytime. Click on this link to submit your consent: [link]

Name:

School:

Birthdate: 
Appendix D

Round One: Cover Letter 


\section{Appendix D}

Round One: Cover Letter

October 4, 2004

Dear Panel Participant:

Thank you for your willingness to serve on this study panel with other school leaders from U.S. accredited, American international schools located throughout Latin America.

This expert panel is part of a Delphi study designed to explore what school leaders in this region would consider to be cultural proficient school-wide policies, programs, practices that might enhance the opportunity to develop global leaders, while also alleviating some of the potential challenges of managing culturally diverse, "U.S. style" schools in Latin American countries. The role of school leaders in influencing cultural proficiency in will also be explored among other ideas.

\section{Consent Form}

Attached please find an informed consent form for participation in this study as required by the Institutional Review Board at the University of San Diego. Please review the information and provide consent by clicking on the link under "Voluntary Participation," completing the boxes (e.g., name, etc.), and clicking DONE.

\section{Questionnaire}

Then, please click on this link to complete the first, four-question questionnaire:

[link]

Please submit your on-line questionnaire by Monday, October 17, 2004. You may be sent a friendly reminder as the final submittal date approaches. A few weeks after submittal of this questionnaire, panelists will receive summarized feedback on the responses of the group and may be asked to prioritize items and add new ideas.

Feel free to contact me with questions at any time at rebeccab@sandiego.edu. Your support for this research is highly appreciated.

Rebecca McBride Bustamante

Doctoral Program in Leadership Studies

International Educator Cohort

University of San Diego

rebeccab@sandiego.edu 
Appendix E

Round One Questionnaire 


\section{Appendix E}

\section{Round One Questionnaire}

\section{Essential Features of Cultural Proficiency in America International Schools in Latin} America: A Delphi Study

By Rebecca McBride Bustamante

1. International schools are frequently cited as ideal settings for modeling and developing global leadership skills among students, teachers, and other school community members.

Based on your experiences and perspectives as a school leader, please name TWO key ways that you believe U.S.-accredited, American international schools can effectively model and promote global leadership.

1.

2.

Others to add?

2. What do you perceive to be the THREE greatest challenges to managing a culturally diverse U.S.-accredited (American) international school in the Latin American region? Please feel free to include any additional challenges below.

1.

2.

3.

Other major cultural challenges?

3. While recognizing that each individual school is unique, one model of CULTURAL PROFICIENCY for schools provides a framework for understanding how culturally diverse schools go about: (a) valuing various cultural perspectives, (b) managing intercultural conflicts and tensions, (c) institutionalizing cultural knowledge, (d) adapting to and learning from different cultures, and (e) assessing culture (including school culture). Cultural proficiency is typically reflected in a school's policies (e.g. stated mission, hiring, language), programs (e.g. training, curriculum, special services), and practices (e.g. communication patterns, customs, events). 
With this general idea in mind, what should U.S.-accredited (American) international schools, in the Latin American region, do to promote CULTURAL PROFICIENCY among the following groups in schools?

Faculty and Staff:

Students:

Parents:

Outer Community (local, national, international)

4. How do/can school leaders influence the development of global leadership and cultural proficiency in U.S.-accredited (American) international schools?

Note. The exact content of this questionnaire was distributed in an on-line format. Participant responses recorded into an on-line data bank for downloading and analysis. 
Appendix F

Cover Letter

Round One: Compiled Results 


\section{Appendix F \\ Cover Letter \\ Round One: Compiled Results}

October 23,2004

Dear Panel Participant:

Attached please find the compiled results from the first round questionnaire for the Delphi study on "Essential Features of Cultural Proficiency in U.S.-accredited international schools in Latin America." Thirty-five school leaders, primarily School Heads and Principals, are participating on this expert panel and represent schools throughout the Latin American region.

I thought is might be helpful to send you this information in advance of the next on-line questionnaire (Round Two) for a few reasons: (1) so that you could review the information in advance; (2) so you can print it and have it before you as you respond to the next questionnaire; and (3) so you can have the access to ALL the ideas expressed by other school leader colleagues represented on the panel, as the next questionnaire will only include the ideas most frequently reported by panel members.

To make it easier to process this information, I have included some tables that illustrate categories for the most frequently reported ideas, along with tables containing a breakdown of compiled responses reported. The number of panel members who mentioned a particular idea is noted under (\#) in the far left column of each chart. The percentage of panel members who gave a particular response is also noted in the second column. Categories are not meant to be completely mutually exclusive and some overlap of ideas may be evident.

On Friday, October 29, 2004 you will receive the on-line questionnaire for Round Two of the Delphi process. The Round Two questionnaire is designed to begin to narrow group/panel consensus on the ideas presented thus far and begin to identify success indicators for and barriers to cultural proficiency and global leadership in schools. This questionnaire may be submitted anytime within a two-week time frame.

Thank you so much for your time and commitment to serving on this expert panel of school leaders. I look forward to your responses to the Round Two questionnaire.

Sincerely,

Rebecca McBride Bustamante

rebeccab@sandiego.edu 
Appendix G

Round One: Compiled Results 


\section{Appendix G}

\section{Round One: Compiled Results}

Question 1 Results: International schools are frequently cited as ideal settings for modeling and developing global leadership skills among students, teachers, and other school community members. Based on your experiences and perspectives as a school leader, please name TWO key ways that you believe U.S.-accredited, American international schools can effectively model and promote global leadership.

Table G1. Global leadership development: policies, programs and practices

\section{Reported Items}

Active role modeling and teaching the value of culturally diverse perspectives

Global curriculum with learning outcomes

Model United Nations

Student Leadership organizations

Vision/ Mission/ Values providing more local control

Diverse staffing policy with high qualification criteria

Community Service

Teaching acceptance /tolerance for diversity

Traditional cultural celebrations and events (e.g., international fair)

"Due process" in incidents with faculty and staff

Vision/ Mission providing more local control

Clearly stated behavioral expectations for student
No. Percent

$43 \quad 14 \%$

$30 \quad 10 \%$

$23 \quad 8 \%$

$21 \quad 7 \%$

$21 \quad 7 \%$

$17 \quad 6 \%$

$9 \quad 3 \%$

$9 \quad 3 \%$

$\begin{array}{ll}7 & 2 \% \\ 7 & 2 \% \\ 7 & 2 \%\end{array}$


Table Gl. (cont'd)

Reported Items

No. Percent

Making multicultural resources available

$6 \quad 2 \%$

Examining/assessing school culture to facilitate school change

$6 \quad 2 \%$

Language studies

$4 \quad 1 \%$

Recognizing potential leadership qualities of each member of the 3 $1 \%$ school community (e.g., support staff, maintenance worker, etc.)

Character education

$2 \quad 1 \%$

Virtual global projects

$21 \%$

Award/ recognition program for global leadership qualities

$21 \%$

TOTAL

Note. $n=35$ 
Question 2 Results: What do you perceive to be the THREE greatest CHALLENGES to managing a culturally diverse U.S.-accredited (American) international school in the Latin American region? Please feel free to include any additional challenges below.

Table G2. Academic challenges

\begin{tabular}{lcc} 
Challenges & No. & Percent \\
\hline Satisfying curriculum requirements of multiple national school systems & 9 & $64 \%$ \\
Academic expectations of international community not aligned with an & 2 & $14 \%$ \\
U.S. curriculum. & & \\
Differences in training and educational philosophy between local and & 1 & $7 \%$ \\
overseas hire staff & 1 & $7 \%$ \\
Teaching students to think critically and imaginatively & 1 & $7 \%$ \\
Provision of differentiated instruction and special services & 14 & $100 \%$ \\
\hline
\end{tabular}


Table G3. Behavioral/attitudinal/value-related challenges

\begin{tabular}{lcc}
\hline Responses & No. & Percent \\
\hline Differing expectations for values and social behavior related to & 11 & $30 \%$ \\
culture & & \\
Intercultural conflicts/tensions among various groups in the school & 9 & $24 \%$ \\
Conflicting needs/agendas of local parents and international & 8 & $22 \%$ \\
(expatriate) parents & & \\
Prejudices of host country and international staff and parents against & 5 & $14 \%$ \\
each other & & \\
Poor communication & 2 & $5 \%$ \\
Teacher perceptions that the U.S. holds the "truth" in everything & 1 & $3 \%$ \\
Differences in socioeconomic class values & 1 & $3 \%$ \\
TOTAL & 37 & $100 \%$ \\
\hline
\end{tabular}


Table G4. Challenges related to school mission and policies

\begin{tabular}{lcc} 
Responses & No. & Percent \\
\hline Misperceptions about the mission and direction of the school. & 5 & $31 \%$
\end{tabular}

Vision/purpose becomes blurred when a high percent of students are $\quad 4 \quad 25 \%$ from the host country.

Differential pay/benefits for overseas and local hire staff.

Constant faculty changes/turnover

Majority local hire faculty in Latin America

Cultural clashes in the overall running of the school (e.g. Board of

1

$6 \%$

Directors)

TOTAL

$16 \quad 100 \%$

Table G5. Demographic challenges

\begin{tabular}{lcc}
\hline Responses & No. & Percent \\
\hline Intercultural integration barriers when high percent of local host & 6 & $46 \%$ \\
country students & & \\
English as common language with high populations of local children & 4 & $31 \%$ \\
who speak a non-English language & 2 & $15 \%$ \\
General language barriers & 1 & $8 \%$ \\
Differences in average stays of community members (either $2-4$ & 13 & $100 \%$ \\
years OR 12-15 years) & & \\
TOTAL & & \\
\hline
\end{tabular}


Table G6. Societal/governmental challenges

\begin{tabular}{lcc}
\hline Responses & No. & Percent \\
\hline Local government & 6 & $55 \%$ \\
interference/restrictions/threats/instability/disorganization & & \\
Political turmoil/tensions and insecurity & 4 & $36 \%$ \\
Overall difficult world situation & 1 & $9 \%$ \\
TOTAL & 11 & $100 \%$ \\
\hline
\end{tabular}

Table G7. Skills and resource challenges

\begin{tabular}{lcc}
\hline Responses & No. & Percent \\
\hline Lack of multicultural/multilingual skills of administrators and & 6 & $43 \%$ \\
teachers & & \\
Monetary/Financial (e.g. tuition, fees, exchange rates, budget) & 5 & $36 \%$ \\
Lack of time to recognize each culture and build relationships & 2 & $14 \%$ \\
Limited multicultural resources (e.g., texts) & 1 & $7 \%$ \\
TOTAL & 14 & $100 \%$ \\
\hline
\end{tabular}

Question 3 Results: While recognizing that each individual school is unique, one model of CULTURAL PROFICIENCY for schools provides a framework for understanding how culturally diverse schools go about:

(1) Valuing various cultural perspectives

(2) Managing intercultural conflicts and tensions

(3) Institutionalizing cultural knowledge

(4) Adapting to and learning from different cultures

(5) Assessing culture (including school culture) 
Cultural proficiency is typically reflected in a school's policies (e.g. stated mission, hiring, language), programs (e.g. training, special services), and practices (e.g. communication patterns, customs, events). With this general idea in mind, what should U.S.-accredited (American) international schools, in the Latin American region, do to promote cultural proficiency among the following groups in schools?

Table G8. Cultural proficiency for faculty and staff

\begin{tabular}{lcc}
\hline Responses & No. & Percent \\
\hline Provide staff development/workshops/orientations/simulations on cultural & 11 & $28 \%$ \\
awareness and the value of diversity. & 5 & $13 \%$ \\
Language acquisition and culture orientation courses for faculty & 5 & $13 \%$ \\
Provide international staff with information about the local culture, history, & & \\
customs, etc. & 4 & $10 \%$ \\
Ensure diversity in staffing and leadership positions and work teams & 3 & $8 \%$ \\
Hire fully multicultural administrators & 3 & $8 \%$ \\
Model culturally proficient practices with staff and students & 2 & $5 \%$ \\
Seek ways to establish more equal hiring practices, salaries, and benefits. & 2 & $5 \%$ \\
Staff participation to ensure diverse perspectives in developing mission. & & $3 \%$ \\
training/orientations, mentoring, etc. & 1 & $3 \%$ \\
Facilitate personal relationships among faculty through social events. & 40 & $100 \%$ \\
Manage intercultural conflicts and tensions & 1 & $3 \%$ \\
Clearly state diversity objectives and hold staff accountable to them & & $3 \%$ \\
TOTAL & & \\
\hline
\end{tabular}


Table G9. Cultural proficiency for parents

\begin{tabular}{lcc}
\hline Responses & No. & Percent \\
\hline Conduct training sessions/orientations for parents on culture and school values & 14 & $33 \%$ \\
Encourage participation of all cultures on the PTO/PTA & 9 & $21 \%$ \\
Ensure diversity issues are clearly addressed in all school communication (e.g. & 5 & $12 \%$ \\
newsletters, documents) & 3 & $7 \%$ \\
Demonstrate value for various cultural perspectives & 3 & $7 \%$ \\
Provide opportunities for parents to interact with others from different cultures & 3 & $7 \%$ \\
Create formal and informal settings where parents can mix with faculty & 1 & $2 \%$ \\
Address issues of culture with the Board of Directors to obtain endorsement of & & \\
culturally proficient policies & 1 & $2 \%$ \\
Seek opportunities for parents to share their cultural knowledge & 1 & $2 \%$ \\
Sponsor multicultural celebrations & 1 & $2 \%$ \\
Offer parent language courses & 1 & $2 \%$ \\
Provide translations at events and in documents & 42 & $100 \%$ \\
TOTAL & & \\
\hline
\end{tabular}

Note. $(\mathrm{n}=35)$ 
Table G10. Cultural proficiency for students

\begin{tabular}{llc}
\hline Responses & No. & Percent \\
\hline Integrate curriculum to insure cultural diversity and global perspective & 9 & $25 \%$ \\
are reflected & & \\
Community service & 5 & $14 \%$ \\
Allow for student participation in vision building through student & 4 & $11 \%$ \\
leadership organizations and focus groups (give students voice) & & \\
Encourage intercultural interactions and dialogue among students & 4 & $11 \%$ \\
Emphasize benefits of diversity & 3 & $8 \%$ \\
Have student leadership training programs & 2 & $6 \%$ \\
Teach tolerance & 2 & $6 \%$ \\
Use multicultural resources/texts/materials with students & 2 & $6 \%$ \\
Special events celebrating diverse cultures & 2 & $6 \%$ \\
Model dignity and respect with students & 1 & $3 \%$ \\
Have high behavioral standards & 1 & $3 \%$ \\
Recognize and reward students who exemplify intercultural & 1 & $3 \%$ \\
understanding in their interactions with others & 36 & $100 \%$ \\
TOTAL & & \\
\hline
\end{tabular}


Question 4 Results: How do/can school leaders influence the development of global leadership and cultural proficiency in U.S.-accredited (American) international schools?

Table G11. School leader influence

\begin{tabular}{|c|c|c|}
\hline Responses & No. & Percent \\
\hline $\begin{array}{l}\text { Be a model/example (and set the tone) for all by consistently exhibiting culturally } \\
\text { proficient values, attitudes, words, and actions, in both overt and subtle ways. Be } \\
\text { knowledgeable. }\end{array}$ & 19 & $25 \%$ \\
\hline $\begin{array}{l}\text { Incorporate cultural proficiency and global leadership into the daily life and activities } \\
\text { of the school, curricular and extracurricular. Make sure EVERYTHING the school is } \\
\text { and does reflect cultural proficiency (from mission statement to classroom } \\
\text { decorations). }\end{array}$ & 16 & $21 \%$ \\
\hline Put objectives of intercultural understanding in mission/vision as a top priority. & 7 & $9 \%$ \\
\hline Demonstrate value for local/host country cultural values in attitudes or behavior. & 5 & $7 \%$ \\
\hline Have culture and language training sessions for various groups in the school. & 5 & $7 \%$ \\
\hline $\begin{array}{l}\text { Sponsor community service and citizenship programs that actually build relationships } \\
\text { and are not just charity. }\end{array}$ & 5 & $7 \%$ \\
\hline $\begin{array}{l}\text { See each student as a leader and potential future leader by giving all students } \\
\text { opportunities to develop their leadership skills. }\end{array}$ & 3 & $4 \%$ \\
\hline Allow for the participation of ALL stakeholders in determining school policy. & 3 & $4 \%$ \\
\hline Sponsor cultural activities/events/programs. & 2 & $3 \%$ \\
\hline Promote civic education and democracy. & 2 & $3 \%$ \\
\hline $\begin{array}{l}\text { Form links with other international schools by participating in learning opportunities } \\
\text { and forging relationships with other international school leaders. }\end{array}$ & 2 & $3 \%$ \\
\hline Develop good interpersonal skills and open communication mechanisms. & 2 & $3 \%$ \\
\hline $\begin{array}{l}\text { Remember that leadership is viewed in very different ways in different cultures } \\
\text { because there is a tendency to support and nurture only a North American leadership } \\
\text { perspective. }\end{array}$ & 1 & $1 \%$ \\
\hline
\end{tabular}


Table G11. (cont'd)

\begin{tabular}{lcc}
\hline Responses & No. & Percent \\
\hline Emphasize teamwork at the administrative level. & 1 & $1 \%$ \\
Align awards and recognition with values. & 1 & $1 \%$ \\
Monitor and assess to measure and determine whether or not policies, programs, and & 1 & $1 \%$ \\
practices actually support cultural proficiency and global leadership. & & \\
TOTAL & 75 & $100 \%$ \\
\hline
\end{tabular}

Note. $(\mathrm{n}=35)$

\section{Question 4 Participant Quotes}

Quote 1. Effective leaders create an environment where it is clear to all that global leadership and cultural proficiency are important, that these characteristics will be modeled by the administration and staff and incorporated into the daily life of the school, and that a means of assessment will be implemented to monitor reality with the ideal. It is one thing to say it, but quite another to measure it and determine if you are actually doing it.

Quote 2. School leaders must be aware that cultural proficiency is enhanced in a myriad of ways. Not only through activities and programs, but also through communications, curriculum, training workshops, etc. Culture (like values) is not something you "teach", it is something you have to experience and model. Everything the school is and does reflects our values: from classroom decorations to the celebrations we decide to include in the calendar. Cultural proficiency is reflected in the "hidden curriculum," as well.

Quote 3. Develop curricular essential knowledge and skills that speak specifically to the desire to develop global leadership skills. It is not enough to place these comments in the mission statement. Rather, schools must actively choose to 
pursue these goals on an ongoing basis. International schools must also recognize that leadership is viewed in very different ways in different cultures. There is a tendency to support and nurture an American leadership perspective. On one hand, American overseas schools missions often include a focus on providing the community with insights into an American approach/philosophy. However, the school needs to be aware of this at a conscious level and make transparent those traits that are more global and more American in nature.

Quote $4 . .$. by sharing their resources, training, and knowledge with the local population. An easy way to do this is by offering training sessions on modern educational techniques to teachers in the public school system. At the same time, the promotion of social service programs within the school that focus not on charity but on the building of relationship between the students and the community being helped may prove to be an invaluable contribution to the future of these countries (by reducing the pervasive social segregation that tends to exist in Latin America). For better or for worse, many of the students in American schools in Latin America will become the political, industry, and business leaders of their countries. Our schools cannot afford to miss the opportunity to help these youngsters become agents of change towards lasting democracies in the region. Quote 5. School leaders provide the vision and guide the resources and staff of a school. They determine the agenda and create the channels of communication. In order to better develop cultural proficiency, these leaders need to construct these agendas and channels with the end goal of global leadership and cultural proficiency. They must be open to the voices of all constituency groups, but they 
must also encourage and guide these groups to better understand one another. An international learning community must clearly delineate the role of language and culture in their school. This cannot be left to chance or there will be continuous confusion, frustration and complaints. They must also create better modes of communication among international American schools. This cannot be achieved in isolated learning communities, but rather must be done in concert with others. 


\section{Appendix H}

Cover Letter

Round Two: Questionnaire 


\title{
Appendix $\mathbf{H}$
}

\author{
Cover Letter \\ Round Two Questionnaire
}

October 29,2005

Dear Claudia,

As promised, here is the link to the Round Two questionnaire on school leader perceptions of "Essential Features of Cultural Proficiency in U.S.-accredited International Schools in Latin America":

[Link-Round Two Questionnaire]

The questionnaire can be submitted anytime over the next two weeks. The final submission date is Monday, November 14, 2004. Please let me know if you may need more time or have any technical difficulties and I will do my best to accommodate your needs.

Thank you kindly for your valuable time and enthusiastic participation. I look forward to your responses as the group begins to move toward panel consensus on the ideas explored in this study.

Sincerely,

Rebecca McBride Bustamante 


\section{Appendix I}

Round Two Questionnaire 


\begin{abstract}
Appendix I
Round Two Questionnaire

Essential Features of Cultural Proficiency in American International Schools in Latin America: A Delphi Study
\end{abstract}

By Rebecca McBride Bustamante

Instructions: There are two purposes to this questionnaire: (1) to begin to narrow panel consensus regarding the essential features of global leadership and cultural proficiency in American international schools in the Latin American/Caribbean Region, and (2) to begin to identify potential success indicators and barriers to cultural proficiency that may be used to inform practice.

\title{
Question \#1
}

In reference to $\mathrm{Q} \# 1$ on the Round One questionnaire, at least four panel members named the following ways that they believe U.S.-accredited schools can effectively model and promote global leadership among students and other school community members.

On a scale of 1 (not at all essential) to 5 (very essential), please rate how essential you believe the following factors are to the effective development of global leadership capabilities in a school.

$\begin{array}{llllll}\text { A global curriculum with learning outcomes. } & 1 & 2 & 3 & 4 & 5 \\ \text { Model United Nations for students. } & 1 & 2 & 3 & 4 & 5 \\ \text { Community service. } & 1 & 2 & 3 & 4 & 5\end{array}$

Actively teaching and modeling of the values of cultural diversity.

\begin{tabular}{|c|c|c|c|c|}
\hline & 1 & 2 & 3 & 4 \\
\hline Demonstrating democratic process. & 1 & 2 & 3 & 4 \\
\hline Cultural awareness activities/training/workshops. & 1 & 2 & 3 & 4 \\
\hline
\end{tabular}

Teaching tolerance and acceptance of diverse cultures.

$\begin{array}{llllllll}1 & 2 & 3 & 4 & 5\end{array}$

A school mission/vision that reflects culturally diverse perspectives.

$\begin{array}{llllll} & 1 & 2 & 3 & 4 & 5 \\ \text { Traditional cultural celebrations and events. } & 1 & 2 & 3 & 4 & 5\end{array}$


Role modeling the value of diverse perspectives. $\begin{array}{lllllll}1 & 2 & 3 & 4 & 5\end{array}$

\section{Question \#2}

In reference to $\mathrm{Q} \# 3$ related to how to promote and influence cultural proficiency for various groups in the school and the school community, four or more panel members provided the following ideas. Please rate the following strategies on a scale of 1 (not at all essential) to 5 (very essential), to developing cultural proficiency in a U.S.accredited international schools that operate in the Latin American region.

Staff development/training on cultural awareness and value of diversity.

$$
\begin{array}{lllll}
1 & 2 & 3 & 4 & 5
\end{array}
$$

Training and orientations sessions for parents on culture and school values.

$$
\begin{array}{lllll}
1 & 2 & 3 & 4 & 5
\end{array}
$$

Language acquisition and cultural orientations for faculty.

$$
\begin{array}{lllll}
1 & 2 & 3 & 4 & 5
\end{array}
$$

Participation of all represented cultures on the PTA/PTO.

$$
\begin{array}{lllll}
1 & 2 & 3 & 4 & 5
\end{array}
$$

Encouragement of intercultural interactions and dialogue between students.

$$
\begin{array}{lllll}
1 & 2 & 3 & 4 & 5
\end{array}
$$

Orientations on local culture for overseas (international) staff.

$$
\begin{array}{lllll}
1 & 2 & 3 & 4 & 5
\end{array}
$$

Outline diversity values in all school communications (e.g. webpage, newsletters, etc.).

$$
\begin{array}{lllll}
1 & 2 & 3 & 4 & 5
\end{array}
$$

Diversity in staffing and leadership positions.

$$
\begin{array}{lllll}
1 & 2 & 3 & 4 & 5
\end{array}
$$

Integration of curriculum to reflect global perspectives and cultural diversity.

$$
\begin{array}{lllll}
1 & 2 & 3 & 4 & 5
\end{array}
$$

Student community service.

$$
\begin{array}{lllll}
1 & 2 & 3 & 4 & 5
\end{array}
$$

Allowing student participation/input in school vision building.

$\begin{array}{lllll}1 & 2 & 3 & 4 & 5\end{array}$

\section{Question\# 3}

How school leaders influence the development of global leadership and cultural proficiency in U.S.-accredited international school (in reference to responses listed for question \#4 on the Round One questionnaire). The following ideas were shared by four or more panel members.

Please rate on a scale of 1 (not at all essential) to 5 (very essential) how essential it is for school leaders to influence the development of global leadership and cultural proficiency in U.S.-accredited international schools in the following ways. 
By modeling/setting an example through culturally proficient values, attitudes, and $\begin{array}{lllllll}\text { behaviors (overt and subtle). } & 1 & 2 & 3 & 4 & 5\end{array}$

By prioritizing objectives of intercultural understanding in the mission statement/school vision.

$\begin{array}{lllll}1 & 2 & 3 & 4 & 5\end{array}$

By incorporating cultural proficiency and global leadership into everything the school is and does, both curricular and extracurricular (from mission statement to classroom

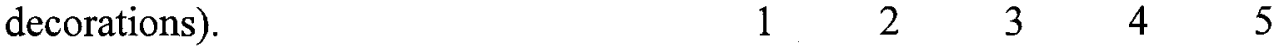

By demonstrating value for local/host country cultures in attitudes and behaviors.

$\begin{array}{lllll}1 & 2 & 3 & 4 & 5\end{array}$

By ensuring culture and language training sessions are conducted for various groups in the school.

$\begin{array}{lllll}1 & 2 & 3 & 4 & 5\end{array}$

By sponsoring community service and citizenship projects that actually build relationships. $\begin{array}{lllll}1 & 2 & 3 & 4 & 5\end{array}$

Question \# 4

What do you consider to be the primary BARRIERS to implementing the above-listed strategies for cultural proficiency and global leadership most frequently reported by this expert panel (in matrixes for questions 1-3)?

\section{Question \# 5}

How can we MEASURE and MONITOR how well we are doing in developing organizational cultural proficiency and global leadership capabilities in our schools? What might be some SUCCESS INDICATORS?

\section{Question \#6}

Some people believe that movement toward developing school-wide cultural proficiency enhances global leadership capabilities among all school members and helps alleviate some of the cultural challenges involved in managing U.S.-accredited international school in Latin America described by the panel in Round One. Please briefly discuss why you agree or disagree with this idea.

Note. The exact content of this questionnaire was formatted and distributed on-line. Participant responses to questions were recorded into an on-line data bank for downloading and analysis. 


\section{Appendix $\mathbf{J}$}

Round Two: Compiled Results 


\section{Appendix J}

\section{Round Two: Compiled Results}

Question 1: Essential strategies for the effective development of global leadership qualities in students and other school members.

Table J1. Essential strategies for the effective development of global leadership

\begin{tabular}{|c|c|c|c|c|c|c|}
\hline \multirow[t]{2}{*}{ Strategies } & \multicolumn{6}{|c|}{ Strategy ratings } \\
\hline & 1 & 2 & 3 & 4 & 5 & Average \\
\hline A global curriculum with learning outcomes & $0 \%$ & $7 \%$ & $10 \%$ & $43 \%$ & $40 \%$ & 4.17 \\
\hline Model United Nations program for students & $0 \%$ & $7 \%$ & $47 \%$ & $37 \%$ & $10 \%$ & 3.50 \\
\hline Community Service & $0 \%$ & $0 \%$ & $7 \%$ & $30 \%$ & $63 \%$ & 4.57 \\
\hline Actively teaching and role modeling the value & $0 \%$ & $0 \%$ & $0 \%$ & $17 \%$ & $83 \%$ & 4.83 \\
\hline \multicolumn{7}{|l|}{ of cultural diversity } \\
\hline Demonstrating democratic process & $0 \%$ & $0 \%$ & $7 \%$ & $37 \%$ & $57 \%$ & 4.50 \\
\hline Cultural awareness & $0 \%$ & $0 \%$ & $10 \%$ & $57 \%$ & $33 \%$ & 4.23 \\
\hline \multicolumn{7}{|l|}{ activities/training/workshops } \\
\hline Emphasizing tolerance and acceptance of & $0 \%$ & $0 \%$ & $3 \%$ & $13 \%$ & $83 \%$ & 4.80 \\
\hline \multicolumn{7}{|l|}{ diverse cultures } \\
\hline A school mission/vision that reflects culturally & $0 \%$ & $0 \%$ & $7 \%$ & $23 \%$ & $70 \%$ & 4.63 \\
\hline \multicolumn{7}{|l|}{ diverse perspectives } \\
\hline Traditional cultural celebrations and events & $0 \%$ & $0 \%$ & $23 \%$ & $47 \%$ & $30 \%$ & 4.07 \\
\hline
\end{tabular}

Note. Ratings are indicated on a scale of 1 to $5: 1=$ not at all essential; $5=$ very essential. 
Question 2: Essential strategies for developing cultural proficiency in American international schools in Latin America.

Table J2. Strategies for developing cultural proficiency

\begin{tabular}{|c|c|c|c|c|c|c|}
\hline & \multicolumn{6}{|c|}{ Ratings } \\
\hline & 1 & 2 & 3 & 4 & 5 & Average \\
\hline $\begin{array}{l}\text { Staff development/training on cultural awareness and } \\
\text { value of diversity. }\end{array}$ & $0 \%$ & $3 \%$ & $10 \%$ & $50 \%$ & $37 \%$ & 4.20 \\
\hline $\begin{array}{l}\text { Training and orientation sessions for parents on } \\
\text { culture and school values. }\end{array}$ & $0 \%$ & $7 \%$ & $23 \%$ & $33 \%$ & $37 \%$ & 4.00 \\
\hline $\begin{array}{l}\text { Language acquisition and cultural orientations for } \\
\text { faculty. }\end{array}$ & $0 \%$ & $3 \%$ & $3 \%$ & $43 \%$ & $50 \%$ & 4.40 \\
\hline Participation of all represented cultures on the & $0 \%$ & $7 \%$ & $27 \%$ & $53 \%$ & $13 \%$ & 3.73 \\
\hline PTA/PTO. & & & & & & \\
\hline Encouragement of intercultural interactions and & $0 \%$ & $0 \%$ & $10 \%$ & $50 \%$ & $40 \%$ & 4.30 \\
\hline dialogue between students. & & & & & & \\
\hline $\begin{array}{l}\text { Orientations on local culture for overseas } \\
\text { (international) staff }\end{array}$ & $0 \%$ & $0 \%$ & $3 \%$ & $33 \%$ & $63 \%$ & 4.60 \\
\hline $\begin{array}{l}\text { Outline diversity values in all school communications } \\
\text { (e.g., webpage, newsletters) }\end{array}$ & $0 \%$ & $0 \%$ & $27 \%$ & $53 \%$ & $20 \%$ & 3.93 \\
\hline Diversity in staffing and leadership positions & $0 \%$ & $7 \%$ & $17 \%$ & $53 \%$ & $23 \%$ & 3.93 \\
\hline $\begin{array}{l}\text { Integration of curriculum to reflect global perspectives } \\
\text { and cultural diversity }\end{array}$ & $0 \%$ & $0 \%$ & $10 \%$ & $47 \%$ & $43 \%$ & 4.33 \\
\hline Student community service & $0 \%$ & $0 \%$ & $14 \%$ & $43 \%$ & $43 \%$ & 4.29 \\
\hline $\begin{array}{l}\text { Allowing student participation/input in school vision } \\
\text { building }\end{array}$ & $0 \%$ & $3 \%$ & $27 \%$ & $33 \%$ & $37 \%$ & 4.03 \\
\hline
\end{tabular}

Note. Ratings are indicated on a scale of 1 to $5: 1=$ not at all essential; $5=$ very essential 
Question 3: Essential ways that school leaders influence development of global leadership and cultural proficiency.

Table J3. How school leaders influence cultural proficiency

\begin{tabular}{llllllll}
\hline Strategies & \multicolumn{6}{c}{ Ratings } \\
\cline { 1 - 4 } \cline { 6 - 8 } By modeling/setting an example through & & 1 & 2 & 3 & 4 & 5 & Average \\
\hline
\end{tabular}

culturally proficient values, attitudes, and

behaviors (overt and subtle).

By prioritizing objectives of intercultural

$\begin{array}{llllll}0 \% & 0 \% & 13 \% & 53 \% & 33 \% & 4.20\end{array}$

understanding in the mission statement/school

vision.

By incorporating cultural proficiency and global $\quad \begin{array}{lllllll}0 \% & 0 \% & 7 \% & 43 \% & 50 \% & 4.43\end{array}$

leadership into everything the school is and does,

both curricular and extracurricular (from mission

statement to classroom decorations).

By demonstrating value for local/host country

$0 \% \quad 0 \% \quad 0 \% \quad 17 \% \quad 83 \% \quad 4.83$

cultures in attitudes and behaviors.

By ensuring culture and language training $\quad \begin{array}{llllll}0 \% & 3 \% & 13 \% & 60 \% & 23 \% & 4.03\end{array}$

sessions are conducted for various groups in the

school.

By sponsoring community service and citizenship $\quad \begin{array}{llllll}0 \% & 0 \% & 10 \% & 40 \% & 50 \% & 4.40\end{array}$ projects that actually build relationships.

Note. Ratings are indicated on a scale of 1 to $5: 1=$ not at all essential; $5=$ very essential 
Question 4: Reported BARRIERS to implementing panel suggested strategies to enhance cultural proficiency and global leadership in American international schools in Latin America.

Table J4. Barriers to cultural proficiency and global leadership development

\begin{tabular}{|c|c|c|}
\hline Panel identified BARRIERS & No. & Percent \\
\hline Time constraints & 9 & $15 \%$ \\
\hline Resistance to change/unwillingness to learn & 7 & $12 \%$ \\
\hline Frequent turnover in faculty and administration & 6 & $10 \%$ \\
\hline Ethnocentrisms of both locals and international expats & 5 & $8 \%$ \\
\hline $\begin{array}{l}\text { Influence of the degree of cultural diversity (or lack of) in student enrollment (e.g., } \\
\text { higher percentages of local students) affects vision/interaction/exposure }\end{array}$ & 5 & $8 \%$ \\
\hline $\begin{array}{l}\text { High tuition attracts students and parents from an exclusive, "elite" local population } \\
\text { who tend not to be interested in issues of inclusion or promoting cultural diversity }\end{array}$ & 5 & $8 \%$ \\
\hline Limited financial and other resources & 4 & $7 \%$ \\
\hline Lack of parental commitment to global perspectives. & 3 & $5 \%$ \\
\hline $\begin{array}{l}\text { Need to develop cultural proficiency (awareness, skills, knowledge, integrity, } \\
\text { openness) of school leaders }\end{array}$ & 3 & $5 \%$ \\
\hline Poor levels of awareness or understanding of cultural issues. & 3 & $5 \%$ \\
\hline $\begin{array}{l}\text { Difficulty in defining (agreeing on) the goals of cultural proficiency to satisfy all } \\
\text { school constituencies }\end{array}$ & 2 & $3 \%$ \\
\hline General lack of commitment on the part of the school/other priorities take precedence & 2 & $3 \%$ \\
\hline $\begin{array}{l}\text { Breakdown in converting organizational theory into actual practice/marketing vs. } \\
\text { education }\end{array}$ & 2 & $3 \%$ \\
\hline $\begin{array}{l}\text { Nature of school culture regarding cultural diversity (e.g., history, organizational } \\
\text { vision) }\end{array}$ & 1 & $2 \%$ \\
\hline Parent and teacher orientations not comprehensive enough & 1 & $2 \%$ \\
\hline Poor availability of outstanding educators & 1 & $2 \%$ \\
\hline Security challenges inhibit community service efforts & 1 & $2 \%$ \\
\hline
\end{tabular}


Question 5: SUCCESS INDICATORS to measure and monitor the development of organizational level cultural proficiency and global leadership in American international schools in Latin America.

Table J5. Success indicators for cultural proficiency

\begin{tabular}{ll}
\hline Panel recommended success measures and indicators & No. $\%$ \\
\hline
\end{tabular}

Attitude measures of all stakeholders (e.g., alumni, students, parents, board of directors,

$18 \quad 31 \%$

administrators, teachers, staff, outer community members) using surveys, formal meetings

(focus groups), and informal meetings.

Level of evident (observable) participation in school activities and social events by school

$11 \quad 18 \%$ members representing diverse cultural groups.

Number of student-initiated community service efforts/volunteers that make links between

$10 \quad 17 \%$

school and local culture community

Observed social integration between students and teachers from different cultural groups

$6 \quad 10 \%$

(particularly host country and international groups)

Quantity and quality of student-generated activities (e.g., student government taking a role

$24 \%$

in school policy making)

Data related to the number of culture-related activities

$24 \%$

Fewer student complaints and a reduction in bullying/slurs

$2 \quad 4 \%$

Reported positive communication between teachers and parents.

$12 \%$

Auditing to check for explicitly stated values in mission statement and all school

$12 \%$

communications

Strategic planning to actually identify measurable objectives related to cultural

$12 \%$

proficiency and global leadership development

Focus on how to measure actual effectiveness rather than count \#s

$1 \quad 2 \%$

Number of awards/recognition given to students who demonstrate value for cultural

$12 \%$

diversity

Extensions in visiting teacher contracts (international overseas hires)

$1 \quad 2 \%$ 
Question 6: Whether or not panel members agree that school-wide cultural proficiency could enhance global leadership capabilities and help alleviate some of the cultural challenges of managing U.S. accredited international schools in Latin America (previously discussed in Round One). The expert panel members, who responded to this question, expressed one hundred percent agreement with this statement. Here are some randomly selected quotes from a few of the panel members in response to this question: Table J6. Randomly selected quotes from panel members

Panel member Quote

Member 1 We are teaching the future decision makers. They may be involved in a variety of fields, such as manufacturing, development, finance, government or education, yet they will be leaders of those fields. We need to give our students voice and expose them to other voices.

Member 2 If the purpose of education is to prepare our students to lead the world of tomorrow, then developing school-wide cultural proficiency is not only a sound school principle, but also a necessary obligation to our host nation and wider society.

Member 3 I believe that one of the biggest problems in achieving this has to do with the parent community of the school. A school can have many programs that work on cultural proficiency but many times it is the parents that are not willing to look at it with a different perspective.

Member 4 If all of the stakeholders know and understand the mission and accept the policies, then the school can move forward educating the students 
Table J6. (cont'd)

Panel member
and helping the host country understand the benefits of a global
education. The students will graduate knowing the value of service,
inclusiveness, and being well educated for all global societies.

Member 5 The higher the cultural proficiency is in an organization, the more successful it can be as it can encourage any and all members to take a leadership role. If all members of the school feel supported and equally valued in the school, more emphasis will naturally be placed on developing excellence rather than finding excuses and focusing on problems and barriers. A culturally proficient school environment can be a model for all school members to learn from and emulate within a more global context. Students will grow to expect a culturally proficient community and will have high expectations of larger communities they may become a part of. They, due to their experiences in a culturally proficient environment, can become models within larger global communities.

Member 6 The perception of the local community of what our school is tends to be negative (again, a symbol of foreign power). Unwittingly, we contribute to that perception by seeming to be detached from events around us. By fostering school-wide cultural proficiency, members of the school community will be more likely to participate, appreciate, 
Table J6. (cont'd)

\begin{tabular}{l}
\hline Panel member \\
\hline or even embrace some of the cultural norms of the country. As it \\
becomes apparent that this is the case, the community may see us in a \\
more positive light while at the same time allowing us to reach out \\
and provide expertise in the areas where that aid may be required. \\
As the world moves steadily toward a more interconnected and \\
interdependent economic, political, and social environment, the next \\
generation will be required to have increased cultural proficiency and \\
global leadership skills. I have always believed that schools mirror \\
society. As such, schools are obliged to incorporate the \\
understanding, skills and concepts necessary for the reality of our \\
ever-increasing global world.
\end{tabular}


Appendix K

Background Questionnaire 


\section{Appendix K}

Background Questionnaire

\section{$\underline{\text { Instructions }}$}

This quick response questionnaire is designed to obtain basic demographic background information on the expert panel participants in this Delphi study on leadership and cultural proficiency in U.S. accredited, American international schools in the Latin American region.

Please take a moment to click on the one, most approximate and appropriate response for each of the following background questions. Thank you kindly.

1. Please indicate your current position/title.

$\begin{array}{ll}- & \text { Head of School/Director/Superintendent } \\ & \text { Country Director } \\ & \text { K-12 Principal } \\ \square & \text { Elementary Principal } \\ \square & \text { Secondary Principal (MS/HS) } \\ & \text { Counselor } \\ \square & \text { Curriculum Coordinator/Lead Teacher/Department Head } \\ & \text { Other (please specify): }\end{array}$

2. About how many people do you supervise?

3. Approximately how many students (PreK-12) are currently enrolled in the school you work in?

4. What percentage of the total student population would be considered local/host country students?

5. What is the approximate percentage of foreign/international/overseas hire faculty at your current school?

6. Please indicate your gender. Male Female

7. How many years have you been in your current position?

8. How many total, cumulative years of experience do you have working in schools in Latin America (including Mexico, Brazil, and countries in Central America, South America, and the Spanish speaking Caribbean)? 
9. In reflecting on your career, how many total years of experience (e.g., as a teacher, staff member, administrator) do you have working in U.S. accredited American international schools anywhere in the world?

10. How would you describe (or identify) yourself culturally? Please indicate some of the major cultural influences in your life.

11. Can the name of your school be used in association with this study?<smiles>C[As]=[W]</smiles>

12. If yes, please write in the name of your school.

13. Are you willing to be identified as one of the expert panel participants in this study? If so, your name will be shared with other expert panel members upon completion of the study.

Yes No

14. Please write your name below if you wish to be identified in association with participation in this study:

15. Would you be willing to participate in follow up research or conference presentations related to the topics discussed in this exploratory study?

Yes _ No Nossibly

Note. The exact content of this questionnaire was formatted in an on-line. Participant $c$ responses to questions were directly recorded into an on-line data bank for downloading and analysis. 


\section{Appendix L}

Background Questionnaire: Compiled Results 


\section{Appendix L \\ Background Questionnaire:Compiled Results}

The following tables display panel participant responses to the background

questionnaire completed by 34 of the study participants who had completed Rounds One and Two of the Delphi study.

Table L1. Expert panel member job titles

Job titles

No. panel members

Head of school/superintendent/director

11

Principals $^{\mathrm{a}}$

17

Curriculum coordinator/department head/lead teacher

Country directors

Counselor

Note. $(\mathrm{n}=34)$. Total $=36$ because two participants have dual job titles (e.g., Head and Secondary Principal;

Secondary Principal and Country Director).

${ }^{\text {a }}$ Principals included: 8 Secondary Principals; 6 Elementary Principals; 2 K-12 Principals; 1 Early

Childhood Principal; 1 Middle School Vice Principal; and 1 Elementary Vice Principal.

Table L2. Supervisory responsibilities of panel members

No. supervised Percent panel members

\begin{tabular}{lc}
\hline Less than 25 & $9 \%$ \\
$25-50$ & $29 \%$ \\
$50-75$ & $21 \%$ \\
$75-100$ & $15 \%$ \\
Over 100 & $26 \%$ \\
\hline
\end{tabular}

Note. $(\mathrm{n}=34)$ 
Table L3. Participant years of experience in current position

Years in current position Percent panel members

\begin{tabular}{lc}
\hline Less than 2 & $21 \%$ \\
$2-4$ & $29 \%$ \\
$4-6$ & $29 \%$ \\
$6-10$ & $15 \%$ \\
More than 10 & $6 \%$ \\
\hline
\end{tabular}

Note. $(\mathrm{n}=34)$

Table L4. Participant experience in international schools

Years of experience Percent panel members

$9 \%$

$5-10 \quad 29 \%$

$10-15 \quad 15 \%$

$15-20 \quad 3 \%$

$20-25 \quad 18 \%$

More than $25 \quad 26 \%$

Note. $(\mathrm{n}=34)$

Table L5. Participant experience in schools in Latin America Years in Latin America Percent panel members

\begin{tabular}{lc}
\hline $1-2$ & $3 \%$ \\
$2-4$ & $6 \%$ \\
$4-6$ & $7 \%$ \\
$6-10$ & $24 \%$ \\
More than 10 & $46 \%$ \\
\hline
\end{tabular}

Note. $(\mathrm{n}=34)$ 
Table L6. Panel participant gender

\begin{tabular}{ll}
\hline Gender & No. participants \\
\hline $\mathrm{F}$ & 16 \\
$\mathrm{M}$ & 18 \\
\hline
\end{tabular}

Country locations of panel member schools

Countries

\begin{tabular}{l}
\hline Argentina \\
\hline Bolivia \\
Brazil \\
Chile \\
Colombia \\
Dominican Republic \\
Ecuador \\
Guatemala \\
Mexico \\
Nicaragua \\
Panama \\
Paraguay
\end{tabular}


Table L7. Student enrollment in panel member schools

\begin{tabular}{lc}
\hline Approximate students enrolled & Percent panel responses \\
\hline Less than 300 & $15 \%$ \\
$300-500$ & $21 \%$ \\
$700-900$ & $18 \%$ \\
$900-1100$ & $15 \%$ \\
More than 1100 & $25 \%$ \\
\hline
\end{tabular}

Table L8. Reported percent of local/host country students in panel member schools Percent of local/host country No. panel members

students

Less than $25 \%$

$\begin{array}{ll}25-50 \% & 7\end{array}$

$\begin{array}{ll}50-75 \% & 14\end{array}$

More than $75 \%$

Table L9. Approximate percent of overseas hire faculty at participant schools Percent of international faculty No. panel members

\begin{tabular}{lc}
\hline Less than $25 \%$ & 9 \\
$25 \%$ & 3 \\
$50 \%$ & 19 \\
$75 \%$ & 2 \\
More than $75 \%$ & 1 \\
\hline
\end{tabular}




\section{Cultural Descriptions/Influences of Participants}

Participant self-descriptions of cultural identity and cultural influences varied tremendously. While most participants named the U.S. or Canada as their national identity, others were born and raised in Latin America and some were raised in bicultural/multicultural families. Panel members were also raised in both rural and urban settings and most had considerable experience living and working in different countries and cultures. Some school leader participants permanently reside in the countries they work in because they are either from that country or are North American and are married to host country nationals. Based on participant descriptions, the expert panel was culturally and ethnically diverse.

\section{Participant Schools}

Out of a total of 25 schools that were represented in this study, the following schools agreed to name themselves in association with this study. Panel members from the remaining schools elected not to name their schools in association with this study at this time. School leaders represented the following schools, among several others:

1. American School of Asuncion (Paraguay)

2. American School of Guatemala

3. American School Foundation, Mexico City (Mexico)

4. American School Foundation of Monterrey (Mexico)

5. Balboa Academy (Panama)

6. Carol Morgan School (Dominican Republic)

7. Colegio Franklin D. Roosevelt (Lima, Peru) 
8. Colegio Granadino (Manizales, Colombia)

9. Colegio Internacional Puerto La Cruz (Venezuela)

10. Colegio Maya (Guatemala)

11. Nido de Aguilas (Chile)

12. Santa Cruz Cooperative School (Bolivia)

13. The American Cooperative School (La Paz, Bolivia)

14. The American School of Brasilia (Brazil)

15. The Columbus School (Medellin, Colombia)

16. Uruguayan American School

Participating School Leaders

The following school leaders served on the expert panel for this study and authorized their names to be used in association with the study. Several other school leaders participated on the Delphi panel, but opted to keep their participation anonymous and are not named here: Alex Kremer, Chris Akin, Cory Carson, David Cramer, David Deuel, Dennis Klump, Dr. Don Bergman, Elizabeth Mello Silva, Fabiola Lopez, Fran Combs Gamboa, Guadalupe Mendez, Jack Delman, Jean Lamb, Jean C. Nolan, Joseph Walker, Marilyn Holladay, Marcene Pareja, Margaret Dubeck, Megan Maher, Michael W. Adams, Michael Cooper, Michelle Remington, Nathan Walker, Peter Cooper, Ronald D. Lalonde, Tracy Berry-Lazo, and Warren Grant. 
Appendix M

Round Three Questionnaire 


\section{Appendix M}

\section{Round Three Questionnaire}

Essential Features of Cultural Proficiency in America International Schools in Latin America: A Delphi Study

\section{By Rebecca McBride Bustamante}

1. The following strategies were rated as essential or very essential by the majority of the expert panel members in the Round Two questionnaire. Please rank (order) the following panel-cited strategies from 1 (most important) to 5 (least important) in terms of school-wide strategies for developing global leadership qualities in students and other school community members. Each number column should only be checked once to convey your ranking order.

Traditional cultural celebrations and events.

A school mission/vision that reflects culturally diverse perspectives.

A global curriculum with learning outcomes.

Community service.

Cultural awareness training/activities/workshops.

2. The majority of panel participants agreed that the following three strategies were also essential to developing GLOBAL LEADERSHIP qualities in students and other school members.

To better inform our practice, please describe HOW this could be done by providing some real life examples of culturally proficient programs and practices from schools you have worked in or are familiar with. [NOTE: Continuous text can be written in the provided spaces].

Actively teach and role model value of cultural diversity:

Demonstrate democratic process:

Emphasize tolerance and acceptance of diverse cultures. 
3. The following strategies for developing school-wide CULTURAL

PROFICIENCY were rated essential or very essential by the majority of the expert panel members. Based on your experiences and perspectives, please rank (order) each item on the list from 1 (most important) to 7 (least important) in terms of their level of importance in developing school-wide cultural proficiency. Each item may be assigned only ONE ranking number.

Integration of curriculum to reflect global perspectives and cultural diversity.

Encouragement of intercultural interactions and dialogue between students.

Orientations on local culture for overseas (international) staff.

Diversity in staffing and leadership positions.

Staff development/training on cultural awareness and value diversity.

Language acquisition and cultural orientations for faculty.

Student community service.

4. Of the TOP THREE items you ranked above in Q\#3 (strategies for school-wide cultural proficiency), please briefly explain why you believe these three are the most important. You may comment on the other rankings as well, if you choose.

5. In Round 2, the following 6 BARRIERS to implementing school-wide strategies to enhance cultural proficiency and global leadership development were cited by a majority of panel members.

Please rank (order) these items from 1 to 6 based on what you consider to be the GREATEST BARRIER (1) to the LEAST GREATEST BARRIER (6).

Each number column should have only one check to convey your ranking order.

Ethnocentrism of host country and international groups.

Demographic/cultural makeup of student population.

Time constraints.

Frequent faculty and administrative turnover.

Exclusive (elite) values of student and parent populations.

Resistance to change. 
6. Please share some possible strategies for handling the TOP THREE BARRIERS you ranked above in Q\#5. You may comment on other barriers as well, if you choose.

7. In Round Two, the majority of panel members cited the following success indicators to measure and monitor school-wide cultural proficiency and global leadership development in American international schools in Latin America.

Please check (with a click) which measures or indicators, if any, are used at your school.

Attitudes of all stakeholders (e.g., measured via surveys, focus groups, formal/informal meetings).

Visible participation of various cultural group in school activities and social events.

Student-initiated community service.

Observed social integration between students and teachers from different cultural groups.

None of these.

8. Now, please describe how your school goes about identifying the success indicators you checked. (e.g., What kind of attitudinal and behavioral measures do you use and for which stakeholders? How do you objectively measure "participation," "social integration," and "student-initiated community service?" If you are NOT using measurements of any kind, why not?).

9. As a school leader, what kinds of specific SKILLS, FORMAL TRAINING, and EXPERIENCES do you believe might help other school leaders more effectively influence and sustain the development of cultural proficiency and global leadership in American international schools in Latin America?

10. Please feel free to comment here on anything else you would like to say related to the topics discussed in this study. 


\section{Appendix N}

Round Three: Compiled Results 


\section{Appendix N}

\section{Round Three: Compiled Results}

Question 1: The following strategies were rated as essential or very essential by the majority of the expert panel members in the Round Two questionnaires. Please rank (order) the following panel-cited strategies from 1 (most important) to 5 (least important) in terms of school-wide strategies for developing global leadership qualities in students and other school community members. Each number column should only be checked once to convey your ranking order.

Table N1. Rank order of essential strategies for global leadership

\begin{tabular}{lcccccc}
\hline \multicolumn{1}{c}{ Ranking } & \multicolumn{2}{c}{ Most important } & \multicolumn{2}{c}{$\begin{array}{c}\text { Least } \\
\text { important }\end{array}$} \\
\hline & 1 & 2 & 3 & 4 & 5 \\
& & & & & \\
Community Service & $15 \%$ & $12 \%$ & $21 \%$ & $32 \%$ & $21 \%$ \\
& $(5)$ & $(4)$ & $(7)$ & $(11)$ & $(7)$ \\
Cultural Awareness training activities workshops. & $9 \%$ & $26 \%$ & $24 \%$ & $21 \%$ & $21 \%$ \\
& $(3)$ & $(9)$ & $(8)$ & $(7)$ & $(7)$ \\
A school mission/vision that reflects culturally & $50 \%$ & $12 \%$ & $18 \%$ & $6 \%$ & $15 \%$ \\
diverse perspectives. & $(17)$ & $(4)$ & $(6)$ & $(2)$ & $(5)$ \\
& & & & & \\
Traditional cultural celebrations and events. & $9 \%$ & $9 \%$ & $18 \%$ & $26 \%$ & $38 \%$ \\
& $(3)$ & $(3)$ & $(6)$ & $(9)$ & $(13)$ \\
A global curriculum with learning outcomes. & $18 \%$ & $41 \%$ & $21 \%$ & $15 \%$ & $6 \%$ \\
& $(6)$ & $(14)$ & $(7)$ & $(5)$ & $(2)$ \\
\hline
\end{tabular}

Note. Number of participants is indicated with (). 
Question 2. HOW American international schools could (a) actively teach and role model diversity and (b) emphasize tolerance and acceptance of diverse cultures. Responses below are combined, based on similarity of responses, and are listed beginning with items mentioned by the greatest number of participants. Examples with an asterisk $\left(^{*}\right)$ were suggested by four or more panel members.

- $\quad{ }^{*}$ Hold international day/week/month celebrations and activities that are linked to the curriculum and more than a "food fair."

- $\quad{ }^{*}$ Create an integrated curriculum that reflects global cultures, religions, history, and geography, including host culture.

- $\quad{ }^{*}$ Hire people who value cultural diversity and represent diverse backgrounds.

- $\quad$ * Require school-wide community service programs (e.g. service learning, Habitat for Humanity project).

- $\quad$ *Clearly state expectations for adult and student behavior (e.g. handbooks) to emphasize zero tolerance for exclusionary or discriminatory behavior.

- $\quad$ *Use literature and drama from difference cultures to enhance empathy and understanding.

- $\quad$ *Ensure administrators and teacher model a value for diversity.

- $\quad$ *Provide "real-life" opportunities to learn from and about others who are culturally different (e.g., experiential education, simulations).

- $\quad *$ Create culturally diverse teaching and project teams. 
- *Have a character education program that incorporates cultural acceptance and learning.

- "Tap into" students' cultural background in the classroom and throughout the school.

- Hold open discussions and sensitivity workshops on cultural issues.

- $\quad$ Participate in the Model United Nations program.

- Admit more economically disadvantaged students through special scholarship programs.

- $\quad$ Sponsor second language learning programs for teachers.

- $\quad$ Establish a Gay/Straight Alliance.

- Have a clearly stated school mission that emphasizes cultural diversity and is supported by action (e.g., in-services, orientations, etc.)

- Create a special council that represents various groups of stakeholders (e.g. students, alumni, teachers, parents, etc.) to "build community" and address school-wide issues, including those that relate to culture.

- Create "student ambassador" programs to facilitate the adaptation of new students.

[There was an overwhelming consensus on two main points by panel members in describing ways to "demonstrate democratic process."]

1) Sponsor student programs such as: Model United Nations, student council, and other student government organizations, with an emphasis on 
authentic student "voice" and input into decision-making so students could truly learn from and experience democratic process.

2) Consider more ways to encourage collaborative, consensus making throughout the school (with all school members) and ensure greater, balanced input from various cultural groups and stakeholders. 
Question 3: The following strategies for developing school-wide CULTURAL

PROFICIENCY were rated essential or very essential by the majority of the expert panel members. Based on your experiences and perspectives, please rank (order) each item on the list from 1 (most important) to 7 (least important) in terms of their level of importance in developing school-wide cultural proficiency. Each item may be assigned only ONE ranking number.

Table N2. Ranking of Essential Strategies for School-wide Cultural Proficiency

Percentages of total participant responses

\begin{tabular}{|c|c|c|c|c|c|c|c|}
\hline \multirow{2}{*}{ Ranking } & \multicolumn{3}{|c|}{ Most important } & \multicolumn{4}{|c|}{ Least important } \\
\hline & 1 & 2 & 3 & 4 & 5 & 6 & 7 \\
\hline Student Community Service & $\begin{array}{l}6 \% \\
(2)\end{array}$ & $\begin{array}{c}15 \% \\
(5)\end{array}$ & $\begin{array}{c}12 \% \\
(4)\end{array}$ & $\begin{array}{l}9 \% \\
(3)\end{array}$ & $\begin{array}{l}9 \% \\
\text { (3) }\end{array}$ & $\begin{array}{c}29 \% \\
(10)\end{array}$ & $\begin{array}{c}21 \% \\
(7)\end{array}$ \\
\hline Integration of curriculum to reflect & & & & & & & \\
\hline $\begin{array}{l}\text { global perspectives and cultural } \\
\text { diversity. }\end{array}$ & $\begin{array}{c}44 \% \\
(15)\end{array}$ & $\begin{array}{c}12 \% \\
(4)\end{array}$ & $\begin{array}{c}18 \% \\
(6)\end{array}$ & $\begin{array}{l}3 \% \\
(1)\end{array}$ & $\begin{array}{c}18 \% \\
(6)\end{array}$ & $\begin{array}{l}3 \% \\
(1)\end{array}$ & $\begin{array}{l}3 \% \\
(1)\end{array}$ \\
\hline $\begin{array}{l}\text { Diversity in staffing and leadership } \\
\text { positions. }\end{array}$ & $\begin{array}{c}18 \% \\
(6)\end{array}$ & $\begin{array}{c}24 \% \\
(8)\end{array}$ & $\begin{array}{l}9 \% \\
(3)\end{array}$ & $\begin{array}{l}0 \% \\
(0)\end{array}$ & $\begin{array}{l}9 \% \\
\text { (3) }\end{array}$ & $\begin{array}{c}24 \% \\
(8)\end{array}$ & $\begin{array}{c}18 \% \\
(6)\end{array}$ \\
\hline $\begin{array}{l}\text { Orientations on local culture for } \\
\text { overseas (international) staff. }\end{array}$ & $\begin{array}{l}6 \% \\
(2)\end{array}$ & $\begin{array}{c}12 \% \\
(4)\end{array}$ & $\begin{array}{c}15 \% \\
(5)\end{array}$ & $\begin{array}{c}24 \% \\
(8)\end{array}$ & $\begin{array}{c}21 \% \\
(7)\end{array}$ & $\begin{array}{c}12 \% \\
(4)\end{array}$ & $\begin{array}{c}12 \% \\
(4)\end{array}$ \\
\hline Encouragement of intercultural & & & & & & & \\
\hline $\begin{array}{l}\text { interactions and dialogue between } \\
\text { students. }\end{array}$ & $\begin{array}{c}15 \% \\
(5)\end{array}$ & $\begin{array}{c}15 \% \\
(5)\end{array}$ & $\begin{array}{c}12 \% \\
(4)\end{array}$ & $\begin{array}{c}24 \% \\
(8)\end{array}$ & $\begin{array}{l}9 \% \\
\text { (3) }\end{array}$ & $\begin{array}{c}18 \% \\
(6)\end{array}$ & $\begin{array}{l}9 \% \\
(3)\end{array}$ \\
\hline $\begin{array}{l}\text { Language acquisition and cultural } \\
\text { orientations for faculty. }\end{array}$ & $\begin{array}{l}6 \% \\
(2)\end{array}$ & $\begin{array}{l}9 \% \\
\text { (3) }\end{array}$ & $\begin{array}{c}21 \% \\
(7)\end{array}$ & $\begin{array}{c}18 \% \\
(6)\end{array}$ & $\begin{array}{c}18 \% \\
(6)\end{array}$ & $\begin{array}{l}9 \% \\
\text { (3) }\end{array}$ & $\begin{array}{c}21 \% \\
(7)\end{array}$ \\
\hline Staff development/training on & & & & & & & \\
\hline $\begin{array}{l}\text { cultural awareness and value of } \\
\text { diversity. }\end{array}$ & $\begin{array}{l}6 \% \\
(2)\end{array}$ & $\begin{array}{c}15 \% \\
(5)\end{array}$ & $\begin{array}{c}15 \% \\
(5)\end{array}$ & $\begin{array}{c}24 \% \\
(8)\end{array}$ & $\begin{array}{c}18 \% \\
(6)\end{array}$ & $\begin{array}{l}6 \% \\
(2)\end{array}$ & $\begin{array}{c}18 \% \\
(6)\end{array}$ \\
\hline
\end{tabular}

Note. Number of participants is indicated with ( ). 
Question 4. Of the TOP THREE items you ranked above in Question 3 (strategies for school-wide cultural proficiency), please briefly explain why you believe these three are the most important. You may comment on the other rankings as well, if you choose. [produced numerous participant quotes that have been integrated into dissertation text] Question 5. In Round 2, the following 6 BARRIERS to implementing schoolwide strategies to enhance cultural proficiency and global leadership development were cited by a majority of panel members.Please rank (order) these items from 1 to 6 based on what you consider to be the GREATEST BARRIER (1) to the LEAST GREATEST BARRIER (6). Each number column should have only one check to convey your ranking order.

Table N3. Barriers to cultural proficiency by rank order

\begin{tabular}{lcccccc}
\hline \multirow{2}{*}{ Ranking } & \multicolumn{3}{c}{ Greatest } & \multicolumn{3}{c}{ Least great } \\
\cline { 2 - 7 } & 1 & 2 & 3 & 4 & 5 & 6 \\
\hline Time Constrains & $9 \%$ & $3 \%$ & $15 \%$ & $15 \%$ & $9 \%$ & $50 \%$ \\
& $(3)$ & $(1)$ & $(5)$ & $(5)$ & $(3)$ & $(17)$ \\
Resistance to change & $18 \%$ & $15 \%$ & $9 \%$ & $32 \%$ & $21 \%$ & $6 \%$ \\
& $(6)$ & $(5)$ & $(3)$ & $(11)$ & $(7)$ & $(2)$ \\
Frequent faculty and administrative turnover & $15 \%$ & $12 \%$ & $15 \%$ & $24 \%$ & $21 \%$ & $6 \%$ \\
& $(5)$ & $(4)$ & $(5)$ & $(8)$ & $(7)$ & $(2)$ \\
Ethnocentrism of host country and & $21 \%$ & $9 \%$ & $24 \%$ & $18 \%$ & $12 \%$ & $18 \%$ \\
international groups & $(7)$ & $(3)$ & $(8)$ & $(6)$ & $(4)$ & $(6)$ \\
Demographic/cultural makeup of student & $9 \%$ & $29 \%$ & $24 \%$ & $6 \%$ & $21 \%$ & $12 \%$ \\
population. & $(3)$ & $(10)$ & $(8)$ & $(2)$ & $(7)$ & $(4)$ \\
Exclusive (elite) values of student and parent & $29 \%$ & $24 \%$ & $15 \%$ & $6 \%$ & $18 \%$ & $9 \%$ \\
populations. & $(10)$ & $(8)$ & $(5)$ & $(2)$ & $(6)$ & $(3)$ \\
\hline
\end{tabular}

Note. Number of participants is indicated with ( ). 
Question 6. Please share some possible strategies for handling the TOP THREE BARRIERS you ranked above in Question 5. You may comment on other barriers as well, if you choose.

a. Exclusive (elite) values of student and parent populations.

- Require community service and service learning to help overcome elite, sheltered upbringing of students.

- Purposeful parent education and dialogue about cultural issues.

- Social opportunities for parents to interact.

- Help parents understand the importance of global understanding by allowing it to come from them (those in the community that express this value or interest) so it does not seem imposed.

- Have equitable and consistent policies and the integrity to truly practice democratic values. Don't be bullied by powerful, influential families.

- Get commitment to school-wide cultural proficiency at the Board of Director level and then work down.

b. Demographic/cultural makeup of student population.

- With more homogeneous populations (e.g., large percentages of local students), create a strong marketing campaign to diversify student population, limit number of dominate culture students, and promote different types of cultural exchanges.

- Ensure appropriate and high quality English as a Second Language support. 
- Provide more "real life" opportunities to interact with other culture groups through school-to-school partnerships with the U.S. or other countries and include on-line (electronic communities) as an outlet/opportunity in culturally homogeneous schools.

- Emphasize the importance of speaking English throughout the school using incentives, modeling, and positive reinforcement, not punishment.

c. Ethnocentrisms of host country and international groups.

- Directly influence student attitudes (future global and country leaders) by creating a culturally proficient and sensitive school culture.

- Seek numerous ways to encourage intercultural interactions and foster relationships.

- Build common vision and involve all potential stakeholders.

- Sensitize and educate people in the school community.

- Diversify the leadership body at the board, administrative, faculty, and student levels.

- Parent volunteer groups to stimulate intercultural interactions.

d. Resistance to change.

- Rotate local hires in administrative positions.

- Train top staff to handle change.

- Work out proposed changes bottom-up by slowly working with individual segments of the community and slowly integrating larger groups.

- Celebrate "small victories" toward desired change. 
- Teach and learn about the change process (Board, administrators, teachers, parents).

- Practices can be imposed in a school, even if points of view cannot.

Sometimes resistance is only broken down by doing, learning, accomplishing.

- Strategic planning.

- Open and continuous communication.

e. Frequent Faculty turnover.

- Stagger foreign hire renewal.

- Create a school culture and curriculum that survives staff turnover.

Newcomers should fit the fundamental philosophy of the school culture.

- Create a school climate that makes quality staff members want to stay.

- Create incentives and attractive professional development opportunities.

- Have longer contracts.

- Create supports for staff (e.g., Personnel Officer) to handle "life stuff."

f. Time constraints.

- Develop inter-disciplinary study units.

- Have a strategic plan for organizational level cultural proficiency that should naturally be integrated into all other programs and activities targeted to various school groups. Not a separate, additional task. 
Question 7: In Round Two, the majority of panel members cited the following success indicators to measure and monitor school-wide cultural proficiency and global leadership development in American international schools in Latin America.

Table N4. Reported use of success indicators to measure school-wide cultural proficiency

\begin{tabular}{lll}
\hline Indicator & $\begin{array}{l}\text { Percent of } \\
\text { Participants }\end{array}$ & Participants \\
\hline Measured attitudes of all stakeholder groups & $73.50 \%$ & 25 \\
Student-initiated community service & $73.50 \%$ & 25 \\
Participation levels of various cultural groups in school- & $70.60 \%$ & 24 \\
wide events. & & \\
Observed intercultural (social) integration & $58.80 \%$ & 20 \\
None of these & $8.80 \%$ & 3 \\
\hline
\end{tabular}

Question 8. Now, please describe how your school goes about identifying the success indicators you checked. (e.g., What kind of attitudinal and behavioral measures do you use and for which stakeholders? How do you objectively measure "participation," "social integration," and "student-initiated community service?" If you are NOT using measurements of any kind, why not?).

- Strategic planning process that includes data collection and analysis.

- SACS re-accreditation process.

- Attitudinal surveys of various groups in the school including: teacher and student surveys; anonymous parent surveys; community climate surveys to address questions related to diversity and leadership; an NSSE survey with all school members including students in grades 3 and up. 
- "Building a Better Community Council" with stakeholders representing various school community members, including students.

- Tracking of stability of enrollment and staff, positive comments from families, teacher, and students.

- Exit surveys and interviews for families and teachers.

- Documented disciplinary action related to lack of cultural tolerance.

- Informal sessions (e.g., coffees, meetings, etc.) with various groups, including new students and international families.

- Number of student community service organizations, student initiated projects, sustainability of these projects, and participation in them.

- Assessment of curriculum standards for diversity and global understanding.

- Counting actual numbers of participants who participate in a school activity. Hourly participation recorded.

- Amnesty International club.

- Focus groups.

- Informal observations around the school.

Question 9. As a school leader, what kinds of specific SKILLS, FORMAL TRAINING, and EXPERIENCES do you believe might help other school leaders more effectively influence and sustain the development of cultural proficiency and global leadership in American international schools in Latin America? 
- International/cross-cultural work experiences.

- Language abilities (incentive package for proficiency).

- University coursework in intercultural communication and cross-cultural management for administrators and teachers.

- University level required exchange programs (to and from the U.S.).

- Collegial contact with other school leaders through associations, conferences, workshops.

- Training in Change Management.

- Greater involvement of relevant associations in these topics (e.g. SACS, AASSA, AISH, Tri-Association, AIE, etc.) to support school leaders.

- Conflict Resolution training.

- More thorough understanding of cultures and subcultures in Latin America, as well as other world cultures.

- Forums for Board Members and Heads of Schools to address global leadership issues.

- Understanding of organizational (school) culture and how to incorporate and address diversity.

- Knowledge of action research methods for gathering organizational level data.

- Skills in strategic planning and vision building.

- Team building and facilitation skills. 
- School-to-school partnerships.

- Personal qualities of openness, ethics, culturally competent values and behaviors.

- Stakeholder integration and community outreach abilities.

Question 10. Please feel free to comment here on anything else you would like to say related to the topics discussed in this study. [six participants responded to this question]

Participant Quotes

1. I personally believe that as international educators we are light years ahead of most equivalent educators in the U.S. However, I know many 'international' schools that have an almost entirely host country national student population that are far from tolerant and respectful of others. There is a lot of work to be done.

2. Thank you for the opportunity to participate with such a diverse group with a range of experiences. It has sharpened my thinking on these issues and has had an impact on the way we address them at our school already. This kind of talk among administrators allows us to look at our own situation in a broader context and find new ways of managing complex situations.

3. I still do not understand exactly what is meant by the term 'cultural proficiency' other than knowledge about and ability to function effectively in a culture different from one's own. I am eager to learn more.

4. Perhaps if all regional organizations had a student leadership conference focusing on these issues, this would be desirable. What can we do to bring our faculty together as a region around issues of culture?

5. This is a long overdue research topic and the approach taken is very appealing. Our 
chance to influence student attitudes toward others is invaluable. If, as educators, we give out signals that show intolerance or elitism, our students will pick up those signals very quickly. By doing that, we are either fostering intolerance, or closing the door to a more open relationship with our students.

6. It is easy to get people to agree with 'what is right' but it is not so easy to get them to change their behaviors to match this. 